\title{
Dynamic Factor Demand Models and Productivity Analysis ${ }^{1}$
}

\author{
M. Ishaq Nadiri ${ }^{2}$ and Ingmar R. Prucha ${ }^{3}$ \\ March 1998 \\ Revised May 1999
}

\begin{abstract}
${ }^{1}$ We would like to thank, in particular, William Baumol and Dale Jorgenson, and the participants of the CRIW Conference on New Developments in Productivity Analysis for helpful comments. Das Debabrata and Michel Kumhof provided excellent research assistance. We are also grateful for the support received from the C.V. Starr Center for Applied Economics at New York University.

${ }^{2}$ Department of Economics, New York University, New York, NY 10003, and National Bureau of Economic Research, Cambridge, MA 02138

${ }^{3}$ Department of Economics, University of Maryland, College Park, MD 20852
\end{abstract}




\section{Contents}

1 Introduction 1

2 On the Conventional Approach to Productivity Analysis 5

2.1 Definition of Technical Change . . . . . . . . . . . . 5

2.1.1 Primal measures of technical change . . . . . . . . 6

2.1.2 Dual measures of technical change . . . . . . . . . . 8

2.1.3 Capacity Utilization and Technical Change . . . . . . . 10

2.2 Divisia Index Approach . . . . . . . . . . . . . . . . . . 11

2.2.1 The Conventional Measure of Total Factor Productivity 12

2.2.2 Growth Accounting Equation for Technical Change . . 14

2.2.3 Sources of Bias in the Conventional Measure of Total Factor Productivity . . . . . . . . . . . . 16

3 Recent Developments in Modeling Dynamic Factor Demand 20

3.1 Theoretical Model Specification . . . . . . . . . . . . . 23

3.1.1 Technology and Optimal Control Policy . . . . . . . 23

3.1.2 Generalized Expressions for Technical Change and Total Factor Productivity Decomposition . . . . . . . . 28

3.1.3 Flexible Functional Forms of Restricted Cost Functions 28

3.2 Solution and Estimation of Dynamic Factor Demand Models

in Case of Linear Quadratic Technologies . . . . . . . . . . . . 31

3.2.1 Illustrative Example with Endogenous Depreciation Rate 32

3.2.2 Solution and Estimation of a General Class of Models . 38

3.2.3 Discrete versus Continuous Time Specifications . . . . 41

3.3 Estimation of Dynamic Factor Demand Models for General

Technologies . . . . . . . . . . . . . . . . 42

3.3.1 Estimation of Variable Factor Demand Equations . . . 42

3.3.2 Euler Equation Estimation Approach . . . . . . . . . . 43

3.3.3 Finite Horizon Modeling Approach . . . . . . . . . . . 45

3.4 Further Developments . . . . . . . . . . . . . . 45

4 Applications $\quad 47$

4.1 Tax Incentives, Financing and Technical Change . . . . . . . . 48

4.2 R\&D Investment, Production Structure and TFP Decomposition 51

4.3 Technological Spillovers and Productivity Growth . . . . . . . 52 
4.4 Capital Utilization, Depreciation Rates, and Replacement Investment . . . . . . . . . . . . . . 55

5 Effects of Misspecification: A Monte Carlo Study 60

6 Concluding Remarks $\quad 66$

A Appendix: Supplementary Material for Section 2

B Appendix: Supplementary Material for Section $3 \quad \mathbf{7 6}$

B.1 Interpretation of Optimality Conditions . . . . . . . . . 76

B.2 Some Mathematical Derivations . . . . . . . . . . . 77

B.3 Extension of the Reparameterization Approach for a General Class of Models . . . . . . . . . . . . . . . . . . . 80

C Appendix: Supplementary Material for Section 5 


\begin{abstract}
In this paper we discuss recent advances in modeling and estimating dynamic factor demand models, and review the use of such models in analyzing the production structure, the determinants of variable and quasi-fixed factors, and productivity growth. The paper also discusses the traditional approach to productivity analysis based on the Divisia index number methodology. Both approaches may be seen a complementary. The conventional index number approach will measure the rate of technical change correctly if certain assumptions about the underlying technology of the firm and output and input markets hold. Furthermore, the conventional index number approach is appealing in that it can be easily implemented. However, if the underlying assumptions do not hold, then the conventional index number approach will, in general, yield biased estimates of technical change. The econometric approach based on general dynamic factor demand models allows for a careful testing of various features of a postulated model. Furthermore it not only provides for estimates of technical change, but can also yield a rich set of critical information on the structure of production, the dynamics of investment in physical and R\&D capital, the effects of spillovers, the depreciation rate of capital, the impact of taxes, expectations, etc. The paper also explores in terms of a Monte Carlo study how estimates of important characteristics of the production process can be affected by model misspecification. The results suggest adopting a simple specification for reasons of convenience may result in serious biases.
\end{abstract}

JEL No. C5, D2, O3, O4 


\section{Introduction}

The traditional approach to productivity analysis is to use the Divisia index number methodology. This approach has the advantage of simplicity as well as the benefit of not requiring direct estimation of the underlying technology. Therefore, the often difficult tasks of econometric specification and estimation of structural models can be avoided. However, for the index number approach to provide meaningful estimates of technical change, fairly strong assumptions about the underlying technology and allocation decisions by the firm must be maintained. In particular, it is necessary to assume a constant returns to scale technology, competitive input and output markets, full utilization of all inputs, and instantaneous adjustment of all inputs to their desired demand levels. As a result the productivity measures based on the index number approach will in general yield biased estimates of technical change, if any of these assumptions are violated.

Technical change is an integral feature of the production process. Changes in variable factor inputs, the accumulation of quasi-fixed factor inputs, and technical change are in general intertwined in that the demand for inputs and the supply of outputs depend on the rate of technical change, while technical change, in turn depends typically on the input and output mix. The traditional measure of total factor productivity only measures technical change, but does not explain the complex and simultaneously determined process that governs the evolution of outputs, inputs and technical change.

A rationale for a general structural econometric modeling approach is that it allows for the careful testing of various features of a postulated model, rather than to simply impose those features a priori. We note that any misspecification of the underlying technology of the firm will typically lead to inconsistent estimates of technical change and the determinants of the investment decisions. A simple illustration of misspecification is the case where the true technology is translog but the hypothesized model is Cobb-Douglas, or the case where the input adjustments involve considerable time lags but are ignored, or where the expectation process is not taken into account or not formulated correctly. In such cases the estimates of the model parameters, including the estimates of technical change, will be inconsistent. Thus, if the objective is to obtain a consistent estimate of the true model parameters, 
choosing, e.g., a simple model for convenience of presentation and estimation is not admissible empirical practice. The reason for considering a dynamic rather than a static factor demand model is to not impose a priori that all factors are in long-run equilibrium.

A general dynamic factor model, as considered in this paper, has a fairly elaborate structure, requires an extensive data set and poses considerable estimation challenges. However, there seem to be two important advantages to this approach: First, the model contains "simpler" models as special cases. In particular, it contains static factor demand models as special cases, but does not impose a priori the premise that all factors are in long-run equilibrium. As in case of static factor demand models the analysis can be carried out by specifying the technology in terms of a production function, cost/profit function, or restricted cost/profit function, and the model can be estimated from a subset or the complete set of the factor demand equations. Of course, if the model is only estimated from the variable factor demand equations, then we do not have to formulate an intertemporal optimal control problem.

Second, the dynamic factor demand model generates a very rich set of critical information about the structure of production, sources of productivity growth, impact of technical change and effects of policy instruments and expectations on output supply, input demand, direction of technical change and productivity growth. Not only is it possible to calculate the components of traditional productivity measure but also the determinants of employment and investment decisions of the firm simultaneously.

More specifically, the advantages of the estimation of (dynamic) factor demand models - apart from providing for the possibility of testing various modeling hypotheses - may include:

- In estimating the technology we obtain explicit information on the process that transforms inputs into outputs, and on changes of the technological frontier over time. In particular we obtain estimates of technological characteristics such as, e.g., technical change, scale and scope. We may also gain estimates of the effects of R\&D, spillovers, etc. Furthermore, we can compute marginal products, elasticities of substitution among the inputs, describing the underlying structure of production.

- In estimating the demand for variable and quasi-fixed factors we gain additional insight into the underlying dynamics of factor allocation and 
factor accumulation - short-run, intermediate-run and long-run - as a function of the variables that are exogenous to the firm. The latter variables typically include (expected) factor prices, taxes, exogenous technical change, spillovers, etc.

- As a by-product of estimating dynamic factor demand equations, we may gain insight into the expectation formation process and the firms planning horizon, and how this process affects production decisions in general and investment decisions in particular.

- Furthermore, given that we allow the depreciation rate of capital goods to be endogenously determined, we obtain an economic model for replacement investment and expansion investment. (We note, however, that the modeling framework also covers the case of an exogenous and constant depreciation rate.)

The paper is organized as follows: In Section 2, we start by precisely defining input- and output-based technical change on the primal (production) side in the presence of adjustment costs. We then discuss how those measures can be evaluated on the dual (cost) side. We also show how capacity utilization rates can be derived in the context of dynamic factor demand models. Next we discuss the conventional measure of total factor productivity (TFP) based on the Divisia index, and show how this measure can be biased (as a measure of technical change) if the assumptions underlying its derivation are not satisfied. The biases can, e.g., be due to presence of economies of scale, adjustment costs, and the difference between the shadow prices and long-run rental prices of the quasi-fixed inputs.

In Section 3 we first specify a general class of dynamic factor demand models, which allows several non-separable quasi-fixed factors, allows for the utilization rate/depreciation rate of some of the quasi-fixed factors to be endogenously determined, and allows expectations to be non-static. We then discuss the class of linear quadratic dynamic factor demand models in more detail. For this class of models we give explicit analytic expressions for the firm's optimal control solution, i.e., for the firm's optimal factor inputs. Those expressions make clear the dependence of the firm's investment decisions on the expectations of future exogenous variables. We also discuss convenient ways of estimating such models based on a re-parameterization. Since some of this material may be unfamiliar and technically involved, we 
have attempted to show step-by-step how the models are derived and estimated. After our discussion of linear quadratic dynamic factor demand models we discuss several approaches towards the estimation of dynamic factor demand models in general. This includes the estimation of the Euler equations by the generalized method of moments approach, given rational expectations. We also consider the formulation and estimation of models with finite planning horizons, and discuss the relationship of models with a finite and infinite planning horizon.

Section 4 reviews several empirical applications of dynamic factor demand models. Dynamic factor demand models have been widely employed to study the behavior of factor demands including investment and employment decisions, output supply behavior, profitability, nature of technical change, spillover effects of R\&D investment, international technology spillovers, role of public investment, taxes and subsidies, etc. The empirical examples are provided to illustrate the versatility of these models.

In Section 5 we present briefly the results of a Monte Carlo study that explores the effects of misspecifications. The true data generating process corresponds to a general dynamic factor demand specification with nonseparable quasi-fixed factors, non-constant returns to scale and non-static expectations. The model and various implied characteristics including technical change are then estimated under the correct specification and under various forms of misspecification. This allows us to assess the degree of bias induced by various forms of misspecifications as when a simple model of the firm's technology is adopted for convenience of presentation and estimation instead of the true model. Concluding comments are given in the last section of the paper. Many of the underlying mathematical derivations are relegated to the appendices. 


\section{On the Conventional Approach to Produc- tivity Analysis}

As remarked in the Introduction a focus of this paper is the presentation of recent developments in the dynamic factor demand literature and their application to estimation of technical change and output growth. To set the stage we first give a brief review of the conventional Divisia index based approach to productivity analysis. To put the discussion on sound footing we start with a formal definition of technical change. ${ }^{1}$

\subsection{Definition of Technical Change}

The conventional Divisia index based measure of total factor productivity growth assumes, in particular: (1) that producers are in long-run equilibrium, (2) that the technology exhibits constant returns to scale, (3) that output and input markets are competitive, and (4) that factors are utilized at a constant rate. $^{2}$ The puzzle of the observed slowdown of productivity growth during the 1970s has initiated a critical methodological review of the conventional measure of productivity growth. ${ }^{3}$

The model considered in the following discussion relaxes these assumptions corresponding to the conventional measure of total factor productivity growth. In the following we define, within the context of that model, appropriate measures of technical change. More specifically, in defining technical change we first give such a definition on the (primal) production side. We then show how the measure of technical change so defined can be expressed

\footnotetext{
${ }^{1}$ The subsequent discussion makes use of the following notational conventions (unless explicitly indicated otherwise): Let $Z_{t}$ be some $l \times 1$ vector of goods in period $t$, then $p_{t}^{Z}$ refers to the corresponding $l \times 1$ price vector; $Z_{t i}$ and $p_{t i}^{Z}$ denote the $i$-th elements of $Z_{t}$ and $p_{t}^{Z}$, respectively. Furthermore, in the following we often write $\left(p_{t}^{Z}\right)^{\prime} Z_{t}$ for $\sum_{i=1}^{l} p_{t i}^{Z} Z_{t i}$ where "'" stands for transpose.

${ }^{2}$ The assumption of constant returns to scale is not necessary in cases where an independent observation of the rental price of capital is available.

${ }^{3}$ See, e.g, Berndt and Fuss (1981, 1986, 1989), Bernstein (1994a), Bernstein and Mohnen (1988, 1991), Caves, Christensen and Swanson (1980, 1981), Caves, Christensen and Diewert (1982a,b), Denny, Fuss and Waverman (1981a), Griliches (1987), Hall (1988), Hulten (1986), Mohnen (1992a), Mohnen, Nadiri and Prucha (1983), Morrison (1985a,b, 1986a, 1989, 1992a,b), Nadiri and Prucha (1983, 1984, 1986, 1990a,b), Nadiri and Schankerman (1981a,b), and Prucha and Nadiri (1996).
} 
alternatively on the (dual) cost side. To interpret the expressions on the cost side we also discuss measures of capacity utilization.

The following discussion allows, in particular, for a technology with multiple outputs, allows for some of the factors to be quasi-fixed (and thus does not assume that the firm is in long-run equilibrium), and allows for nonconstant returns to scale. ${ }^{4}$ Now let $Y_{t}=\left(Y_{t 1}, \ldots, Y_{t k}\right)^{\prime}$ be the vector of output goods produced by a firm during period $t$, and let $V_{t}=\left(V_{t 1}, \ldots, V_{t m}\right)^{\prime}$ and $X_{t}=\left(X_{t 1}, \ldots, X_{t n}\right)^{\prime}$ be the vectors of variable and quasi-fixed inputs utilized during period $t$, respectively. We then assume that the technology can be represented by the following transformation function

$$
F\left(Y_{t}, V_{t}, X_{t}, \Delta X_{t}, T_{t}\right)=0
$$

where the vector of first differences $\Delta X_{t}$ represent internal adjustment costs in terms of foregone output due to changes in the quasi-fixed factors, and $T_{t}$ represents an index of (exogenous) technical change.

In the following it will also be useful to decompose the variable factors into $M_{t}=V_{t 1}$ and $L_{t}=\left(V_{t 2}, \ldots, V_{t m}\right)^{\prime}$, and to represent the technology in terms of the following factor requirement function

$$
M_{t}=M\left(Y_{t}, L_{t}, X_{t}, \Delta X_{t}, T_{t}\right)
$$

We can then think of the transformation function to be of the form

$$
\begin{aligned}
& F\left(Y_{t}, V_{t}, X_{t}, \Delta X_{t}, T_{t}\right) \\
= & M\left(Y_{t}, L_{t}, X_{t}, \Delta X_{t}, T_{t}\right)-M_{t} \equiv 0 .
\end{aligned}
$$

For ease of notation in the following we drop time-subscripts whenever those subscripts are obvious from the context.

\subsubsection{Primal measures of technical change}

To define technical change formally assume that the technology index $T$ shifts by, say, $\delta$. Now let $a=a(\delta, Y, V, X, \Delta X, T)$ be the proportionality factor by which all outputs $Y$ can be increased, and let $b=b(\delta, Y, V, X, \Delta X, T)$ be the proportionality factor by which all inputs can be decreased corresponding to this shift in technology when the firm remains on its production surface, i.e., $F(a Y, V, X, \Delta X, T+\delta)=0$ and $F(Y, b V, b X, b \Delta X, T+\delta)=0$.

\footnotetext{
${ }^{4}$ Generalizations that allow for variable factor utilization rates will be discussed later.
} 
Furthermore let $c=c(\kappa, Y, V, X, \Delta X, T)$ be the proportionality factor by which all outputs $Y$ can be increased corresponding to an increase in all inputs by a factor $\kappa$ when the firm remains on its production surface, i.e., $F(c Y, \kappa V, \kappa X, \kappa \Delta X, T)=0$. We can then give the following two definitions of technical change, $\lambda^{Y}$ and $\lambda^{X}$, and returns to scale, $\rho$ :

$$
\begin{aligned}
\lambda^{Y}= & \left.\frac{\partial a}{\partial \delta}\right|_{\delta=0}=-\frac{\partial F}{\partial T} /\left[\sum_{i=1}^{k} \frac{\partial F}{\partial Y_{i}} Y_{i}\right], \\
\lambda^{X}= & -\left.\frac{\partial b}{\partial \delta}\right|_{\delta=0}=\frac{\partial F}{\partial T} /\left[\sum_{j=1}^{m} \frac{\partial F}{\partial V_{j}} V_{j}\right. \\
& \left.+\sum_{l=1}^{n} \frac{\partial F}{\partial X_{l}} X_{l}+\sum_{l=1}^{n} \frac{\partial F}{\partial \Delta X_{l}} \Delta X_{l}\right], \\
\rho= & \left.\frac{\partial c}{\partial \kappa}\right|_{\kappa=1}=\lambda^{Y} / \lambda^{X},
\end{aligned}
$$

where $F($.$) is evaluated at (Y, V, X, \Delta X, T)$. We refer to $\lambda^{Y}$ and $\lambda^{X}$, respectively, as the rates of output and input based technical change or productivity growth. For an explicit derivation of the above expressions see Appendix A. We note that the definitions given above are consistent with those given, e.g., in Caves, Christensen and Swanson (1981) and Caves, Christensen and Diewert $(1982 \mathrm{a}, \mathrm{b})$ for the case of technologies without explicit adjustment costs.

In case of a single output good we can also represent the technology in terms of a production function, say,

$$
Y=f(V, X, \Delta X, T) .
$$

Input and output based technical change can then also be expressed as usual $\mathrm{as}^{5}$

$$
\begin{aligned}
\lambda^{Y}= & \frac{\partial f}{\partial T} / Y, \\
\lambda^{X}= & \frac{\partial f}{\partial T} /\left[\sum_{j=1}^{m} \frac{\partial f}{\partial V_{j}} V_{j}\right. \\
& \left.+\sum_{l=1}^{n} \frac{\partial f}{\partial X_{l}} X_{l}+\sum_{l=1}^{n} \frac{\partial f}{\partial \Delta X_{l}} \Delta X_{l}\right] .
\end{aligned}
$$

\footnotetext{
${ }^{5}$ See Appendix A for a derivation.
} 


\subsubsection{Dual measures of technical change}

We next show how these measures can be evaluated from the cost side, using simple arguments of duality theory. We note that the expressions developed below are given in terms of a restricted or variable cost function. Expressions in terms of the (unrestricted) cost function are contained as a special case, in that for the case where all factors are variable the restricted cost function and the (unrestricted) cost function coincide.

Let $p^{L}$ denote the price vector for the variable inputs $L$ normalized by the price of the variable input $M$. The normalized variable cost is then given by $M(Y, L, X, \Delta X, T)+\left(p^{L}\right)^{\prime} L$. The normalized variable cost function is obtained by minimizing this expression w.r.t. L. Assuming that the factor requirement function $M($.$) is differentiable and that a unique interior$ minimum exists, the corresponding first order conditions are given by:

$$
\frac{\partial M}{\partial L}+\left(p^{L}\right)^{\prime}=0 .
$$

Let $\widehat{L}$ denote the minimizing vector. The normalized variable cost function is then given by

$$
G\left(p^{L}, Y, X, \Delta X, T\right)=\widehat{M}+\left(p^{L}\right)^{\prime} \widehat{L}
$$

where

$$
\widehat{M}=M(Y, \widehat{L}, X, \Delta X, T) .
$$

For duality results between factor requirement functions and normalized restricted cost functions $G($.$) see, e.g., Diewert (1982) and Lau (1976). We$ assume that the function $G($.$) is twice continuously differentiable in all its$ arguments, homogeneous of degree zero in $p^{L}$, non-decreasing in $Y,|\Delta X|$, and $p^{L}$, non-increasing in $X$, concave in $p^{L}$, and convex in $X$, and $\Delta X$.

Differentiating (2.3) yields

$$
\frac{\partial F}{\partial Z}=\frac{\partial M}{\partial Z} \quad \text { for } Z=Y, L, X, \Delta X, T .
$$

Differentiating (2.8) and utilizing (2.7) yields

$$
\frac{\partial G}{\partial Z}=\frac{\partial M}{\partial Z} \quad \text { for } Z=Y, X, \Delta X, T .
$$

Consequently we have

$$
\frac{\partial F}{\partial Z}=\frac{\partial G}{\partial Z} \quad \text { for } Z=Y, X, \Delta X, T .
$$


From (2.9) with $Z=L$ and (2.7) we obtain

$$
\frac{\partial F}{\partial L}=-\left(p^{L}\right)^{\prime} .
$$

Furthermore we have from $(2.3)$

$$
\frac{\partial F}{\partial M}=-1
$$

Given the variable inputs $V=\left[M, L^{\prime}\right]^{\prime}$ are chosen optimally, i.e., $L=\widehat{L}$ and $M=\widehat{M}$, it follows from (2.12) and (2.13), and from (2.8) that

$$
G\left(p^{L}, Y, X, \Delta X, T\right)=\widehat{M}+\left(p^{L}\right)^{\prime} \widehat{L}=-\sum_{j=1}^{m} \frac{\partial F}{\partial V_{j}} V_{j} .
$$

Substituting the expressions in (2.11) and (2.14) into (2.4) yields the following expressions for technical change and returns to scale in terms of the normalized restricted cost function $G$ :

$$
\begin{aligned}
\lambda^{Y}= & -\frac{\partial G}{\partial T} /\left[\sum_{i=1}^{k} \frac{\partial G}{\partial Y_{i}} Y_{i}\right], \\
\lambda^{X}= & -\frac{\partial G}{\partial T} /\left[G-\sum_{l=1}^{n} \frac{\partial G}{\partial X_{l}} X_{l}-\sum_{l=1}^{n} \frac{\partial G}{\partial \Delta X_{l}} \Delta X_{l}\right], \\
\rho= & \lambda^{Y} / \lambda^{X}=\left[G-\sum_{l=1}^{n} \frac{\partial G}{\partial X_{l}} X_{l}-\sum_{l=1}^{n} \frac{\partial G}{\partial \Delta X_{l}} \Delta X_{l}\right] / \\
& {\left[\sum_{i=1}^{k} \frac{\partial G}{\partial Y_{i}} Y_{i}\right] . }
\end{aligned}
$$

The total shadow cost (normalized by the price of the variable factor $M$ ) is defined as

$$
C=G\left(p^{L}, Y, X, \Delta X, T\right)-\sum_{l=1}^{n} \frac{\partial G}{\partial X_{l}} X_{l}-\sum_{l=1}^{n} \frac{\partial G}{\partial \Delta X_{l}} \Delta X_{l},
$$

where $-\partial G / \partial X_{l}$ and $-\partial G / \partial \Delta X_{l}$ denote the respective "shadow values". The above expressions for output based and input based technical change and 
returns to scale generalize those given in Caves, Christensen and Swanson (1981) in that they allow explicitly for adjustment costs. ${ }^{6}$

Observe that substituting (2.16) into (2.15) yields the following expressions for input based technical change and scale: $\lambda^{X}=-(\partial G / \partial T) / C$ and $\rho=1 /\left[\sum_{i=1}^{k}\left(\partial G / \partial Y_{i}\right) Y_{i} / C\right]$. In the case where all factors are variable we have $C=G$, and thus in the case of a single output good we have the following simplifications: $\lambda^{Y}=\rho^{-1} \lambda^{X}$ with $\lambda^{X}=-(\partial C / \partial T) / C$ and $\rho=1 /[(\partial C / \partial Y) Y / C]$. This relationship was established by Otha (1974).

\subsubsection{Capacity Utilization and Technical Change}

The issue of a proper measure of technical change, given the firm is in shortrun or temporary equilibrium, but not in long run equilibrium, has also been discussed, among others, by Berndt and Fuss (1981, 1986, 1989), Berndt and Morrison (1981), Hulten (1986), and Morrison (1983, 1986a, 1989). Those authors discuss proper measures of technical change in terms of adjustments of traditional technical change measures by utilization rate measures. Berndt and Fuss $(1981,1986)$ and Hulten (1986) consider single output technologies with constant returns to scale. Morrison also considers single output technologies, but allows for (possibly) non-constant returns to scale and explicitly takes into account adjustment costs. Berndt and Fuss (1989) consider multiple output technologies with (possibly) non-constant returns to scale, but do not explicitly consider adjustment costs.

We now show that the measures for $\lambda^{Y}$ and $\lambda^{X}$ are consistent with the technical change measures of Berndt, Fuss, Hulten and Morrison by demonstrating that $\lambda^{Y}$ and $\lambda^{X}$ can also be viewed as having been obtained via a capacity utilization adjustment of conventional (long-run) measures of technical change. For this purpose consider the following restricted total cost function (normalized by the price of the variable factor $M$ ):

$$
\begin{aligned}
C^{+} & =\widehat{M}+\left(p^{L}\right)^{\prime} \widehat{L}+\left(c^{X}\right)^{\prime} X \\
& =G\left(p^{L}, Y, X, \Delta X, T\right)+\left(c^{X}\right)^{\prime} X
\end{aligned}
$$

\footnotetext{
${ }^{6}$ We note that the mathematics used in deriving the expressions in (2.15) is analogous to that used by Caves, Christensen and Swanson (1981). The expressions also generalize those previously given in Nadiri and Prucha $(1983,1984,1990 a, b)$ for single-output technologies with adjustment costs. A generalization of those expressions for multiple-output technologies with adjustment costs and variable factor utilization rates is given in Prucha and Nadiri (1990, 1996), and will be discussed below.
} 
where $c^{X}$ denote the vector of rental prices for the quasi-fixed factors $X$ (normalized by the price of the variable factor $M$ ). Recall that in long-run equilibrium, or in the case where all factors are variable, we have shown above that input based technical change equals $-(\partial C / \partial T) / C$. Now suppose we attempt to measure technical change in terms of the total restricted cost function $C^{+}$analogously by

$$
\lambda_{+}^{X}=-\left(\partial C^{+} / \partial T\right) / C^{+} .
$$

Observing that $\partial C^{+} / \partial T=\partial G / \partial T$ it follows immediately from (2.15) and (2.16) that

$$
\begin{aligned}
\lambda^{Y} & =\rho \lambda_{+}^{X}\left(C^{+} / C\right), \\
\lambda^{X} & =\lambda_{+}^{X}\left(C^{+} / C\right) .
\end{aligned}
$$

Analogously to Berndt, Fuss, Hulten and Morrison we can interpret

$$
C U=C / C^{+}
$$

as a measures of capacity utilization and we can therefore interpret our input and output based measures for technical change as being derived from $\lambda_{+}^{X}$ via an adjustment in terms of a capacity utilization measure to account for temporary equilibrium. Clearly, in long-run equilibrium $C^{+}$equals $C$ and hence in the long run $\lambda_{+}^{X}$ equals $\lambda^{X}$. In general, however, $\lambda_{+}^{X}$ differs from $\lambda^{X}$ by the factor $C^{+} / C$.

\subsection{Divisia Index Approach}

In the productivity literature technical change is often estimated as the difference between the growth rate of a measure of aggregate output minus the growth rate of a measure of aggregate input. This approach to estimate technical change in terms of a residual dates back to Solow (1957). In computing aggregate output and input one of the most widely used methods of aggregation is Divisia aggregation. The conceptual justifications for Divisia aggregation were developed by Jorgenson and Griliches (1967), Richter (1966), Hulten (1973) and Diewert (1976), among others. ${ }^{7}$ In the following we first define the conventional measure of total factor productivity based on

\footnotetext{
${ }^{7}$ For recent reviews see, among others, Griliches (1996) and Hulten (1987, 1997, this volume).
} 
the Divisia index formula. As remarked, the Divisia index approach is based on a set of particular assumptions concerning the technology and the inputs and output markets. If any one of those assumptions is violated, the measure of total factor productivity based on the Divisia index formula will in general yield biased estimates of technical change in that it may then include, e.g., effects of scale economies or temporary equilibrium in addition to shifts in the production frontier. ${ }^{8}$ In the following we first develop a growth accounting equation for technical change. We then compare this expression with that for the conventional measure of total factor productivity, and based on this comparison discuss potential sources of bias in the latter measure. The subsequent discussion builds on Denny, Fuss and Waverman (1981a), who consider a model where all factors are variable, but where scale is allowed to differ from unity. In the following discussion we take $T=t$.

\subsubsection{The Conventional Measure of Total Factor Productivity}

For ease of presentation we start our discussion in continuous time. Recall that $V=\left[M, L^{\prime}\right]^{\prime}$ denotes the vector of all variable factors, and let $p^{V}=$ $\left[1, p^{L \prime}\right]^{\prime}$ denote the corresponding price vector (normalized by the price of $M$ ). Furthermore let $p^{Y}$ denote the vector of output prices, and let $c^{X}$ denote the vector of rental prices for the quasi-fixed factors $X$ (normalized by the price of $M)$. The Divisia index for aggregate output, say $Y^{a}$, is now defined by

$$
\frac{\dot{Y}^{a}}{Y^{a}}=\sum_{i=1}^{k} s_{i}^{Y} \frac{\dot{Y}_{i}}{Y_{i}}
$$

where the $s_{i}^{Y}$ 's denotes output shares in total revenue $R^{+}=\sum_{i=1}^{k} p_{i}^{Y} Y_{i}$, i.e.,

$$
s_{i}^{Y}=\frac{p_{i}^{Y} Y_{i}}{R^{+}},
$$

and where dots over variables denote derivatives w.r.t. time $t$. The Divisia index for aggregate input, say $F^{a}$, is analogously defined by

$$
\frac{\dot{F}^{a}}{F^{a}}=\sum_{j=1}^{m} s_{j}^{V} \frac{\dot{V}_{j}}{V_{j}}+\sum_{l=1}^{n} s_{l}^{X} \frac{\dot{X}_{l}}{X_{l}}
$$

\footnotetext{
${ }^{8}$ The total factor productivity measure based on the Divisia index may, however, be of interest in itself in a welfare sense.
} 
where the $s_{j}^{V}$ 's and $s_{l}^{X}$ 's denote input shares in total cost $C^{+}=\sum_{j=1}^{m} p_{j}^{V} V_{j}+$ $\sum_{l=1}^{n} c_{l}^{X} X_{l}$, i.e.,

$$
s_{j}^{V}=\frac{p_{j}^{V} V_{j}}{C^{+}}, \quad s_{l}^{X}=\frac{c_{l}^{X} X_{l}}{C^{+}} .
$$

The conventional measure of total factor productivity, say $T F P$, is now defined as the ratio of the Divisia index of aggregate output over the Divisia index of aggregate input, i.e., $T F P=Y^{a} / F^{a}$, and thus

$$
\begin{aligned}
\frac{T \dot{F} P}{T F P} & =\frac{\dot{Y}^{a}}{Y^{a}}-\frac{\dot{F}^{a}}{F^{a}} \\
& =\sum_{i=1}^{k} s_{i}^{Y} \frac{\dot{Y}_{i}}{Y_{i}}-\sum_{j=1}^{m} s_{j}^{V} \frac{\dot{V}_{j}}{V_{j}}-\sum_{l=1}^{n} s_{l}^{X} \frac{\dot{X}_{l}}{X_{l}} .
\end{aligned}
$$

The above Divisia index based definition of total factor productivity growth is given in continuous time. Empirical data typically refer to discrete time points. For discrete data the above formulae for the growth rates of aggregate output, aggregate input and total factor productivity are typically approximated by the following Törnqvist approximations, where $\Delta$ denotes the first difference operator:

$$
\begin{aligned}
\Delta \ln Y_{t}^{a}= & \frac{1}{2} \sum_{i=1}^{k}\left[s_{t i}^{Y}+s_{t-1, i}^{Y}\right] \Delta \ln \left(Y_{t i}\right), \\
\Delta \ln F_{t}^{a}= & \frac{1}{2} \sum_{j=1}^{m}\left[s_{t j}^{V}+s_{t-1, j}^{V}\right] \Delta \ln \left(V_{t j}\right) \\
& +\frac{1}{2} \sum_{l=1}^{n}\left[s_{t l}^{X}+s_{t-1, l}^{X}\right] \Delta \ln \left(X_{t l}\right),
\end{aligned}
$$

and

$$
\begin{aligned}
\Delta \ln T F P_{t}= & \Delta \ln Y_{t}^{a}-\Delta \ln F_{t}^{a} \\
= & \frac{1}{2} \sum_{i=1}^{k}\left[s_{t i}^{Y}+s_{t-1, i}^{Y}\right] \Delta \ln \left(Y_{t i}\right) \\
& -\frac{1}{2} \sum_{j=1}^{m}\left[s_{t j}^{V}+s_{t-1, j}^{V}\right] \Delta \ln \left(V_{t j}\right) \\
& -\frac{1}{2} \sum_{l=1}^{n}\left[s_{t, l}^{X}+s_{t-1, l}^{X}\right] \Delta \ln \left(X_{t l}\right) .
\end{aligned}
$$


Diewert (1976) has shown that the Törnqvist index is in fact exact if the underlying potential function has a translog form. We note further that a primary feature of the Divisia/Törnqvist index approach is that it can be implemented even if the number of inputs and outputs is large; see Diewert (1980).

\subsubsection{Growth Accounting Equation for Technical Change}

For ease of presentation we again start our discussion in continuous time. Consider the continuous time analog of (2.8)

$$
G\left(p^{L}, Y, X, \dot{X}, t\right)=\widehat{M}+\left(p^{L}\right)^{\prime} \widehat{L}
$$

Differentiation of the above equation w.r.t. $t$ and observing that $L=\widehat{L}$ and $M=\widehat{M}$ yields

$$
\begin{aligned}
& {\left[\frac{\partial G}{\partial p^{L}}\right] \dot{p}^{L}+\left[\frac{\partial G}{\partial Y}\right] \dot{Y}+\left[\frac{\partial G}{\partial X}\right] \dot{X}+\left[\frac{\partial G}{\partial \dot{X}}\right] \ddot{X}+\frac{\partial G}{\partial t} } \\
= & \dot{M}+\left(p^{L}\right)^{\prime} \dot{L}+(L)^{\prime} \dot{p}^{L} .
\end{aligned}
$$

By Shephard's lemma $L=\left(\partial G / \partial p^{L}\right)^{\prime}$. Upon substitution of this expression into the above equation it is easily seen that

$$
-\frac{\partial G}{\partial t}=\left[\frac{\partial G}{\partial Y}\right] \dot{Y}-\dot{M}-\left(p^{L}\right)^{\prime} \dot{L}-\left[\frac{-\partial G}{\partial X}\right] \dot{X}-\left[\frac{-\partial G}{\partial \dot{X}}\right] \ddot{X} .
$$

As implied by (2.15), input based technical change is now obtained by dividing the above equation by the continuous time analog of the restricted total shadow cost defined in (2.16), i.e., $C=G\left(p^{L}, Y, X, \dot{X}, t\right)-\sum_{l}\left(\partial G / \partial X_{l}\right) X_{l}-$ $\sum_{l}\left(\partial G / \partial \dot{X}_{l}\right) \dot{X}_{l}$. Some simple algebra - and recalling that $V=\left[M, L^{\prime}\right]^{\prime}$ and $p^{V}=\left[1, p^{L \prime}\right]^{\prime}-$ then yields the following expression for input based technical change:

$$
\begin{aligned}
\lambda^{X} & =-\frac{1}{C} \frac{\partial G}{\partial t} \\
& =\sum_{i=1}^{k} \bar{g}_{i} \frac{\dot{Y}_{i}}{Y_{i}}-\sum_{j=1}^{m} \bar{s}_{j}^{V} \frac{\dot{V}_{j}}{V_{j}}-\sum_{l=1}^{n} \bar{s}_{l}^{X} \frac{\dot{X}_{l}}{X_{l}}-\sum_{l=1}^{n} \bar{s}_{l} \dot{X}_{\frac{X_{l}}{\dot{X}_{l}}}
\end{aligned}
$$


with

$$
\begin{aligned}
\bar{g}_{i} & =\frac{\partial G}{\partial Y_{i}} \frac{Y_{i}}{C}, \quad \bar{s}_{j}^{V}=\frac{p_{j}^{V} V_{j}}{C} \\
\bar{s}_{l}^{X} & =\frac{-\partial G}{\partial X_{l}} \frac{X_{l}}{C}, \quad \bar{s}_{l}^{\dot{X}}=\frac{-\partial G}{\partial \dot{X}_{l}} \frac{\dot{X}_{l}}{C} .
\end{aligned}
$$

For given "shadow values" $-\partial G / \partial X_{l}$ and $-\partial G / \partial \dot{X}_{l}$ we have $\partial G / \partial Y_{i}=$ $\partial C / \partial Y_{i}$, and the $\bar{g}_{i}$ 's can be interpreted as the elasticities of the restricted total shadow cost $C$ with respect to the output $Y_{i}$. Furthermore, $\bar{s}_{j}^{V}, \bar{s}_{l}^{X}$ and $\bar{s}_{l}^{\dot{X}}$ represent the input cost shares for, respectively, $V_{j}, X_{l}$ and $\dot{X}_{l}$ in the restricted total shadow cost. An analogous expression to (2.32) for single output technologies is, e.g., given in Morrison (1986a, 1992a). Analogous expressions for models without explicit adjustment costs are given in, e.g., Denny, Fuss and Waverman (1981a) and Berndt and Fuss (1989). Generalizations that allow for endogenous factor utilization are given in Prucha and Nadiri (1990, 1996), and will be discussed in Section 3.

For purposes of interpretation of (2.32) observe that in light of (2.15) $\sum_{i=1}^{k} \bar{g}_{i}=1 / \rho$, where $\rho$ denotes the scale elasticity. In case of the single output good the above expression for input based technical change simplifies to

$$
\lambda^{X}=\rho^{-1} \frac{\dot{Y}}{Y}-\sum_{j=1}^{m} \bar{s}_{j}^{V} \frac{\dot{V}_{j}}{V_{j}}-\sum_{l=1}^{n} \bar{s}_{l}^{X} \frac{\dot{X}_{l}}{X_{l}}-\sum_{l=1}^{n} \bar{s}_{l} \dot{X}_{X_{l}} .
$$

From this expression we see that in calculating input based technical change in case of increasing [decreasing] returns to scale, output growth is diminished [enhanced] before subtracting the growth in aggregate inputs. In case of a single output good, constant returns to scale, and in case all factors are variable the growth accounting equation for technical change simplifies further to

$$
\lambda^{X}=\lambda^{Y}=\frac{\dot{Y}}{Y}-\sum_{j=1}^{m} \bar{s}_{j}^{V} \frac{\dot{V}_{j}}{V_{j}}
$$

which corresponds to the expression developed by Solow (1957).

The above expressions for technical change were derived in continuous time. In Appendix A we derive the following discrete time approximation of $(2.32)$ :

$$
\frac{1}{2}\left(\lambda_{t}^{X}+\lambda_{t-1}^{X}\right)=\frac{1}{2}\left(-\frac{1}{C_{t}} \frac{\partial G_{t}}{\partial t}-\frac{1}{C_{t-1}} \frac{\partial G_{t-1}}{\partial(t-1)}\right)
$$




$$
\begin{aligned}
& \doteq \frac{1}{2} \sum_{i=1}^{k}\left[\bar{g}_{t i}+\bar{g}_{t-1, i}\right] \Delta \ln \left(Y_{t i}\right) \\
& -\frac{1}{2} \sum_{j=1}^{m}\left[\bar{s}_{t j}^{V}+\bar{s}_{t-1, j}^{V}\right] \Delta \ln \left(V_{t j}\right)-\frac{1}{2} \sum_{l=1}^{n}\left[\bar{s}_{t l}^{X}+\bar{s}_{t-1, l}^{X}\right] \Delta \ln \left(X_{t l}\right) \\
& -\frac{1}{2} \sum_{l=1}^{n}\left[\bar{s}_{t l}^{\Delta X}+\bar{s}_{t-1, l}^{\Delta X}\right] \Delta \ln \left(\Delta X_{t l}\right)
\end{aligned}
$$

with

$$
\begin{aligned}
\bar{g}_{t i} & =\frac{\partial G_{t}}{\partial Y_{t i}} \frac{Y_{t i}}{C_{t}}, \quad \bar{s}_{t j}^{V}=\frac{p_{t j}^{V} V_{t j}}{C_{t}} \\
\bar{s}_{l t}^{X} & =-\frac{\partial G_{t}}{\partial X_{t l}} \frac{X_{t l}}{C_{t}}, \quad \bar{s}_{l t}^{\Delta X}=-\frac{\partial G_{t}}{\partial X_{t l}} \frac{\Delta X_{t l}}{C_{t}} .
\end{aligned}
$$

\subsubsection{Sources of Bias in the Conventional Measure of Total Factor Productivity}

We now compare the growth accounting expression for technical change with the conventional measure of total factor productivity, and explore sources of potential bias in the latter measure. For ease of presentation we again start the discussion in continuous time. Consider the following alternative index for aggregate output, say $Y^{b}$, defined by

$$
\frac{\dot{Y}^{b}}{Y^{b}}=\sum_{i=1}^{k} \bar{s}_{i}^{Y} \frac{\dot{Y}_{i}}{Y_{i}}
$$

where

$$
\bar{s}_{i}^{Y}=\frac{\bar{g}_{i}}{\sum_{i=1}^{k} \bar{g}_{i}}=\frac{\left(\partial G / \partial Y_{i}\right) Y_{i}}{R}
$$

with $R=\sum_{i=1}^{k}\left(\partial G / \partial Y_{i}\right) Y_{i}$. Furthermore, consider the following index for aggregate input, say $F^{b}$, defined by

$$
\frac{\dot{F}^{b}}{F^{b}}=\sum_{j=1}^{m} \bar{s}_{j} \frac{\dot{V}_{j}}{V_{j}}+\sum_{l=1}^{n} \bar{s}_{l}^{X} \frac{\dot{X}_{l}}{X_{l}}+\sum_{l=1}^{n} \bar{s}_{l} \frac{\ddot{X}_{l}}{\dot{X}_{l}} .
$$

Recalling that in light of (2.15) $\sum_{i=1}^{k} \bar{g}_{i}=1 / \rho$, where $\rho$ denotes the scale elasticity, we can now write the growth accounting equation (2.32) for input 
based technical change as

$$
\lambda^{X}=\rho^{-1} \frac{\dot{Y}^{b}}{Y^{b}}-\frac{\dot{F}^{b}}{F^{b}} .
$$

As demonstrated in Appendix A comparing (2.25) with (2.38) yields the following decomposition of the conventional measure of total factor productivity growth in continuous time.

$$
\frac{T \dot{F} P}{T F P}=\lambda^{X}+(1-1 / \rho) \frac{\dot{Y}^{b}}{Y^{b}}+\left(\frac{\dot{Y}^{a}}{Y^{a}}-\frac{\dot{Y}^{b}}{Y^{b}}\right)+\left(\frac{\dot{F}^{b}}{F^{b}}-\frac{\dot{F}^{a}}{F^{a}}\right)
$$

with

$$
\begin{aligned}
\frac{\dot{Y}^{a}}{Y^{a}}-\frac{\dot{Y}^{b}}{Y^{b}}= & \sum_{i=1}^{k}\left(\frac{\left(p_{i}^{Y}-\partial G / \partial Y_{i}\right) Y_{i}}{R}\right)\left(\frac{\dot{Y}_{i}}{Y_{i}}-\frac{\dot{Y}^{a}}{Y^{a}}\right), \\
\frac{\dot{F}^{b}}{F^{b}}-\frac{\dot{F}^{a}}{F^{a}}= & \sum_{l=1}^{n}\left(\frac{\left(-\partial G / \partial X_{l}-c_{l}^{X}\right) X_{l}}{C}\right)\left(\frac{\dot{X}_{l}}{X_{l}}-\frac{\dot{F}^{a}}{F^{a}}\right) \\
& +\sum_{l=1}^{n}\left(\frac{\left(-\partial G / \partial \dot{X}_{l}\right) \dot{X}_{l}}{C}\right)\left(\frac{\ddot{X}_{l}}{\dot{X}_{l}}-\frac{\dot{F}^{a}}{F^{a}}\right) .
\end{aligned}
$$

The first term in the above decomposition of $T \dot{F} P / T F P$ corresponds to actual (input based) technical change. The remaining terms decompose the difference between $T \dot{F} P / T F P$ and technical change, i.e., they reflect sources of potential bias of $T \dot{F} P / T F P$ as a measure of technical change. More specifically, the second term reflects scale effects. We note that under increasing returns to scale and positive output growth $T \dot{F} P / T F P$ will overestimate technical change. The third term reflects the effects of deviations from marginal cost pricing. The fourth term is due to the presence of adjustment costs. It consists of two effects: One effect stems from the difference in the marginal conditions for the quasi-fixed factors between shortand long-run equilibrium due to adjustment cost, i.e., the difference between the shadow price and (long-run) rental price. ${ }^{9}$ The other effect reflects the

\footnotetext{
${ }^{9}$ Suppose the shadow price for a particular quasi-fixed factor exceeds the long-run price used in the computation of $T \dot{F} P / T F P$. In this case $T \dot{F} P / T F P$ will, ceteris paribus, overestimate the technical change effects given the growth rate of the quasi-fixed input exceeds that of the aggregate input index.
} 
direct effect of adjustment costs in the sense that due to the presence of $\dot{X}$ in the transformation function the growth rates of those terms also enter the decomposition of the output growth rate.

Empirical data typically refer to discrete time points. Equations (2.26)(2.28) provided Törnqvist approximations for the growth rates of the aggregate output $Y^{a}$, the aggregate input $F^{a}$ and total factor productivity TFP. Analogously, consider the following approximations for the growth rates of the aggregate output $Y^{b}$, and of the aggregate input $F^{b}$ :

$$
\Delta \ln Y_{t}^{b}=\frac{1}{2} \sum_{i=1}^{k}\left[\bar{s}_{t i}^{Y}+\bar{s}_{t-1, i}^{Y}\right] \Delta \ln \left(Y_{t i}\right)
$$

where

$$
\bar{s}_{t i}^{Y}=\frac{\bar{g}_{t i}}{\sum_{i=1}^{k} \bar{g}_{t i}}=\frac{\left(\partial G_{t} / \partial Y_{t i}\right) Y_{t i}}{R_{t}}
$$

with $R_{t}=\sum_{i=1}^{k}\left(\partial G_{t} / \partial Y_{t i}\right) Y_{t i}$, and

$$
\begin{aligned}
\Delta \ln F_{t}^{b}= & \frac{1}{2} \sum_{j=1}^{m}\left[\bar{s}_{t j}^{V}+\bar{s}_{t-1, j}^{V}\right] \Delta \ln \left(V_{t j}\right) \\
& +\sum_{l=1}^{n}\left[\bar{s}_{t l}^{X}+\bar{s}_{t-1, l}^{X}\right] \Delta \ln \left(X_{t l}\right) \\
& +\sum_{l=1}^{n}\left[\bar{s}_{t l}^{\Delta X}+\bar{s}_{t-1, l}^{\Delta X}\right] \Delta \ln \left(\Delta X_{t l}\right) .
\end{aligned}
$$

As demonstrated in Appendix A, it is then possible to decompose the Törnqvist index based approximation of the growth rate of the conventional measure of total factor productivity as follows:

$$
\begin{aligned}
& \Delta \ln T F P_{t} \doteq \frac{1}{2}\left(\lambda_{t}^{X}+\lambda_{t-1}^{X}\right)+\frac{1}{2} \sum_{\tau=t, t-1}\left(1-1 / \rho_{\tau}\right) \Delta \ln Y_{t}^{b, \tau} \\
& +\left(\Delta \ln Y_{t}^{a}-\Delta \ln Y_{t}^{b}\right)+\left(\Delta \ln F_{t}^{b}-\Delta \ln F_{t}^{a}\right)
\end{aligned}
$$

with

$$
\begin{aligned}
& \Delta \ln Y_{t}^{a}-\Delta \ln Y_{t}^{b} \\
= & \sum_{i=1}^{k}\left[\frac{1}{2} \sum_{\tau=t, t-1}\left(\frac{\left(p_{\tau i}^{Y}-\partial G_{\tau} / \partial Y_{\tau i}\right) Y_{\tau i}}{R_{\tau}}\right)\left(\Delta \ln \left(Y_{t i}\right)-\Delta \ln Y_{t}^{a, \tau}\right)\right]
\end{aligned}
$$




$$
\begin{aligned}
& \Delta \ln F_{t}^{b}-\Delta \ln F_{t}^{a} \\
= & \sum_{l=1}^{n}\left[\frac{1}{2} \sum_{\tau=t, t-1}\left(\frac{\left(-\partial G_{\tau} / \partial X_{\tau l}-c_{\tau l}^{X}\right) X_{\tau l}}{C_{\tau}}\right)\left(\Delta \ln \left(X_{t l}\right)-\Delta \ln F_{t}^{a, \tau}\right)\right] \\
+ & \sum_{l=1}^{n}\left[\frac{1}{2} \sum_{\tau=t, t-1}\left(\frac{\left(-\partial G_{\tau} / \partial \Delta X_{\tau l}\right) \Delta X_{\tau l}}{C_{\tau}}\right)\left(\Delta \ln \left(\Delta X_{t l}\right)-\Delta \ln F_{t}^{a, \tau}\right)\right]
\end{aligned}
$$

and

$$
\begin{aligned}
\Delta \ln Y_{t}^{a, \tau} & =\sum_{i=1}^{k} s_{\tau i}^{Y} \Delta \ln \left(Y_{t i}\right) \\
\Delta \ln F_{t}^{a, \tau} & =\sum_{j=1}^{m} s_{\tau j}^{V} \Delta \ln \left(V_{t j}\right)+\sum_{l=1}^{n} s_{\tau l}^{X} \Delta \ln \left(X_{t l}\right)
\end{aligned}
$$

for $\tau=t, t-1$. This decomposition and its interpretation is analogous to the continuous time decomposition of $T F P$ growth given in (2.39) and (2.40). It generalizes analogous expressions given in Denny, Fuss and Waverman (1981a) for technologies without adjustment costs and in Nadiri and Prucha (1983, 1986, 1990a,b) for single output technologies with adjustment costs. Expressions that allow for endogenous factor utilization have been considered in Prucha and Nadiri (1990, 1996), and will be discussed in Section 3. We note that variations of the decomposition (2.39) or (2.43) have also appeared in various other studies, including Nadiri and Schankerman (1981b), Bernstein and Mohnen (1991), Mohnen (1992a), and Bernstein (1994a). 


\section{Recent Developments in Modeling Dynamic Factor Demand}

The recent dynamic factor demand literature rests on the seminal work of several contributors. Four advances in the theory and estimation methodology are of particular importance: The neoclassical theory of investment, the advances in flexible functional forms of the production (cost) functions, the development of duality theory, and the theoretical and empirical developments concerning adjustment costs. It is the confluence of these strands of literature that made the wide empirical applications of factor demand models possible.

First, in a seminal contribution Jorgenson (1963) laid the foundation of the neoclassical model of investment. He developed the concept of the user cost of capital, that included explicitly various taxes and incentives. Also he modeled the lagged response of investment to changes in demand for capital by generalizing the Koyck (1954) geometric lag distribution to what is called the rational distributed lag; see Jorgenson (1966) and Jorgenson and Stephenson (1967). Many other facets of investment decisions such as the rate of depreciation and the distinction between net and replacement investment were explicitly considered in a series of papers dealing with theory and application of the neoclassical theory of investment; see Jorgenson (1996a,b) for a collection of this important body of work.

Building on the neoclassical model of investment Nadiri and Rosen (1969, 1973) introduced their interrelated disequilibrium model, whereby disequilibrium in one factor market was formally related to the extent of disequilibrium in other factor markets. As a result short-run overshooting is possible, and the difference between short- and long-run price elasticities for a particular input depends not only on its own partial adjustment parameter, but also on all cross adjustment parameters of other inputs.

A second major advance in the literature has been the formulation of flexible functional forms for the description of the technology. The purpose was

to avoid restrictive features inherent in, e.g., the Leontief and Cobb-Douglas production functions. Flexible functional forms of cost and production functions have first been introduced in the economics literature in seminal papers 
by Christensen, Jorgenson and Lau (1971, 1973) and Diewert (1971). These authors introduced the transcendental logarithmic and the generalized Leontief functional forms, respectively. ${ }^{10}$ These functional forms do not impose a priori restrictive constraints such as homotheticity, constancy of elasticity of substitution, additivity, and so on. Another important flexible functional form has been proposed by McFadden (1978) and extended by Diewert and Wales (1987).

The third strand of literature contributing to advances in the theory of production was the development of duality theory. Fundamental contributions include Shephard (1953), Diewert (1971, 1974, 1982), Lau (1976), and McFadden (1978). ${ }^{11}$ Of course, there was close interaction between the development of flexible functional forms and duality theory. Profit and cost functions (or restricted versions thereof) are widely used in empirical analysis. This may be explained in part by the following observation of McFadden (1978): "In econometric applications, use of the cost function as the starting point of developing models avoids the difficulty of deriving demand systems constructively from production possibilities, while at the same time insuring consistency with the hypothesis of competitive cost minimization."

Fourth, in an effort to construct a dynamic framework capable of yielding a demand for investment Eisner and Strotz (1963) introduced adjustment cost into the neoclassical theory of the firm. Several other important contributions were made by Lucas (1967a,b), Gould (1968), Treadway (1969, 1970, 1971, 1974), Uzawa (1969), Mortenson (1973) and Steigum (1983). These studies indicated that the multivariate flexible accelerator model can be justified theoretically as a solution of a dynamic optimization problem that incorporates adjustment cost for the quasi-fixed factors. The adjustment cost incurred in order to change the level of the quasi-fixed factors can take two forms. The first type is internal and reflects the fact that firms may have to make trade-offs between producing current output and diverting some of the resources from current production to accumulate capital for future production (e.g., Treadway (1974)). The second type is external: As the firm adjusts its quasi-fixed factors it may face either a higher purchase

\footnotetext{
${ }^{10}$ The transcendental logarithmic form has been used by Jorgenson with different associates to study the properties of the production structure and productivity analysis in a number of sectors in the US and Japanese economies and to compare productivity growth among different countries; see Jorgenson (1995a,b).

${ }^{11}$ For a detailed review of the literature and a collection of various other important contributions see Fuss and McFadden (1978a,b).
} 
price for these factors (e.g., Lucas $(1967 a, b))$ or a higher financing cost for the accumulation of these inputs (e.g., Steigum (1983)).

Based on these theoretical development on cost of adjustments a number of dynamic factor demand models referred to as the "third generation models" have been estimated. For comprehensive reviews of this influential literature see Berndt, Morrison and Watkins (1981) and Watkins (1991). Examples include Berndt, Fuss and Waverman (1980), Denny, Fuss and Waverman (1981b), Morrison and Berndt (1981), Morrison (1986a,b), Galeotti (1990), Watkins and Berndt (1992) and Lee and Kwon (1994). Several features of the "third generation" dynamic factor demand models are important to note. First, those models are explicitly dynamic and provide the optimal path of investment from temporary to full long-run equilibrium. The dynamic path of adjustment to long-run equilibrium is based on economic optimization at each point in time; thus short-, intermediate-, and long-run are clearly defined. Second, the speed of adjustment of the quasi-fixed factors to their long-run equilibrium levels is allowed to be endogenous and time varying, rather than exogenous and fixed. Third, the short-run demand equations for variable inputs depend on, among other things, prices of variable inputs, output, and stocks of the quasi-fixed inputs. Variable inputs may in the short-run overshoot their long-run equilibrium values to compensate for the partial adjustment of the quasi-fixed factors.

Empirical applications of third generation dynamic factor demand models typically only allowed for one quasi-fixed factor, or, slightly more generally, for several separable quasi-fixed factors. As a consequence of the separability assumption the models did not allow for interactions between the optimal investment paths. The technical reason for maintaining separability between the quasi-fixed factors was that it facilitated a major simplification in the computation of the firm's optimal investment decision. More specifically, separability implies the absence of interaction between the difference equations describing the optimal investment paths of the respective quasi-fixed factors. As a consequence, each of those equations can be solved separately. Technically this entails the solving of a quadratic equation for each of the quasi-fixed factors - which, of course, can readily be done analytically. If, however, separability is not maintained, then rather than having to solve several quadratic scalar equations, one is confronted with a quadratic matrix equation. Analytic expressions for the solution of this quadratic matrix equation, and hence for optimal investment, are then generally not available.

Other characteristics of the empirical implementation of third generation 
dynamic factor demand models were that the underlying technology was modeled in a linear quadratic fashion, that expectations were typically modeled as static and that factor utilization rates were assumed to be constant. Recent developments were aimed at a relaxation of those assumptions.

\subsection{Theoretical Model Specification}

\subsubsection{Technology and Optimal Control Policy}

For the subsequent discussion we generalize the setup of Section 2, in that we consider a firm that combines the set of variable inputs $V_{t}$ and the set of quasi-fixed inputs $X_{t}$ to produce the set of outputs for current sale $Y_{t}$, as well as a set of capital inputs for future production. More specifically, in the generalized setup we allow the firm to also choose how much of the beginning-of-period stocks of some (but not necessarily all) of the quasifixed capital inputs will be left over at the end of the period. We note that this adopted modeling framework dates back to Hicks (1946), Malinvaud (1953), and Diewert $(1977,1980)$. In the empirical dynamic factor demand literature this framework was first adopted by Epstein and Denny (1980) and Kollintzas and Choi (1985) for the case of a single quasi-fixed factor. Prucha and Nadiri (1990, 1996) generalized the setup by allowing for more than one quasi-fixed factor. They also discuss measures of technical change and capacity utilization for the generalized modeling framework. ${ }^{12}$ We note that the generalized modeling framework contains - as discussed in more detail below - the case where a constant fraction of the beginning-of-period stocks is left over at the end of the period as a special case.

In the following we use $K_{t}$ to denote the vector of the stocks of the quasifixed capital inputs at the end of period $t$ for which the firm chooses how much of the beginning-of-period stocks will be left over at the end of the period, and $K_{t}^{o}$ to denote the vector of "old" stocks left over at the end of period $t$ from the beginning-of-period stocks $K_{t-1}$. Of course, being able to choose the

\footnotetext{
${ }^{12}$ On a theoretical level the generalized modeling framework has also been considered by Bernstein and Nadiri (1987a,b). A special case of the model was implemented in Nadiri and Prucha (1996). Bischoff and Kokkelenberg (1987) adopt a related framework in which the depreciation rate is modeled as a function of capacity utilization. Other contributions to the dynamic factor demand literature that allows for the firm to operate at different levels of utilization, but are based on an alternative modeling framework, include papers by Abel (1981), Bernstein (1983), Kokkelenberg (1984), Honkapohija and Kanniainen (1985), and Shapiro (1986).
} 
level of $K_{t}^{o}$ by, e.g., to choose appropriate levels of maintenance, is equivalent to being able to choose endogenously the rate of depreciation for those stocks, since we can always write $K_{t}^{o}=\left(1-\delta_{t}^{K}\right) K_{t-1}$ and interpret $\delta_{t}^{K}$ as a diagonal matrix of depreciation rates. $R_{t}$ is the vector of the end-of-period stocks of the quasi-fixed factors, whose depreciation rates are exogenous to the firm. We assume furthermore that all quasi-fixed factors become productive with a lag. ${ }^{13}$ In the notation of Section 2 we then have $X_{t}=\left[K_{t-1}^{\prime}, R_{t-1}^{\prime}\right]^{\prime}$ and $\Delta X_{t}=\left[\Delta K_{t}^{\prime}, \Delta R_{t}^{\prime}\right]^{\prime}$. Furthermore, as in Section 2 we will decompose the variable inputs as $V_{t}=\left[M_{t}, L_{t}^{\prime}\right]^{\prime}$.

In more detail, we assume that the firm's technology can be represented by the following factor requirement function:

$$
M_{t}=M\left(Y_{t}, L_{t}, K_{t}^{o}, K_{t-1}, R_{t-1}, \Delta K_{t}, \Delta R_{t}, T_{t}\right) .
$$

This specification generalizes the factor requirement function considered in (2.2) in that it includes the vector of capital stocks left over at the end of the period $K_{t}^{o}$. The stocks $K_{t}$ and $R_{t}$ accumulate according to the following equations:

$$
K_{t}=I_{t}^{K}+K_{t}^{o}, \quad R_{t}=I_{t}^{R}+\left(I-\delta_{t}^{R}\right) R_{t-1},
$$

where $I_{t}^{K}$ and $I_{t}^{R}$ denote the respective vectors of gross investment and $\delta_{t}^{R}$ denotes the diagonal matrix of exogenous depreciation rates (some of which may be zero).

The firm's cost in period $t$, normalized by the price of the variable factor $M_{t}$, is given by

$$
M_{t}+\left(p_{t}^{L}\right)^{\prime} L_{t}+\left(q_{t}^{K}\right)^{\prime} I_{t}^{K}+\left(q_{t}^{R}\right)^{\prime} I_{t}^{R}
$$

where $q_{t}^{K}$ and $q_{t}^{R}$ denote the prices of new investment goods after taxes, possibly normalized by $1-u_{t}$, where $u_{t}$ denotes the corporate tax rate. ${ }^{14} \mathrm{We}$

\footnotetext{
${ }^{13}$ This assumption is made for simplicity of exposition. For a generalization where some of the quasi-fixed factors immediately become productive and some become productive with a lag see Prucha and Nadiri $(1990,1996)$.

${ }^{14}$ As an illustration, suppose $K$ is a scalar and corresponds to the stock of a certain capital good; then $q^{K}$ may equal $[1-c-u(1-m c) B] p^{I K} /(1-u)$, where $p^{I K}$ denotes the price of new investment goods, $u$ denotes the corporate tax rate, $c$ is the rate of the investment tax credit, $m$ is the portion of the investment tax credit which reduces the depreciable base for tax purposes, and $B$ is the present value of depreciation allowances. We note that the appropriate expressions for the price of new investment goods after taxes are actually obtained by explicitly introducing taxes into the firm's objective function. As a result, the price of new investment goods after taxes will in general also depend on expectations on future tax variables. We have not chosen this route for simplicity of presentation.
} 
assumed that the firm faces perfectly competitive markets with respect to its factor inputs.

Suppose the firm's objective is to minimize the expected present value of its future cost stream. ${ }^{15}$ Substitution of (3.1) and (3.2) into (3.3) then yields the following expression for the firm's objective function:

$$
\begin{aligned}
& E_{t} \sum_{\tau=t}^{\infty}\left[M\left(Y_{\tau}, L_{\tau}, K_{\tau}^{o}, K_{\tau-1}, R_{\tau-1}, \Delta K_{\tau}, \Delta R_{\tau}, T_{\tau}\right)+\left(p_{\tau}^{L}\right)^{\prime} L_{\tau}-\left(q_{\tau}^{K}\right)^{\prime} K_{\tau}^{o}\right. \\
& \left.+\left(q_{\tau}^{K}\right)^{\prime} K_{\tau}+\left(q_{\tau}^{R}\right)^{\prime}\left[R_{\tau}-\left(I-\delta_{\tau}^{R}\right) R_{\tau-1}\right]\right] \prod_{s=t}^{\tau}\left(1+r_{s}\right)^{-1}
\end{aligned}
$$

where $E_{t}$ denotes the expectations operator conditional on the set of information available in period $t$ and $r$ denotes the real discount rate (which may possibly also incorporate variations in the corporate tax rate).

Suppose the firm follows a stochastic closed loop feedback control policy in minimizing the expected present value of its future cost stream (3.4). Then, in period $t$ the firm will choose optimal values for its current inputs $L_{t}$, $K_{t}, R_{t}$, and for $K_{t}^{o}$. At the same time the firm will choose a contingency plan for setting $L_{\tau}, K_{\tau}, R_{\tau}$, and $K_{\tau}^{o}$ in periods $\tau=t+1, t+2, \ldots$ optimally, depending on observed realizations of the exogenous variables and past choices for the quasi-fixed factors. Of course, for given optimal values for $L_{\tau}, K_{\tau}$, $R_{\tau}$, and $K_{\tau}^{o}$ the optimal values for $M_{\tau}$ are implied by (3.1). Prices, output and the discount rate are assumed to be exogenous to the firm's optimization problem.

Since $L_{\tau}$ and $K_{\tau}^{o}$ can be changed without adjustment costs the stochastic closed loop feedback control solution can be found conveniently in two steps. In the first step we minimize the total (normalized) cost in each period $\tau=$ $t, t+1, \ldots$ with respect to $L_{\tau}$ and $K_{\tau}^{o}$ for given values of the quasi-fixed factors and the exogenous variables. Substitution of the minimized expressions into (3.4) then leads in the second step to an optimal control problem that only involves the quasi-fixed factors $K_{\tau}$ and $R_{\tau}$.

The part of total cost that actually depends on $L_{\tau}$ and $K_{\tau}^{o}$ is given by

$$
M\left(Y_{\tau}, L_{\tau}, K_{\tau}^{o}, K_{\tau-1}, R_{\tau-1}, \Delta K_{\tau}, \Delta R_{\tau}, T_{\tau}\right)+\left(p_{\tau}^{L}\right)^{\prime} L_{\tau}-\left(q_{\tau}^{K}\right)^{\prime} K_{\tau}^{o}
$$

i.e., variable cost minus the value of the "old" stocks left over at the end of the period from the beginning of period stocks. Assuming that $M($.$) is$

\footnotetext{
${ }^{15}$ We note that the subsequent theoretical discussion can be readily modified also to apply to the case of a profit maximizing firm.
} 
differentiable and that a unique interior minimum of the above expression exists, the first order conditions for that minimum are given by:

$$
\frac{\partial M_{\tau}}{\partial L_{\tau}}+\left(p_{\tau}^{L}\right)^{\prime}=0, \quad \frac{\partial M_{\tau}}{\partial K_{\tau}^{o}}-\left(q_{\tau}^{K}\right)^{\prime}=0 .
$$

Let $\hat{L}_{\tau}$ and $\hat{K}_{\tau}^{o}$ denote the minimizing vectors, then the minimum of the variable cost minus the value of the "old" stocks is given by

$$
\begin{aligned}
G_{\tau} & =G\left(p_{\tau}^{L}, q_{\tau}^{K}, Y_{\tau}, K_{\tau-1}, R_{\tau-1}, \Delta K_{\tau}, \Delta R_{\tau}, T_{\tau}\right) \\
& =\hat{M}_{\tau}+\left(p_{\tau}^{L}\right)^{\prime} \hat{L}_{\tau}-\left(q_{\tau}^{K}\right)^{\prime} \hat{K}_{\tau}^{o},
\end{aligned}
$$

with $\hat{M}_{\tau}=M\left(Y_{\tau}, \hat{L}_{\tau}, \hat{K}_{\tau}^{o}, K_{\tau-1}, R_{\tau-1}, \Delta K_{\tau}, \Delta R_{\tau}, T_{\tau}\right)$. The function $G($.$) has$ the interpretation of a normalized variable cost function net of the value of the "old" stocks left over at the end of the period from the beginning of period stocks. Technically it can be viewed as the negative of a normalized restricted profit function. For duality results between factor requirement functions and normalized variable profit functions see, e.g., Diewert (1982) and Lau (1976). We assume that the function $G($.$) is twice continuously$ differentiable in all its arguments, homogeneous of degree zero in $p^{L}$ and $q^{K}$, non-decreasing in $Y,|\Delta K|,|\Delta R|$ and $p^{L}$, non-increasing in $K_{-1}, R_{-1}$ and $q^{K}$, concave in $p^{L}$ and $q^{K}$, and convex in $K_{-1}, R_{-1}, \Delta K$ and $\Delta R$.

As indicated above, the stochastic closed loop optimal control solution for the quasi-fixed factors can now be found by replacing $M_{\tau}+\left(p_{\tau}^{L}\right)^{\prime} L_{\tau}-\left(q_{\tau}^{K}\right)^{\prime} K_{\tau}^{o}$ in (3.4) by $G\left(p_{\tau}^{L}, q_{\tau}^{K}, Y_{\tau}, K_{\tau-1}, R_{\tau-1}, \Delta K_{\tau}, \Delta R_{\tau}, T_{\tau}\right)$ defined in (3.7), and then by minimizing

$$
\begin{aligned}
& E_{t} \sum_{\tau=t}^{\infty}\left[G\left(p_{\tau}^{L}, q_{\tau}^{K}, Y_{\tau}, K_{\tau-1}, R_{\tau-1}, \Delta K_{\tau}, \Delta R_{\tau}, T_{\tau}\right)\right. \\
& \left.+\left(q_{\tau}^{K}\right)^{\prime} K_{\tau}+\left(q_{\tau}^{R}\right)^{\prime}\left[R_{\tau}-\left(I-\delta_{\tau}^{R}\right) R_{\tau-1}\right]\right] \prod_{s=t}^{\tau}\left(1+r_{s}\right)^{-1}
\end{aligned}
$$

with respect to the quasi-fixed factors $\left\{K_{\tau}, R_{\tau}\right\}_{\tau=t}^{\infty}$ only. Standard control theory implies that the stochastic closed loop feedback control solution that minimizes (3.8), say $\left\{\hat{K}_{\tau}, \hat{R}_{\tau}\right\}_{\tau=t}^{\infty}$, must satisfy the following set of stochastic Euler equations $(\tau=t, t+1, \ldots):{ }^{16}$

$$
-E_{\tau} \frac{\partial G_{\tau+1}}{\partial K_{\tau}}\left(1+r_{\tau+1}\right)^{-1}=\left(q_{\tau}^{K}\right)^{\prime}
$$

\footnotetext{
${ }^{16}$ Compare, e.g., Stokey, Lucas and Prescott (1989), ch.9, for a more detailed list of assumptions and a careful exposition of stochastic control theory, as well as for a discussion of the transversality condition.
} 


$$
\begin{aligned}
& +\frac{\partial G_{\tau}}{\partial \Delta K_{\tau}}-E_{\tau} \frac{\partial G_{\tau+1}}{\partial \Delta K_{\tau+1}}\left(1+r_{\tau+1}\right)^{-1} \\
-E_{\tau} \frac{\partial G_{\tau+1}}{\partial R_{\tau}}\left(1+r_{\tau+1}\right)^{-1}= & \left(c_{\tau}^{R}\right)^{\prime} \\
& +\frac{\partial G_{\tau}}{\partial \Delta R_{\tau}}-E_{\tau} \frac{\partial G_{\tau+1}}{\partial \Delta R_{\tau+1}}\left(1+r_{\tau+1}\right)^{-1}
\end{aligned}
$$

where

$$
c_{\tau}^{R}=E_{\tau}\left[q_{\tau}^{R}\left(1+r_{\tau+1}\right)-\left(I-\delta_{\tau}^{R}\right) q_{\tau+1}^{R}\right] /\left(1+r_{\tau+1}\right)
$$

can be viewed as a vector of rental prices. The firm's optimization decisions with respect to $L_{\tau}$ and $K_{\tau}^{o}$ are incorporated in the stochastic Euler equations via $G_{\tau}$. (Recall from (3.7) that $G_{\tau}$ gives the minimal value of the variable cost net of the value of the "old" stocks for given values of the quasi-fixed factors and exogenous variables.) A detailed economic interpretation of the stochastic Euler equations is given in Appendix B.

The optimal values for $L_{\tau}$ and $K_{\tau}^{o}$ can be found by differentiating $G_{\tau}$ with respect to $p_{\tau}^{L}$ and $q_{\tau}^{K}$ and then making use of (3.6), i.e., via Shephard's and Hotelling's lemma: ${ }^{17}$

$$
\hat{L}_{\tau}=\left(\frac{\partial G_{\tau}}{\partial p_{\tau}^{L}}\right)^{\prime}, \quad \hat{K}_{\tau}^{o}=-\left(\frac{\partial G_{\tau}}{\partial q_{\tau}^{K}}\right)^{\prime} .
$$

The derivatives on the r.h.s. of the above equations need to be evaluated at the optimal control solution for the quasi-fixed factors.

The formulation of a stochastic closed loop control policy generally requires knowledge of the entire distribution of the exogenous variables. Alternatively one may postulate - as will be the case in the empirical application - that the firm formulates a certainty equivalence feedback control policy, which only requires knowledge of the first moment (mean) of the exogenous variables. In that case the firm's objective function is given by (3.4) or (3.8) with the expectations operator moved next to each of the exogenous variables. The firm would now devise in each period $t$ an optimal plan for its inputs in periods $t, t+1, \ldots$ such that its objective function in period $t$ is optimized, and then choose its inputs in period $t$ accordingly. In each future period the firm will revise its expectations and optimal plan for its inputs based on new information. In case of a certainty equivalence feedback control policy the

\footnotetext{
${ }^{17}$ In case of a profit maximizing model we have furthermore the following condition for the output vector: $\partial G_{\tau} / \partial Y_{\tau}=p_{\tau}^{Y}+\left[\partial p_{\tau}^{Y} / \partial Y_{\tau}\right] Y_{\tau}$.
} 
first order conditions for the optimal plan in period $t$ for the quasi-fixed factors would be given by (3.9) and (3.10) with all exogenous variables replaced by their expected values (conditional on information available at time $t$ and the expectations operator in front of the respective derivatives suppressed). Equations (3.11) remain the same. If $G($.$) is linear-quadratic, then the well$ known certainty equivalence principle implies that the stochastic closed loop and the certainty equivalence feedback control policy are identical. ${ }^{18}$

\subsubsection{Generalized Expressions for Technical Change and Total Factor Productivity Decomposition}

The discussion in Section 2 considered the case where the depreciation rates of all of the quasi-fixed factors are exogenously given. In this section we have allowed the depreciation rate of some of the quasi-fixed factors to be endogenously determined. Analogously to equations (2.4) and (2.15) in Section 2.1 we can define primal and dual measures of input based technical change $\lambda^{X}$, output based technical change $\lambda^{Y}$, and scale $\rho$, and we can define measures of capacity utilization for the generalized technology considered in this section. Those expressions are given in Prucha and Nadiri (1990, 1996), and are not repeated here in order to conserve space. ${ }^{19}$ Analogously to equations (2.39), (2.40) and equations (2.43), (2.44) in Section 2.2 one can also obtain, respectively, a decomposition of the growth rate of total factor productivity and its Törnqvist index based approximation. A generalization of the decomposition (2.39), (2.40) of the growth rate of total factor productivity in continuous time is given in Appendix B. The generalization of the Törnqvist index based approximation $(2.43),(2.44)$ is analogous. For the case of a single output good the latter generalization is also given in Prucha and Nadiri (1990, 1996).

\subsubsection{Flexible Functional Forms of Restricted Cost Functions}

Empirical specifications of dynamic factor demand models typically model the underlying technology in a "flexible" fashion. As discussed at the begin-

\footnotetext{
${ }^{18}$ For general technologies input decisions corresponding to the latter policy may be viewed as first-order approximations to those of the former policy; see, e.g., Simon (1956), Theil (1957) and Malinvaud (1969) on the principle of certainty and first-order certainty equivalence.

${ }^{19}$ There are some typos in Prucha and Nadiri (1996) in that between equations (3.4) and (3.6) $c^{K}$ and $c^{R}$ should read $\underline{c}^{K}$ and $\underline{c}^{R}$, and in equation (3.9) $C^{+}$should read $C$.
} 
ning of Section 3, flexible functional forms of cost and production functions have first been introduced by Diewert (1971) and Christensen, Jorgenson and Lau $(1971,1973)$. In the dynamic factor demand literature the technology has often been modeled in terms of a normalized restricted cost function; see, e.g., Berndt, Fuss and Waverman (1980) for an early application. In the following we discuss some of the functional forms used in the recent literature. ${ }^{20}$

Recall that in our notation $K$ refers to the vector of quasi-fixed factors whose depreciation rate is endogenously determined, and $R$ refers to the vector of quasi-fixed factors whose depreciation rates are exogenous. For ease of presentation we focus the subsequent discussion on the case where the depreciation rates of all quasi-fixed factors are exogenous to the firm. ${ }^{21}$ In this case the normalized restricted cost function (3.7) simplifies to

$$
G_{\tau}=G\left(p_{\tau}^{L}, Y_{\tau}, R_{\tau-1}, \Delta R_{\tau}, T_{\tau}\right)
$$

given that we can now suppress $K$ (and thus $q^{K}$ ). Also, we focus the discussion on the case of a single output good $Y$. Furthermore, for ease of presentation, we drop time subscripts in the following.

Observe that for linear homogenous technologies we have

$$
G\left(p^{L}, Y, R_{-1}, \Delta R, T\right)=g\left(p^{L}, \frac{R_{-1}}{Y}, \frac{\Delta R}{Y}, T\right) Y .
$$

The normalized restricted cost function introduced by Denny, Fuss and Waverman (1981b) and Morrison and Berndt (1981) is of the form

$$
\begin{aligned}
& G\left(p^{L}, Y, R_{-1}, \Delta R, T\right) \\
= & Y\left\{\alpha_{0}+\left(a_{L}\right)^{\prime} p^{L}+\left(a_{R}\right)^{\prime} \frac{R_{-1}}{Y}+\left(a_{\dot{R}}\right)^{\prime} \frac{\Delta R}{Y}+\alpha_{T} T\right. \\
& +0.5\left(p^{L}\right)^{\prime} A_{L L} p^{L}+\left(p^{L}\right)^{\prime} A_{L R} \frac{R_{-1}}{Y}+\left(p^{L}\right)^{\prime} A_{L \dot{R}} \frac{\Delta R_{-1}}{Y}+\left(a_{L T}\right)^{\prime} p^{L} T \\
& +0.5 \frac{R_{-1}^{\prime}}{Y} A_{R R} \frac{R_{-1}}{Y}+\frac{R_{-1}^{\prime}}{Y} A_{R \dot{R}} \frac{\Delta R}{Y}+\left(a_{R T}\right)^{\prime} \frac{R_{-1}}{Y} T \\
& \left.+0.5 \frac{\Delta R^{\prime}}{Y} A_{\dot{R} R} \frac{\Delta R}{Y}+\left(a_{\dot{R} T}\right)^{\prime} \frac{\Delta R}{Y} T+0.5 \alpha_{T T} T^{2}\right\}
\end{aligned}
$$

\footnotetext{
${ }^{20}$ For general surveys of functional forms in modeling the firm's technology see, e.g., Fuss, McFadden and Mundlak (1978) and Lau (1986).

${ }^{21}$ The discussion can readily be extended to the case where both types of quasi-fixed factors are present.
} 
where $\alpha_{0}, \alpha_{T}, \alpha_{T T}$ are (scalar) parameters, $a_{L}, a_{R}, a_{\dot{R}}, a_{L T}, a_{R T}, a_{\dot{R} T}$ are conformably dimensioned parameter vectors and $A_{L L}, A_{L R}, A_{L \dot{R}}, A_{R R}, A_{R \dot{R}}$, $A_{\dot{R} \dot{R}}$ are conformably dimensioned parameter matrices. The normalized restricted cost function (3.14) can be viewed as having been obtained from a second order approximation of $g\left(p^{L}, R_{-1} / Y, \Delta R / Y, T\right)$. Following Denny, Fuss and Waverman (1981b) and Morrison and Berndt (1981) the above normalized restricted cost function can be simplified by imposing parameter restrictions such that the marginal adjustment costs are zero at $\Delta R=0$, i.e. $a_{\dot{R}}=0, A_{L \dot{R}}=0, A_{R \dot{R}}=0, a_{\dot{R} T}=0$.

Nadiri and Prucha $(1983,1990 b)$ generalize this normalized restricted cost function to cover also homothetic technologies by replacing $Y$ on the r.h.s. of (3.14) by $h(Y)=Y^{\phi_{0}+\phi_{1}} \ln (Y)$. This generalization is based on the observation that the normalized restricted cost function corresponding to homothetic technologies is of the following general form:

$$
G\left(p^{L}, Y, R_{-1}, \Delta R, T\right)=g\left(p^{L}, \frac{R_{-1}}{H(Y)}, \frac{\Delta R}{H(Y)}, T\right) H(Y)
$$

where $H(Y)$ is some function of $Y$. We note that $h(Y)$ can - apart from a scaling factor - be viewed as a second order translog approximation of $H(Y)$, assuming the latter function is sufficiently smooth. ${ }^{22}$ Utilizing (2.15) it is readily seen that scale is given by $[(d H / d Y)(Y / H)]^{-1}$. In the special case where $H(Y)=Y^{\phi_{1}}$ scale equals $1 / \phi_{1}$.

A convenient feature of the normalized restricted cost function (3.14) and its generalization is that it allows for closed form solutions for the firm's optimal factor demand. However, the factor demand equations implied by these restricted cost functions are not symmetric in the sense that they are not invariant as to which of the variable factors is chosen as the numeraire. Thus different normalizations represent different specifications of the technology, which may seem arbitrary.

Recently Mohnen (1992a) introduced a new restricted cost function which treats all factors symmetrically, but also allows for closed form solutions for the firm's optimal factor demand. This cost function generalizes the symmetric Generalized McFadden cost function put forth by Diewert and Wales (1987) through the inclusion of quasi-fixed factors. The manner in which the quasi-fixed factors are introduced is analogous to that in (3.15).

\footnotetext{
${ }^{22}$ Suppose we approximate $H(Y)$ in terms of a second-order expansion in logs, then $\ln H(Y) \doteq$ const $+\phi_{0} \ln Y+\phi_{1}(\ln Y)^{2}=$ const $+\ln h(Y)$, and therefore $H(Y) \dot{\propto} Y^{\phi_{0}+\phi_{1}} \ln Y$.
} 
A further restricted cost function which treats all factors symmetrically was suggested by Morrison $(1988,1990)$. This restricted cost function represents an extension of the Generalized Leontief restricted cost function introduced by Diewert (1971). Prucha (1990) points out, however, that Morrison's restricted cost function is not invariant to units of measurement. Thus different choices of the units of measurements represent different specifications of the technology, which may again seem arbitrary. Prucha (1990) suggests a modification of Morrison's restricted cost function such that the resulting function is invariant to units of measurement. Based on the observation in (3.15) he also suggests a generalization to cover homothetic technologies.

For all of the above discussed functional forms the implied Euler equations form in essence a linear system of difference equations, which can be solved explicitly along the lines discussed in Section 3.2 below. The Euler equation estimation approach discussed in Section 3.3 below does not require an explicit solution of the Euler equations. A functional form that has been used widely in conjunction with this approach is the tanscendental logarithmic functional form introduced by Christensen, Jorgenson and Lau (1971, 1973).

For pooling data from different units, such as industries or countries, an interesting modeling strategy is the meta-production function approach. This approach dates back to Hayami and Ruttan $(1970,1985)$. It has been recently used and further extended in a series of papers by Boskin and Lau (1991, 1992a, 1992b), Kim and Lau (1994, 1996) and Lau and Yotopoulos (1989).

\subsection{Solution and Estimation of Dynamic Factor De- mand Models in Case of Linear Quadratic Tech- nologies}

Section 3.1 provided a general discussion of recent vintages of dynamic factor demand models. In this section we consider in more detail dynamic factor demand models in case the firm's optimal control problem is of a "linear quadratic" nature. In this case it is possible to obtain explicit analytic solutions for the firm's optimal factor inputs. We start the discussion by considering a specific example. We then consider the solution and estimation of a general class of "linear quadratic" dynamic factor demand models. To keep this discussion widely applicable we only specify the model in terms 
of a set of first order conditions, rather than in terms of a specific cost or profit maximization problem. The last subsection discusses potential pitfalls in using formulae for the optimal factor inputs derived from a continuous time model for estimation from discrete data.

\subsubsection{Illustrative Example with Endogenous Depreciation Rate}

In this subsection we illustrate the solution and estimation of dynamic factor demand models by considering in detail a specific example of the model considered in Section 3.1. As our illustrative model we consider the model employed by Prucha and Nadiri $(1990,1996)$ in analyzing the production structure, factor demand and productivity growth in the US electrical machinery industry. More specifically, we consider a model with two variable inputs $M_{t}$ and $L_{t}$, two quasi-fixed factors $K_{t}$ and $R_{t}$, and one output good $Y_{t}$. Following Prucha and Nadiri $(1990,1996)$ we may assume that $M_{t}$ and $L_{t}$ denote, respectively, material input and labor input, and $K_{t}$ and $R_{t}$ denote, respectively, the end of period stocks of physical capital and R\&D, and $Y_{t}$ denotes gross output. We allow for the firm to determine the depreciation rate of capital endogenously, in that we allow the firm to choose $K_{t}^{o}$, the level of "old" stocks left over at the end of period $t$ from $K_{t-1}$. The depreciation rate of $\mathrm{R} \& \mathrm{D} \delta^{R}$ is fixed. With $p_{t}^{L}$ we denote the price of labor, and $q_{t}^{K}$ and $q_{t}^{R}$ denote the after tax acquisition price for capital and R\&D normalized by the price of material goods. The real discount rate $r$ is taken to be constant over time.

To model the technology, we specify (dropping subscripts $t$ ) the following functional form for the normalized variable cost function net of the value of the "old" stocks as:

$$
\begin{aligned}
& G\left(p^{L}, q^{K}, K_{-1}, R_{-1}, \Delta K, \Delta R, Y, T\right) \\
= & Y^{1 / \rho}\left\{\alpha_{0}+\alpha_{L} p^{L}+\alpha_{L T} p^{L} T+\frac{1}{2} \alpha_{K^{o} K^{o}}\left(q^{K}\right)^{2}+\alpha_{L K^{o}} p^{L} q^{K}+\frac{1}{2} \alpha_{L L}\left(p^{L}\right)^{2}\right\} \\
& +\alpha_{K} K_{-1}+\alpha_{R} R_{-1}+\alpha_{K L} K_{-1} p^{L}+\alpha_{K K^{o}} K_{-1} q^{K} \\
& +\alpha_{R L} R_{-1} p^{L}+\alpha_{R K^{o}} R_{-1} q^{K}+\alpha_{K T} K_{-1} T+\alpha_{R T} R_{-1} T \\
& +Y^{-1 / \rho}\left\{\frac{1}{2} \alpha_{K K} K_{-1}^{2}+\alpha_{K R} K_{-1} R_{-1}+\frac{1}{2} \alpha_{R R} R_{-1}^{2}\right. \\
& \left.+\frac{1}{2} \alpha_{\dot{K} \dot{K}} \Delta K^{2}+\frac{1}{2} \alpha_{\dot{R} \dot{R}} \Delta R^{2}\right\} .
\end{aligned}
$$

We note that the adopted functional form is a special case of the linear 
quadratic restricted cost function specified in (3.14) - abstracting form the fact that for notational simplicity the specification (3.14) was only given for the case where the depreciation rates for all quasi-fixed factors are exogenously given. In light of the above discussion we note further that the technology specified by (3.16) is homogeneous of degree $\rho$. Also recall that by duality theory $G($.$) is convex in K, R, \Delta K, \Delta R$ and concave in $p^{L}$ and $q^{K}$. This implies the following parameter restrictions: $\alpha_{K K}>0, \alpha_{R R}>$ $0, \alpha_{K K} \alpha_{R R}-\alpha_{K R}^{2}>0, \alpha_{\dot{K} \dot{K}}>0, \alpha_{\dot{R} \dot{R}}>0, \alpha_{L L}<0, \alpha_{K^{o} K^{o}}<0$, $\alpha_{L L} \alpha_{K^{o} K^{o}}-\alpha_{L K^{o}}^{2}>0$.

Now suppose the firm's objective is to minimize the present value of its future cost stream. Suppose further that the firm determines its inputs according to a certainty equivalence feedback control policy, and holds static expectations on relative prices, output and the technology. In this case the firm's objective function is given by the certainty equivalence analog of (3.8) with $G($.$) defined by (3.16). As discussed above, in each period t$ the firm establishes a plan for periods $t, t+1, \ldots$ of how to choose its inputs optimally by optimizing this objective function conditional on its expectations, and implements the plan for the current period $t$ (only). The plan is revised every period as new information becomes available. For simplicity we assume that expected (relative) prices equal current (relative) prices. The certainty equivalence analog of the Euler equations (3.9) and (3.10) is then given by $(\tau=0,1, \ldots)$

$$
\begin{aligned}
& -\alpha_{\dot{K} \dot{K}} K_{t+\tau+1}+\left[\alpha_{K K}+(2+r) \alpha_{\dot{K} \dot{K}}\right] K_{t+\tau} \\
& -(1+r) \alpha_{\dot{K} \dot{K}} K_{t+\tau-1}+\alpha_{K R} R_{t+\tau} \\
= & -\left[\alpha_{K}+\alpha_{K T} T_{t}+\alpha_{K L} p_{t}^{L}+q_{t}^{K}\left(1+r+\alpha_{K K^{o}}\right)\right] \widehat{Y}_{t}^{1 / \rho}, \\
& -\alpha_{\dot{R} \dot{R}} R_{t+\tau+1}+\left[\alpha_{R R}+(2+r) \alpha_{\dot{R} \dot{R}}\right] R_{t+\tau} \\
& -(1+r) \alpha_{\dot{R} \dot{R}} R_{t+\tau-1}+\alpha_{K R} K_{t+\tau} \\
= & -\left[\alpha_{R}+\alpha_{R T} T_{t}+\alpha_{R L} p_{t}^{L}+q_{t}^{R}\left(r+\delta^{R}\right)\right] \widehat{Y}_{t}^{1 / \rho} .
\end{aligned}
$$

where $\widehat{Y}_{t}$ denotes expected output. In solving (3.17) we restrict the solution space to the class of processes that are of mean exponential order less than $(1+r)^{1 / 2} .{ }^{23}$ This rules out the unstable roots. (Of course, the unstable

\footnotetext{
${ }^{23} \mathrm{~A}$ vector process, say, $\eta_{t}$ is said to be of mean exponential order less than $\kappa$ if there exist constants $c$ and $\lambda$ with $0<\lambda<\kappa$ such that $E_{t}\left\|\eta_{t+j}\right\| \leq c \lambda^{t+j}$ for all $t$ and $j>0$.
} 
roots can also be ruled out by imposing the transversality condition.) As demonstrated in Appendix B, solving (3.17) yields:

$$
\begin{aligned}
\Delta K_{t} & =m_{K K}\left(K_{t}^{*}-K_{t-1}\right)+m_{K R}\left(R_{t}^{*}-R_{t-1}\right), \\
\Delta R_{t} & =m_{R K}\left(K_{t}^{*}-K_{t-1}\right)+m_{R R}\left(R_{t}^{*}-R_{t-1}\right),
\end{aligned}
$$

with

$$
\begin{aligned}
{\left[\begin{array}{c}
K_{t}^{*} \\
R_{t}^{*}
\end{array}\right]=} & -\left[\begin{array}{ll}
\alpha_{K K} & \alpha_{K R} \\
\alpha_{K R} & \alpha_{R R}
\end{array}\right]^{-1} \\
& \times\left[\begin{array}{l}
\alpha_{K}+\alpha_{K T} T_{t}+\alpha_{K L} p_{t}^{L}+q_{t}^{K}\left(1+r+\alpha_{K K^{o}}\right) \\
\alpha_{R}+\alpha_{R T} T_{t}+\alpha_{R L} p_{t}^{L}+q_{t}^{R}\left(r+\delta^{R}\right)
\end{array}\right] \widehat{Y}_{t}^{1 / \rho}
\end{aligned}
$$

That is, the optimal quasi-fixed inputs can be described in terms of an accelerator model. As demonstrated in the appendix, the accelerator coefficients $M=\left(m_{i j}\right)_{i, j=K, R}$ have to satisfy the following matrix equation:

$$
B M^{2}+(A+r B) M-A=0
$$

with $A=\left(\alpha_{i j}\right)_{i, j=K, R}$ and where $B$ is the diagonal matrix with elements $\alpha_{\dot{K} \dot{K}}$ and $\alpha_{\dot{R} \dot{R}}$ in the diagonal. In the appendix we demonstrate further that the matrix $C=\left(c_{i j}\right)_{i, j=K, R}=-B M$ is symmetric and negative definite.

The firm's demand equations for the variable factors and the firm's optimal choice for the "old" stock (to be left over from the beginning-of-period capital stock) can be derived from (3.16) - using Shephard's and Hotelling's lemma - as $M_{t}=G_{t}-p_{t}^{L} L_{t}+q_{t}^{K} K_{t}^{o}, L_{t}=\partial G_{t} / \partial p_{t}^{L}$, and $K_{t}^{o}=-\partial G_{t} / \partial q_{t}^{K}$ :

$$
\begin{aligned}
M_{t}= & \left\{\alpha_{0}-\frac{1}{2} \alpha_{K^{o} K^{o}}\left(q_{t}^{K}\right)^{2}-\alpha_{L K^{o}} p_{t}^{L} q_{t}^{K}-\frac{1}{2} \alpha_{L L}\left(p_{t}^{L}\right)^{2}\right\} \widehat{Y}_{t}^{1 / \rho} \\
& +\alpha_{K} K_{t-1}+\alpha_{R} R_{t-1}+\alpha_{K T} K_{t-1} T_{t}+\alpha_{R T} R_{t-1} T_{t} \\
& +\left\{\frac{1}{2} \alpha_{K K} K_{t-1}^{2}+\alpha_{K R} K_{t-1} R_{t-1}+\frac{1}{2} \alpha_{R R} R_{t-1}^{2}\right. \\
& \left.+\frac{1}{2} \alpha_{\dot{K} \dot{K}} \Delta K_{t}^{2}+\frac{1}{2} \alpha_{\dot{R} \dot{R}} \Delta R_{t}^{2}\right\} / \widehat{Y}_{t}^{1 / \rho} \\
L_{t}= & \left\{\alpha_{L}+\alpha_{L T} T_{t}+\alpha_{L K^{o}} q_{t}^{K}+\alpha_{L L} p_{t}^{L}\right\} \widehat{Y}_{t}^{1 / \rho} \\
& +\alpha_{K L} K_{t-1}+\alpha_{R L} R_{t-1},
\end{aligned}
$$

and 


$$
K_{t}^{o}=-\left\{\alpha_{L K^{o}} p_{t}^{L}+\alpha_{K^{o} K^{o}} q_{t}^{K}\right\} \widehat{Y}_{t}^{1 / \rho}-\alpha_{K K^{o}} K_{t-1}-\alpha_{R K^{o}} R_{t-1} .
$$

Equation (3.21) provides an economic model for $K_{t}^{o}$ and hence for the depreciation rate of capital $\delta_{t}^{K}$; recall that the depreciation rate of capital is implicitly defined by $K_{t}^{o}=\left(1-\delta_{t}^{K}\right) K_{t-1}$. Equation (3.21) explains $K_{t}^{o}$ as a function of relative prices, output and lagged stocks. The case of a constant and exogenously given depreciation rate is contained as a special case with $\alpha_{L K^{o}}=\alpha_{K^{o} K^{o}}=\alpha_{R K^{o}}=0$ and $\alpha_{K K^{o}}=-\left(1-\delta^{K}\right)$. We emphasize that by imposing those zero restrictions we can formally test whether or not the depreciation rate is constant. ${ }^{24}$

One difficulty we face in trying to estimate this model is that in general the quadratic matrix equation (3.19) cannot be solved for $M$ in terms of $A$ and $B$. The equation can, however, be solved for $A$ in terms of $M$ and $B$ : $A=B M(M+r I)(I-M)^{-1}$. Since the real discount rate $r$ was assumed to be constant, the matrix $M$ is constant over the sample. Hence, instead of estimating the elements of $A$ and $B$, we may estimate those of $M$ and $B .{ }^{25}$ To impose the symmetry of $C$ we can also estimate $B$ and $C$ instead of $B$ and $M$. Observe that $A=C-(1+r)\left[B-B(C+B)^{-1} B\right]$ and hence

$$
\begin{aligned}
\alpha_{K K} & =c_{K K}-(1+r)\left[\alpha_{\dot{K} \dot{K}}-\left(\alpha_{\dot{K} \dot{K}}\right)^{2}\left(\alpha_{\dot{R} \dot{R}}+c_{R R}\right) / f\right], \\
\alpha_{R R} & =c_{R R}-(1+r)\left[\alpha_{\dot{R} \dot{R}}-\left(\alpha_{\dot{R} \dot{R}}\right)^{2}\left(\alpha_{\dot{K} \dot{K}}+c_{K K}\right) / f\right], \\
\alpha_{K R} & =c_{K R}-(1+r)\left(\alpha_{\dot{K} \dot{K}} \alpha_{\dot{R} \dot{R}} c_{K R}\right) / f,
\end{aligned}
$$

with

$$
f=\left(\alpha_{\dot{K} \dot{K}}+c_{K K}\right)\left(\alpha_{\dot{R} \dot{R}}+c_{R R}\right)-c_{K R}^{2} .
$$

To re-parameterize (3.18) it also proves helpful to define $D=\left(d_{i j}\right)_{i, j=K, R}=$ $-M A^{-1}$. Observe that $D=B^{-1}+(1+r)(C-r B)^{-1}$. Hence $D$ is symmetric

\footnotetext{
${ }^{24}$ As discussed in more detail in Section 4, Prucha and Nadiri (1996) cannot reject the hypothesis of a constant depeciation rate for physical capital in the U.S. electrical machinery industry.

${ }^{25}$ This re-parameterization approach was first suggested by Epstein and Yatchew (1985) for a somewhat different model with a similar algebra, and was further generalized by Madan and Prucha (1989). It will be discussed in more detail and within a generalized setting in the next subsection. For additional empirical studies utilizing the reparameterization approach see, e.g., Mohnen, Nadiri and Prucha (1986) and Nadiri and Prucha (1990a,b).
} 
and its elements are given by

$$
\begin{aligned}
d_{K K} & =1 / \alpha_{\dot{K} \dot{K}}+(1+r)\left[c_{R R}-r \alpha_{\dot{R} \dot{R}}\right] / e, \\
d_{R R} & =1 / \alpha_{\dot{R} \dot{R}}+(1+r)\left[c_{K K}-r \alpha_{\dot{K} \dot{K}}\right] / e, \\
d_{K R} & =-(1+r) c_{K R} / e,
\end{aligned}
$$

with

$$
e=\left(c_{K K}-r \alpha_{\dot{K} \dot{K}}\right)\left(c_{R R}-r \alpha_{\dot{R} \dot{R}}\right)-c_{K R}^{2} .
$$

Given the definition of $D$ we can rewrite (3.18) as

$$
\begin{aligned}
\Delta K_{t}= & d_{K K}\left[\alpha_{K}+\alpha_{K T} T_{t}+\alpha_{K L} p_{t}^{L}+q_{t}^{K}\left(1+r+\alpha_{K^{o} K^{o}}\right)\right] \widehat{Y}_{t}^{1 / \rho} \\
& +d_{K R}\left[\alpha_{R}+\alpha_{R T} T_{t}+\alpha_{R L} p_{t}^{L}+q_{t}^{R}\left(r+\delta^{R}\right)\right] \widehat{Y}_{t}^{1 / \rho} \\
& +\left[c_{K K} / \alpha_{\dot{K} \dot{K}}\right] K_{t-1}+\left[c_{K R} / \alpha_{\dot{K} \dot{K}}\right] R_{t-1}, \\
\Delta R_{t}= & d_{K R}\left[\alpha_{K}+\alpha_{K T} T_{t}+\alpha_{K L} p_{t}^{L}+q_{t}^{K}\left(1+r+\alpha_{\left.\left.K^{o} K^{o}\right)\right] \widehat{Y}_{t}^{1 / \rho}}\right.\right. \\
& +d_{R R}\left[\alpha_{R}+\alpha_{R T} T_{t}+\alpha_{R L} p_{t}^{L}+q_{t}^{R}\left(r+\delta^{R}\right)\right] \widehat{Y}_{t}^{1 / \rho} \\
& +\left[c_{K R} / \alpha_{\dot{R} \dot{R}}\right] K_{t-1}+\left[c_{R R} / \alpha_{\dot{R} \dot{R}}\right] R_{t-1} .
\end{aligned}
$$

The re-parameterized factor demand equations are now given by (3.20), (3.21), and (3.24) with $\alpha_{K K}, \alpha_{R R}, \alpha_{K R}, d_{K K}, d_{R R}$ and $d_{K R}$ defined by (3.22) and (3.23). Once the model has been estimated in the re-parameterized form we can obtain estimates for the original model parameters via $A=$ $C-(1+r)\left[B-B(C+B)^{-1} B\right]$.

A further difficulty in estimating the factor demand equations is that

$$
K_{t}=I_{t}^{K}+K_{t}^{o}
$$

is unobserved, since $K_{t}^{o}$ depends on a set of unknown model parameters. (We note that $K_{t}^{o}$ is unobserved even in the special case of a constant and exogenously given depreciation rate, i.e., even in the case where $\alpha_{L K^{\circ}}=$ $\alpha_{K^{o} K^{o}}=\alpha_{R K^{o}}=0$ and $\alpha_{K K^{o}}=-\left(1-\delta^{K}\right)$, as long as $\delta^{K}$ is estimated from the data.) We now assume, analogously to the approach taken by Epstein and Denny (1980), that equation (3.21) for $K_{t}^{o}$ holds exactly. This assumption is clearly strong. However, it facilitates expression of the unobservable stocks $K_{t}$ and $K_{t}^{o}$, at least in principle, as functions of observable variables and the unknown model parameters. More specifically, by solving (3.21) together with the identity $K_{t}=I_{t}^{K}+K_{t}^{o}$ recursively for $K_{t}$ and $K_{t}^{o}$ from some given initial capital stock, say $K_{0}$, we can express $K_{t}$ as a function of 
$I_{t}^{K}, I_{t-1}^{K}, \ldots, K_{0}, R_{t-1}, R_{t-2}, \ldots$, the exogenous variables and the model parameters. Consequently, upon replacing $K_{t}$ and $K_{t-1}$ in the variable factor demand equations (3.20) and in the quasi-fixed factor demand equations (3.24) by the expressions so obtained we can, at least in principle, rewrite the system of factor demand equations as a dynamic system of equations that determines $I_{t}^{K}, R_{t}, M_{t}$, and $L_{t}$, and where in the so obtained system all variables are observable. (If the initial stock is unobserved we may treat it as an additional parameter.)

For purposes of estimation we need to add stochastic disturbance terms to each of the factor demand equations in (3.20) and (3.24). Those disturbances can be viewed as random errors of optimization, errors in the data, or as stemming from random shocks observed by the firm but not by the researcher; cp., e.g., Epstein and Yatchew (1985). Assuming that the disturbances are not correlated with the variables in the firm's information set we can, e.g., use those variables (and functions of them) as instruments in estimating the model by the generalized method of moments (GMM) approach. The GMM estimation approach was introduced by Hansen (1982) within the context of stationary data generating processes. To allow for (possibly unknown) correlation over time we may estimate the variance covariance matrix of the moments with a heteroskedasticity and autocorrelation robust variance covariance matrix estimator. For a general discussion and recent results concerning the asymptotic properties of GMM estimators for (possibly) temporally dependent and nonstationary data generating processes, including a discussion and consistency results of heteroskedasticity and autocorrelation robust variance covariance matrix estimator, see, e.g., Gallant (1987), Gallant and White (1988) and Pötscher and Prucha (1991a,b, 1997).

Numerical algorithms for the computation of estimators that are defined as optimizers of some statistical objective function - as, e.g., the generalized methods of moments estimator or maximum likelihood estimator - generally require the numerical evaluation of the statistical objective function for different sets of parameter values. We note that for the actual numerical computation of estimators of the model parameters it is not necessary to solve (3.21) and (3.25) analytically for $K_{t}$ (and $K_{t}^{o}$ ). Rather we can first solve, for any given set of parameter values, (3.21) and (3.25) numerically for $K_{t}$ (and $K_{t}^{o}$ ), and then employ the numerical solution for $K_{t}$ (rather than the analytic solution) in evaluating the statistical objective function. This approach is, however, typically cumbersome in that it requires the programming of the estimation algorithm by the researcher. Recently Prucha (1995, 1997) 
suggested a more convenient approach based on a reformulation of the analytic solution. This approach can be performed with standard econometric packages such as TSP.

\subsubsection{Solution and Estimation of a General Class of Models}

The illustrative example presented in the previous subsection can be viewed as a special case of a more general class of models where the firm's optimization problem involves the computation of a stochastic closed loop optimal control solution and where the objective function is "linear quadratic". As discussed above, the stochastic closed loop optimal control solution can always be found in two steps. In the first step we optimize the firm's objective function in each period with respect to the variable factors, for given values of the quasi-fixed factors. Substitution of the optimized values for the variable factors back into the firm's objective function then yields a new optimal control problem that only involves the quasi-fixed factors, which can be solved in a second step. In the following let $X_{t}$ denote the, say, $n \times 1$ vector of quasi-fixed factors, i.e., the vector of control variables for the second step.

For a wide class of "linear quadratic" optimal control problems the optimal control solution will have to satisfy a set of linear second order difference equations (possibly after recasting a higher order difference equation system into a second order one). In particular, assume that the control variables satisfy the following set of difference equations $(\tau=t, t+1, \ldots)$ :

$$
-\underline{B} E_{\tau} X_{\tau+1}+\underline{G} X_{\tau}-(1+r) \underline{B^{\prime}} X_{\tau-1}=E_{\tau} \phi_{\tau}
$$

where $\underline{B}$ and $\underline{G}$ are $n \times n$ matrices, the $\phi_{\tau}$ 's represent a set of forcing variables, $r$ is the discount rate, and where the respective expectations are assumed to exist. Since the objective function is "linear quadratic", certainty equivalence implies that solving (3.26) is equivalent to solving the difference equations $(\tau=t, t+1, \ldots)$ :

$$
-\underline{B} X_{\tau+1}+\underline{G} X_{\tau}-(1+r) \underline{B}^{\prime} X_{\tau-1}=(1+r) \underline{a}_{\tau}
$$

with $\underline{a}_{\tau}=E_{t} \phi_{\tau} /(1+r)$.

We note that while the methodology discussed here is presented within the context of dynamic factor demand models, it applies more generally to any rational expectations model where the data generating process $X_{t}$ is deter- 
mined in the preceding manner. ${ }^{26}$ The literature on finding optimal control solutions and solving rational expectations models has a long history. ${ }^{27}$ The aim of the methodology outlined below is not only to obtain a solution of (3.27) for the $X_{t}$, but to express the solution so that the estimation of the model can be performed by standard econometric packages (such as TSP).

We assume that $\underline{B}$ is nonsingular and restrict the solution space to the class of processes $X_{t}$ that are of mean exponential order less than $(1+r)^{1 / 2}$. The characteristic roots of the difference equation system (3.27) are defined as solutions of

$$
p(\lambda)=\operatorname{det}\left[-\underline{B} \lambda^{2}+\underline{G} \lambda-(1+r) \underline{B^{\prime}}\right]=0
$$

It is well known and not difficult to show that those characteristic roots come in pairs multiplying to $(1+r)$. We assume that these roots are distinct. It then follows that there are exactly $n$ roots that are less than $(1+r)^{1 / 2}$ in modulus. Let $\Lambda$ be the $n \times n$ diagonal matrix of these roots, and let $V$ be the $n \times n$ matrix of solution vectors corresponding to those roots, i.e.,

$$
-\underline{B} V \Lambda^{2}+\underline{G} V \Lambda-(1+r) \underline{B^{\prime}} V=0 .
$$

As in Kollintzas (1986) and Madan and Prucha (1989) we assume that $V$ is nonsingular, and define $M=I-V \Lambda V^{-1}$. Given the maintained assumptions, the following theorem follows, e.g., from Madan and Prucha (1989):

Theorem 3.1 The solution for $X_{t}$ of the difference equation system (3.26) (or, because of certainty equivalence, (3.27)) is uniquely given by the following accelerator model:

$$
\begin{aligned}
X_{t} & =M X_{t}^{*}+(I-M) X_{t-1}, \quad X_{t}^{*}=\underline{A}^{-1} J_{t}, \\
J_{t} & =D \sum_{\tau=t}^{\infty}(I+D)^{-(\tau-t+1)} \underline{a}_{\tau}, \\
D & =(1+r)\left(I-M^{\prime}\right)^{-1}-I, \\
\underline{A} & =\left(I-M^{\prime}\right)^{-1}\left(r I+M^{\prime}\right) \underline{B} M /(1+r)=D \underline{B} M /(1+r) .
\end{aligned}
$$

\footnotetext{
${ }^{26}$ We note that the discussion also applies to processes described by a set of higher order difference equations, as long as that system can be rewritten as a second order difference equation system of the above form.

${ }^{27}$ See, e.g., Binder and Pesaran (1995, 1997), Blanchard and Kahn (1980), Broze, Gouriéroux and Szafarz (1985, 1990, 1995), Broze and Szafarz (1991), Cassing and Kollintzas (1991), Epstein and Yatchew (1985), Hansen and Sargent (1980, 1981), King and Watson (1995, 1996), Kokkelenberg and Bischoff (1986), Kollintzas (1985), Madan and Prucha (1989), Uhlig (1995).
} 
The accelerator matrix $M$ satisfies

$$
-\underline{B}(I-M)^{2}+\underline{G}(I-M)-(1+r) \underline{B^{\prime}}=0 .
$$

Furthermore, $S=\underline{B}(I-M)$ is symmetric.

In the case of static expectations on the forcing variables we have $\underline{a}_{\tau}=\underline{a}_{t}$. In this case the above solution simplifies in that in this case $J_{t}=\underline{a}_{t}$.

Madan and Prucha's proof of the theorem is based on a decomposition of $X_{\tau}$ into a backward component, given by $(I-M) X_{\tau-1}$, and a forward component, given by $g_{\tau}=X_{\tau}-(I-M) X_{\tau-1}$, where $M$ is determined by (3.31). This basic approach has recently also been used by Binder and Pesaran (1995, 1997) to solve rational expectations models, where, in our notation, $\underline{B}$ is allowed to be nonsingular. Binder and Pesaran refer to this approach as the quadratic determinantal equation (QDE) method.

The quadratic matrix equation (3.31) can generally not be solved for $M$ in terms of the original parameter matrices $\underline{B}$ and $\underline{G}$, except in case $X_{t}$ is a scalar, i.e., $n=1$. However, we can use (3.31) to express $\underline{G}$ in terms of $M$ and $\underline{B}$, i.e.,

$$
\underline{G}=\underline{B}(I-M)+(1+r) \underline{B}^{\prime}(I-M)^{-1} .
$$

Thus we can re-parameterize the model in terms of $M$ and $\underline{B}$, and estimate $M$ and $\underline{B}$ rather than the original parameter matrices $\underline{G}$ and $\underline{B}$. As remarked above, this re-parameterization approach was first suggested by Epstein and Yatchew (1985) within the context of a symmetric dynamic factor demand model where $\underline{B}=\underline{B}^{\prime}$ (and $\underline{G}=\underline{G}^{\prime}$ ). Madan and Prucha (1989) point out that this symmetry is, e.g., typically violated if factors are allowed to become productive at different points in time - for example, if some factors become productive immediately and some with a lag - and/or if we allow for non-separability between the adjustment cost terms and the inputs. Madan and Prucha (1989) then extend the re-parameterization approach to nonsymmetric dynamic factor demand models with $\underline{B} \neq \underline{B}^{\prime}$ (and $\underline{G}=\underline{G^{\prime}}$ ). This approach is presented in more detail in Appendix B. ${ }^{28}$ The discussion in Appendix B also considers an explicit specification of the stochastic process governing the forcing variables. In adopting also a re-parameterization

\footnotetext{
${ }^{28}$ Both Epstein and Yatchew (1985) and Madan and Prucha (1989) consider matrices $\underline{G}$ with additional structure, which they utilize during the re-parameterization. The discussion in the appendix shows that the re-paramtererization approach works even without additional structure on $\underline{G}$.
} 
for the parameters describing that process it is possible, as demonstrated in Appendix B, to obtain closed form analytic expressions for $X_{t}$ in terms of the model parameters and the forcing variables. The advantage of the reparameterized model is that it can be estimated with standard econometric packages (such as TSP). ${ }^{29}$

\subsubsection{Discrete versus Continuous Time Specifications}

The discussion of dynamic factor demand models has been given in form of a discrete time model. The reason for this is that empirical data typically refer to discrete time points. Much of the early theoretical analysis of dynamic factor demand models was given in continuous time; see, e.g., Eisner and Strotz (1963), Gould (1968), Lucas (1967a,b), Mortenson (1973) and Treadway $(1969,1970,1971,1974)$. Furthermore, in deriving dynamic factor demand equations for empirical estimation, the third generation dynamic factor demand literature typically first solved a continuous time optimal control problem, and then specified the estimating equations as a discrete time approximation to the continuous time optimal control problem. ${ }^{30}$ Prucha and Nadiri (1991) note that the empirical specifications obtained from the latter approach differ from those derived directly from a discrete time model. They emphasize that the formula for the accelerator coefficient obtained from a continuous time optimal control problem model is not appropriate within a discrete setting (without further modification). In particular, they point out that while in a discrete time setting the accelerator coefficient should tend to unity as adjustment cost tend to zero, the continuous time formula for the accelerator coefficient tends to infinity. As expected, the accelerator coefficient derived from a discrete time optimal control problem tends to unity as adjustment cost tend to zero. We emphasize that the point being made here should not be understood as a statement against economic analysis in continuous time, but rather only to point to potential pitfalls if formula obtained in a continuous time setting are used (without modification) to estimate and test economic relationships from discrete data.

\footnotetext{
${ }^{29}$ Of course, one can solve the quadratic matrix equation numerically. However for the purpose of estimation this approach can in general not be implemented in standard econometric packages and is computationally much more involved.

${ }^{30}$ This approach was, e.g., taken by Berndt, Morrison and Watkins (1981), Denny, Fuss and Waverman (1981b), Morrison (1986a,b) and Morrison and Berndt (1981).
} 


\subsection{Estimation of Dynamic Factor Demand Models for General Technologies}

The theoretical model specified in Section 3.1 is quite general, and allows for the firm's technology and optimal control problem to be "non-linear quadratic". We note that in case the firm's optimal control problem is not of a "linear quadratic" nature it is generally not possible to obtain an explicit analytic expression for the firm's stochastic closed loop feedback control solution. In the following we discuss strategies for estimating "non-linear quadratic" dynamic factor demand models. Those strategies can, of course, also be applied in estimating "linear quadratic" dynamic factor demand models.

Before proceeding we re-emphasize that while the model specification in Section 3.1 is quite general, the discussion does not impose this generality. That is, the discussion also covers implicitly less general specifications as special cases. The specification in Section 3.1 contains in particular the case where all factors are variable - and hence the firm is at each point in time in long-run equilibrium - or the case where the depreciation rates of all quasifixed factors are exogenously given as special cases.

\subsubsection{Estimation of Variable Factor Demand Equations}

In estimating a factor demand model we can, in principle, always attempt to estimate the unknown model parameters from only a subset rather than the entire set of factor demand equations. Statistically there are pros and cons for such a strategy: If the model is correctly specified, we will generally obtain more efficient estimates by utilizing the entire set of factor demand equations rather than a subset. However, if one or a subset of the factor demand equations is misspecified, then not only the parameters appearing in the misspecified equations, but in general all model parameters will be estimated inconsistently.

As is evident from the discussion in Section 3.1, certain aspects of the model specification such as the nature of the optimal control policy and the expectation formation process only enter into the specification of the demand equations for the quasi-fixed factors. Consequently, in this sense the demand equations for the quasi-fixed factors are more susceptible to potential misspecification than the demand equations for the variable factors. In cases where the determinants of the demand for the quasi-fixed factors are not of real interest, but where one is especially concerned about the 
possibility of misspecification of the quasi-fixed factor demand equations, it may be prudent only to estimate the variable factor demand equations. By estimating only the variable factor demand equations we are typically also faced with a less complex estimation problem.

The variable factor demand systems can take various forms depending on the specification of the technology. E.g., in case the technology is specified in terms of a translog restricted cost function the variable factor demand system is typically given by a system of share equations. ${ }^{31}$ The model specified in Section 3.1 allows depreciation rates of some of the quasi-fixed factors to be determined endogenously and to be modeled as a function of unknown parameters. As remarked above, as a result the stocks of those quasi-fixed factors are then unobserved. To estimate the system of variable factors we may proceed analogously as outlined at the end of Section 3.2.1; for empirical applications see, e.g., Epstein and Denny (1980) and Nadiri and Prucha (1996).

\subsubsection{Euler Equation Estimation Approach}

In Section 3.1 we derived a general set of stochastic Euler equations that need to be satisfied by the stochastic closed loop feedback optimal control solution for the quasi-fixed factors without restricting the technology to be "linear quadratic". Those stochastic Euler equations are given by equations (3.9) and (3.10). In Section 3.2 we solved those equations explicitly for the case where the technology is indeed "linear quadratic". In case the technology is "non-linear quadratic" such an explicit solution is generally not available. In this case we may then adopt an alternative estimation approach due to Kennan (1979), Hansen (1982), Hansen and Sargent (1982), and Hansen and Singleton (1982). ${ }^{32}$ In this approach all expectations of future variables are replaced by their observed values in future periods. More specifically, in this approach we would rewrite the stochastic Euler equations (3.9) and (3.10) as

\footnotetext{
${ }^{31}$ The variable factor demand equations typically form a triangular structural system. Lahiri and Schmidt (1978) point out that the full information maximum likelihood (FIML) estimator and the iterative seemingly unrelated regressions (SUR) estimator are identical for triangular structural systems. This identity might be thought to imply that for such systems the variance covariance matrix estimator typically associated with the SUR estimator is a consistent estimator for the asymptotic variance covariance matrix. However, Prucha (1987) points out that this is generally not the case.

${ }^{32}$ The approach has been used widely in empirical work. Early empirical implementations include Pindyck and Rotemberg (1983a,b) and Shapiro (1986).
} 


$$
\begin{aligned}
& -\frac{\partial G_{t+1}}{\partial K_{t}} /\left(1+r_{t+1}\right)-\left(q_{t}^{K}\right)^{\prime}-\frac{\partial G_{t}}{\partial \Delta K_{t}} \\
& +\frac{\partial G_{t+1}}{\partial \Delta K_{t+1}} /\left(1+r_{t+1}\right)=v_{t}^{K}, \\
& -\frac{\partial G_{t+1}}{\partial R_{t}} /\left(1+r_{t+1}\right)-\left(c_{t}^{R}\right)^{\prime}-\frac{\partial G_{t}}{\partial \Delta R_{t}} \\
& +\frac{\partial G_{t+1}}{\partial \Delta R_{t+1}} /\left(1+r_{t+1}\right)=v_{t}^{R} .
\end{aligned}
$$

If expectations are truly formed rationally we have $E_{t} v_{t}^{K}=0$ and $E_{t} v_{t}^{R}=0$, and equations (3.33) and (3.34) can then be estimated consistently by the GMM estimation approach. ${ }^{33}$ Of course, the stochastic Euler equations (3.33) and (3.34) can be augmented by the demand equations for the variable factors. Recall that $K_{t}$ denotes the vector of quasi-fixed factors for which the depreciation rates are determined endogenously and are modeled as a function of unknown parameters. Thus, as remarked, $K_{t}$ is unobserved. In estimating the demand equations we may again proceed analogously as outlined at the end of Section 3.2.1.

The Euler equation estimation approach allows considerable flexibility in the choice of the functional form for the technology. Also, it does not require an explicit specification of the process that generates the variables exogenous to the firm's decision process or specific assumptions concerning the firm's planning horizon. However, it is generally not fully efficient in that it neglects information from the entire set of Euler equations (and, e.g., the transversality condition), which only comes into play by actually solving the Euler equations. In their comparison of alternative methods for estimating dynamic factor demand models Prucha and Nadiri (1986) report that small sample biases and efficiency losses seem especially pronounced for parameters that determine the dynamics of the demand for the quasi-fixed factors. We note further that while the fact that the Euler equation estimation approach does not require either an analytic or numerical solution for the firm's optimal demand for the quasi-fixed factors is very attractive, such a solution - or some approximation to it - will be needed, e.g., for tax simulations.

\footnotetext{
${ }^{33}$ For references concerning the asymptotic properties of GMM estimators see the discussion at the end of Section 3.2.1.
} 


\subsubsection{Finite Horizon Modeling Approach}

A further approach for modeling and estimating dynamic factor demand models that allows for "non-linear quadratic" technologies and non-static expectations was suggested by Prucha and Nadiri (1982). In this approach the firm is modeled with a finite but shifting planning horizon of, say $H+1$ periods, and is assumed to set its inputs according to a certainty equivalence feedback control policy. ${ }^{34}$ In contrast to, e.g., Schramm (1970) the firm is not assumed to cease to exist beyond the actual planning horizon. Rather in this approach the firm is assumed to set its inputs beyond the actual planning horizon under the simplifying assumption of static expectations and a constant firm size. Prucha and Nadiri $(1986,1991)$ explore the relationship between the optimal factor demands implied by the finite horizon model vs. that obtained from an infinite horizon model. Their results suggest that the finite horizon model approximates the infinite horizon model well even for moderate sizes of the planning horizon. For recent contributions to the literature on finite horizon dynamic factor demand models see, e.g., Gordon (1996) and Steigerwald and Stuart (1997).

An attractive feature of the finite horizon modeling approach is that it leads to a finite dimensional optimization problem. The optimal plan values in each period $t$ can be obtained by "simply" solving a finite dimensional system of equations. We note that in empirical applications it may be difficult to obtain explicit analytic expressions for the optimal plan values. However, Prucha and Nadiri $(1982,1988)$ discuss numerical algorithms for the estimation of the implied dynamic factor demand equations, without requiring such an explicit analytic solution.

\subsection{Further Developments}

In addition to the developments in modelling dynamic factor demand described above there have been other important developments. In particular, since the late 1970's there was a process of convergence between the investment literature based on Tobin's (1969) $q$ and the investment literature with explicit adjustment costs. In Tobin's investment model the rate of investment is a function of $q$, defined as the ratio of the market value of capital to

\footnotetext{
${ }^{34}$ Concerning certainty equivalence and first-order certainty equivalence of this policy with the stochastic closed loop feedback control policy see also the discussion and references given at the end of Section 3.1.1.
} 
its replacement cost. Hayashi (1982) shows the equivalence of the two investment theories for a general class of models; see also Mussa (1977) and Abel (1983). The literature distinguishes between average $q$, defined as the ratio of the market value of existing capital to its replacement cost, and marginal $q$, defined as the ratio of the market value of an additional unit of capital to its replacement cost. While average $q$ is observable, marginal $q$, which is the quantity relevant for the firm's investment decision, is not observable. However Hayashi (1982) also derives an exact relationship between average $q$ and marginal $q$, which is important for a proper empirical implementation of the $q$ theory of investment.

Another important development is an expanding literature that considers the effects of irreversibility combined with uncertainty and timing flexibility on the firm's investment decision. Irreversibility is another avenue that introduces a dynamic element into the investment decisions. The literature on irreversible investment dates back to Arrow (1968). The more recent literature utilizes option pricing techniques to determine the firm's optimal investment pattern under irreversibility. A survey of this literature and exposition of those techniques is given in Dixit and Pindyck (1994). ${ }^{35}$ One way to incorporate irreversibility into an adjustment cost model is to assume infinitely large adjustment costs for negative investment. This approach was, e.g., taken by Caballero (1991). Another approach was explored by Abel and Eberly (1994). Their model incorporates Arrow's observation that the resale price of capital may be less than the purchase price of new capital, which includes the case where the resale of capital is impossible, corresponding to the extreme case of a resale price of zero. Additionally their model includes adjustment costs as well as fixed costs and thus provides for an interesting integration of the irreversible investment and adjustment cost literature.

\footnotetext{
${ }^{35}$ For early contributions to this literature see Bertola (1988), Pindyck $(1988,1991)$ and Dixit $(1991,1992)$.
} 


\section{Applications}

There are numerous applications of the factor demand models using different sets of data and answering important questions of theoretical, empirical and policy interest. There is a vast literature showing the wide spread use factor demand models for empirical analysis ${ }^{36}$. The class of dynamic factor demand models considered in Section 3 has been used to study a variety of subjects ranging from the analysis of the production structure of various industries, the rate of technical change, the impact of $R \& D$ investment and R\&D spillovers, the convergence of productivity levels, the effect of public infrastructure on the private sector productivity, the impact of financial variables on production decisions, the cyclical behavior of utilization and markup of prices over costs, etc. Here we will provide only a brief description of a few applications of dynamic factor demand models for illustrative purposes. To save space we do not report on the formal structure of the models used in the studies.

As remarked above, besides analyzing productivity behavior, the dynamic factor demand methodology also addresses issues concerning the structure of production such as substitution among factors of production in response to changes in relative prices, technological change, changes in public capital, international or inter-industry or inter-firm spillovers due to R\&D investment, etc. The time path of the adjustment of different types of capital and the linkages between short-, intermediate- and long-run behavior are explicitly modeled and estimated. Changes in capacity utilization rates and depreciation rates of different types of capital and their effects on the demand for other inputs can be estimated. Given estimates of the depreciation rates it is possible to decompose gross investment into replacement and net investments, and generate consistent measures of capital stocks within the framework of the dynamic factor demand model.

\footnotetext{
${ }^{36}$ See, e.g., Berndt, Morrison and Watkins (1981), Jorgenson (1986, 1995a,b, 1996a,b), Watkins (1991), Galeotti (1996) and Good, Nadiri and Sickles (1997) for partial references.
} 


\subsection{Tax Incentives, Financing and Technical Change}

The effect of taxes and other incentives on factor demand and output growth has been of a long and ongoing interest in the literature. The role of taxes as a component of the user cost of capital was made clear in seminal papers by Jorgenson (1963) and Hall and Jorgenson (1967, 1971). Jorgenson and his associates have examined the impact of tax incentives for business investment in the United States in a series of papers; see Jorgenson (1996b) for more detailed references ${ }^{37}$. Hall and Jorgenson $(1967,1971)$ and Jorgenson (1971) modeled the accelerated depreciation of the 1954 tax law and guidelines for asset lifetimes, the investment tax credit introduced in 1962, the reduction in corporate tax rate in 1964 and the suspension of the investment tax credit in 1966. These tax law changes were incorporated as elements of the user cost of capital. The general conclusion of this body of work was that investment incentives exert a considerable long-run effect on the rate of capital accumulation. Each major change in investment incentives was followed by an investment boom which in turn led to increases in the level of economic activity that induced further increases in investment. However, the lag between changes in investment incentives and investment expenditure was found to be fairly long.

As discussed in Section 3, given the underlying intertemporal optimization framework, the notion of a user cost of capital or the after tax acquisition price is also present within the framework of the dynamic factor demand modes reviewed in this paper. A general discussion of the effect of taxes and incentives within the context of dynamic factor demand models is, e.g., provided by Bernstein and Nadiri (1987a). We emphasize that in general the effect of any tax changes designed to affect a particular factor of production will influence also the demand for other inputs ${ }^{38}$. This arises from the interrelatedness of factors. Early generations of dynamic factor demand models assumed separability between the quasi-fixed factors and hence could not fully capture such effects.

Tax policy operates through factor prices. The effect of changes in tax policy depends in general on the degree of substitutability or complemen-

\footnotetext{
${ }^{37}$ Recent extensive studies of the effects of taxes also include, e.g., Auerbach and Hassett (1992), Cummins and Hassett (1992), and Feldstein (1994).

${ }^{38}$ Recently Diewert and Lawrence $(1996,1998)$ have examined the effect of the excess burden of taxes using general models which allow cross price effects of taxes on the demand for factors of productions.
} 
tarity among factors of production. As discussed in Section 2, technological change, if not neutral, depends on relative prices (as is, e.g., evident from its definition on the cost side). Hence, tax policy can also affect technological change. We note that in the short-run the effects of changes in tax policy on factor demands may be quite different from their effects in the long-run in that in the short-run the firm may find it advantageous to over-adjust some of its variable factors to lessen the effects of adjustment costs. The framework of a dynamic factor demand model also provides a natural setting for analyzing the effects of expectations about future tax policies ${ }^{39}$.

As an illustration of the application of the dynamic factor demand models for tax analysis, consider the recent study by Bernstein (1994b). The tax instruments considered are the corporate income tax (CIT), the investment tax allowances (ITA), and capital consumption allowance (CCA). A normalized variable profit function with quadratic adjustment costs for capital stock is formulated and the model is estimated using data for the Turkish electrical machinery, non-electrical machinery, and transportation equipment industries. The empirical results suggest the following findings:

1. The adjustment cost parameter estimate suggest that these industries are not in long-run equilibrium. The mean value of the speed of adjustment ranged between .33 to .36 for each of the industries implying that about 35 percent of the capital stock adjustment occurs within the first year of capital accumulation.

2. The effects of taxes and incentives on production and investment decisions are transmitted though changes in the rental price of capital. The magnitudes of the input elasticities to changes in tax instruments differ in short-, intermediate- and long-run due to presence of adjustment costs. They also differ with respect to the various tax policy instruments, as well as across industries. The long-run elasticities of output and the inputs are quite small, but larger than the short- and intermediate-run elasticities. Another important point is that, because of the inter-dependence among production decisions embedded in the dynamic factor demand models, taxes and incentives targeted toward a particular input also has effects on the other inputs.

3. Productivity growth can be affected by the tax policies. This arises since productivity growth depends on the growth of output and inputs,

\footnotetext{
${ }^{39}$ See, e.g., Dubey (1996).
} 
which are affected by changes in factor prices. As noted above, the latter are in turn affected by changes in tax instruments.

Another example of the use of dynamic factor demand models involves the integration of production and financial decisions of the firm. In the theoretical literature, the existence of informational imperfections has provided the means to generate interdependencies between the production and financial decisions. Generally, in this literature, debt levels are determined through a trade-off between agency costs and tax shields, while dividends are set by a trade-off between tax disadvantages and signaling benefits. ${ }^{39}$ Bernstein and Nadiri (1993) implement this approach using data for U.S. manufacturing. They formulate a dynamic factor demand model which integrates production decisions with decisions on the level of debt and dividend payouts. The model yields a set of simultaneous equations for output, variable inputs, capital, debt and dividends. These conditions define a temporary equilibrium. There are two costs of adjustment. The first is associated with the internal cost of capital installation. The second arises from capital financing and is defined by the agency costs from debt issues. The study reports an estimate of total adjustment cost of approximately $\$ .22$ per dollar of investment. This amount consists of $\$ 0.05$ attributable to the agency cost from bond issues, and the remaining $\$ .17$ arises from capital installation costs. The decomposition of TFP growth calculated by Bernstein and Nadiri show that for the U.S. manufacturing sector the signaling benefits explains about 4.2 percent of the TFP growth rate, while agency costs reduce it by 3.3 percent.

As illustrated by the above described applications, dynamic factor demand models provide a powerful framework to trace the effects of various policy decisions, such as tax and incentive policies and financial decisions. It is possible to examine the impact of these decisions in the short-, intermediate- and long-run on the production decisions and productivity performance. Also, the effect of expectations can be examined in this framework.

\footnotetext{
${ }^{39}$ See the survey by Fazzari, Hubbard and Peterson (1996) and the references therein. Kim and Maksimovic (1990) examine the effect of agency costs on productivity growth for the U.S. airline industry, and Greenwald, Kohn and Stiglitz (1990) look at the influence of agency costs on productivity growth for the U.S. private sector.
} 


\subsection{R\&D Investment, Production Structure and TFP Decomposition}

The role of R\&D and the behavior of other factors of production in the U.S., Japanese, and German manufacturing industries was explored by Mohnen, Nadiri and Prucha $(1983,1986)$ based on a special case of the dynamic factor demand model considered in Section 3. One of the results of the study was that the average net rates of return were similar for both $R \& D$ and capital in the manufacturing sectors of the three countries. However the rate of return on $\mathrm{R} \& \mathrm{D}$ was greater than that on capital in each sector. A further finding was that it takes a considerably longer time for the R\&D stock to adjust to its optimum value than for the physical capital stock. The average lag for capital was approximately three years in the three countries, while the average lag for R\&D was about five years in the U.S., eight years in Japan and ten years in Germany. The patterns of own- and cross-price elasticities of the inputs varied considerably among countries. The ownprice elasticities were generally higher than the cross-price elasticities. There was mostly a substitutional relationship between the inputs. The output elasticities of the inputs in the short- and intermediate-runs differed from each other and across countries. The materials input overshot in the shortrun its long-run equilibrium value to compensate for the sluggish adjustments of the two quasi-fixed inputs, capital and R\&D; the output elasticities of the capital stock were larger than those of R\&D in the short- and intermediateruns; also, there was evidence of short-run increasing returns to labor. The Japanese manufacturing sector seems to have higher elasticities than the U.S. manufacturing sector and to display more flexibility.

Nadiri and Prucha $(1983,1990 b)$ explore the production structure of the U.S. Bell System before its divestiture ${ }^{40}$. They consider a model with two variable factors, labor and materials, and two quasi-fixed factors, physical and $R \& D$ capital. The technology is not assumed to be linear homogeneous, but is allowed to be homothetic of a general form. The estimated degree of scale was about 1.6. As a consequence, in decomposing the traditional TFP measure they find that almost $80 \%$ of the growth of TFP is attributable to scale. The conventional TFP measure, if it is considered as a measure of technical change, was thus seriously biased upwards. The estimated rate

\footnotetext{
${ }^{40}$ For an exploration of Bell Canada see, e.g., Bernstein (1988b,c, 1989b) and Fuss (1994).
} 
of technical change was only about $10 \%$ to $15 \%$ of the measured TFP. The most significant source of output growth was the growth of capital with a contribution of over 50\%, while labor and material contributed about $15 \%$, and the contribution of technical change was about half as much. The growth of R\&D contributed about $2 \%$ which, given its small share in the production is fairly substantial. The rate of return on $R \& D$, however, was much greater than that on plant and equipment investment. The net rate of return for $\mathrm{R} \& \mathrm{D}$ investment is about $20 \%$ in comparison to the net rate of return of about $7 \%$ for investment in physical capital.

The study by Nadiri and Prucha also considers alternative specifications of the length of the planning horizon and the expectation formation process. They find that the optimal plans for the finite horizon model converge rapidly to those of the infinite horizon model as the planning horizon extends. This observation suggests that additional planning costs will quickly exceed additional gains from extending the planning horizon, which may provide a rational for why many firms plan only for short periods into the future. Parameter estimates differ in their sensitivity to alternative specifications of the expectation formation process. Estimates of parameters determining the adjustment path of capital and R\&D turned out to be sensitive. On the other hand, estimates of other characteristics of the underlying technology such as scale seem to be insensitive to the specification of the expectation formation process.

Recently the dynamic factor demand framework has been used to explore the role of high-tech capital and information technology equipment, as well as human capital, on the production structure and productivity growth in U.S. manufacturing; see Morrision (1997) and Morrision and Siegel (1997). One finding is that high-tech capital expansion increases demand for most capital and non-capital inputs overall, but saves on material inputs.

\subsection{Technological Spillovers and Productivity Growth}

An important feature of $R \& D$ investment that distinguishes it from other forms of investment is that firms which undertake R\&D investment are often not able to exclude others from freely obtaining some of the benefits; that is, the benefits from R\&D investment spill over to other firms in the economy, and the recipient firms do not have pay for the use of knowledge generated by the investing firms' $R \& D$ activity. R\&D spillovers may affect the production structure and factor demand in several ways. In particular, R\&D investment 
may shift the production function up (or the cost function downward). This is the direct productivity effect. Also, changes in the R\&D spillover may cause factor substitution. In the language of the technological change literature, changes in R\&D spillovers may cause factor biases, which may be either factor using or factor saving. Changes in the R\&D spillovers may also affect the adjustment process of the quasi-fixed factors.

There are a number of empirical studies using the dynamic factor demand framework to measure the impact of technology spillover. ${ }^{41}$ As an illustration, consider the Bernstein and Nadiri (1989) study which provides an example of intra-industry spillover effects among the U.S. instruments, machinery, petroleum, and chemical industries. Several interesting results are reported:

1. The adjustment process of the two quasi-fixed inputs were shown to be interdependent, i.e., as the physical and R\&D capitals adjust toward their equilibrium levels, the speed of adjustment of one is affected by the adjustment of the other. The estimates indicate that about $33 \%$ to $42 \%$ of the adjustment of physical capital stock occurred within a single year. This adjustment process differs across various industries reflecting the nature of the industries considered. R\&D capital adjustment is lower than that of physical capital; the estimates show that about $22 \%$ to $30 \%$ of the adjustment of R\&D capital occurred in one year. The adjustment processes of the R\&D capital also vary among the industries.

2. There are a number of effects associated with the intra-industry R\&D spillover. First, costs decline as knowledge expands for the externalityreceiving firms. Second, production structures are affected, as factor demands change in response to the spillover. Third, the rates of both physical and knowledge capital accumulation are affected by the R\&D spillover. The results indicate that the short-run demand for $\mathrm{R} \& \mathrm{D}$ and physical capital decreased in response to an increase in the

\footnotetext{
${ }^{41}$ In recent years there has been a considerable effort to model and estimate the role of $R \& D$ spillover. There are a number of different approaches that have been taken to specify and measure technical spillover effects. Recent studies on R\&D spillovers within the framework of dynamic factor demand models other than those dicussed in this section include papers by Bernstein (1989a), Bernstein and Nadiri (1988), Goto and Suzuki (1989), Nadiri and Kim (1996), Mohnen (1990, 1992a), Mohnen and Lepine (1991), Srinivasan (1995). For a more complete list of references on $R \& D$ spillovers the interested reader may consult the survey papers by Griliches (1992) and Nadiri (1993).
} 
intra-industry spillovers. Both the variable and average costs for each industry declined in response to the intra-industry spillovers. Spilloverreceiving firms gained a 0.05 percent, 0.08 percent, 0.11 percent, and 0.13 percent average cost reduction, respectively, in the instruments, machinery, petroleum, and chemical industries as a result of a 1 percent increase in the intra-industry spillover. Not surprisingly, the effect of spillovers on the factor inputs and cost was larger in the long-run than in the short-run.

3. The results also indicate that for all four industries the net social rate of return greatly exceeded the net private rate of return. However, there was significant variation across industries in the differential between the returns. For chemicals and instruments, the social rate of return exceeded the private rate of return by 67 and $90 \%$, respectively. Machinery exhibited the smallest differential of about $30 \%$, and the petroleum industry exhibited the greatest differential as the social rate exceeded the private rate by $123 \%$.

Bernstein's (1988a) study of Canadian industries shows that spillovers occur between rival firms within the same industry and between firms operating in different industries. These spillovers, specially those associated with inter-industry spillovers, caused unit costs to decline and the structure of production of the receiving industries to change as the spillovers induced factor substitution. The productivity effect of the spillovers and the gap between the private and social rates of return to $R \& D$ varied among the industries.

Mohnen (1992b) explored the question of possible cross-country R\&D spillovers among the manufacturing sectors of U.S., Japan, France and UK. He used a cost function with quasi-fixed factors and adjustment cost based on the symmetric generalized McFadden functional form. The results indicated that foreign $R \& D$ yields greater cost reduction than own $R \& D$, own $R \& D$ and foreign $R \& D$ are complementary and foreign $R \& D$ can explain part of the productivity convergence among the manufacturing sectors of the leading industrial countries. In the case of the Canadian manufacturing sector, Mohnen (1992a) reports surprisingly weak spillover effects for R\&D undertaken in other major industrialized countries. Bernstein and Mohnen (1994) have developed a bilateral model of production between U.S. and Japanese economies and trace the effects of international R\&D spillovers on production cost, traditional factor demands, the demand for R\&D capital and productivity growth in each country. Their results show that international spillovers 
increased U.S. productivity growth by about $15 \%$, while productivity growth of the Japanese economy is increased by $52 \%$. The R\&D spillovers affect the structure of production in both countries, particularly the demand for labor in Japan.

\subsection{Capital Utilization, Depreciation Rates, and Re- placement Investment}

In general productivity growth may, at least in the short-run, be influenced by whether or not various factors of production are fully utilized. Most of the studies of firm demand for factors of production assume a constant rate of utilization of inputs and ignore the fact that the firm can choose simultaneously the level and rate of utilization of its inputs. As discussed above, a model which allows for the capital utilization and depreciation rate to be determined endogenously, along the lines of the dynamic factor demand model considered in Section 3, was first implemented empirically by Epstein and Denny (1980). Using only the demand equations for the variable factors their model was estimated from U.S. manufacturing data, based on a data set developed by Berndt and Wood (1975). Epstein and Denny report an average rate of depreciation of 0.126 for physical capital. The estimated depreciation rates vary between 0.11 and 0.145 over the sample. The model generates a capital stock series which is quite different from that implied by the Berndt and Wood (1975) data. Also, their model indicates substantial cross price elasticities, showing the inter-related nature of the choice about capital usage and other inputs and outputs which would be ignored if a simpler framework is used to describe the firm's technology. Kollintzas and Choi (1985) and Bischoff and Kokkelenberg (1987) report estimates of 0.126 and 0.106 on average for the rate of depreciation of physical capital in the U.S. manufacturing sector.

Morrison (1992a) reports that a significant portion of cost declines in the U.S., Canadian and Japanese manufacturing industries, resulting from fluctuations in capacity utilization and scale economies, has been erroneously attributed to technical change. Morrison (1992b) finds furthermore that the markups of prices over costs are significant and influence measured productivity. This conclusion is also supported by Nadiri and Nandi (1997) in their study of the U.S. telecommunications industry. Galeotti and Schiantarelli (1997) have examined the counter-cyclical behavior of markups in 
U.S. two digit manufacturing industries in the context of a dynamic optimization model. Their results show that markups are affected by both the level and growth of the demand facing an industry in the presence of cost of adjustment.

As discussed above, Prucha and Nadiri $(1990,1996)$ apply the dynamic factor demand model specified in Section 3.2.1 to data for the U.S. electrical machinery industry for the period 1960 to 1980. This study builds on an earlier study by Nadiri and Prucha (1990a) that is based on capital stock data from the Office of Business Analysis (OBA). They estimate two versions of the model. In the more general version of the model, $K_{t}^{o}$, the stock of capital left over at the end of the period from the beginning of period stock, or equivalently the depreciation rate of capital, is permitted to be determined as a function of output and relative prices; see equation (3.21). In the other version of the model the depreciation rate of capital is taken to be constant but unknown by imposing the parameter restrictions $\alpha_{L K^{o}}=\alpha_{K^{o} K^{o}}=\alpha_{R K^{o}}=0$. We note that for both models the depreciation rate is estimated and the respective capital stocks are generated internally during estimation in a theoretically consistent fashion. The paper reports the following findings:

1. The depreciation rate of capital is estimated to be 0.038 as compared to 0.055 for the Office of Business Analysis (OBA) capital stock series. This translates into a difference of $16 \%$ in magnitude between the implied capital stock series and the OBA capital stock series at the end of the sample period.

2. Based on their tests Prucha and Nadiri accept the model corresponding to a constant depreciation rate. This finding is interesting, since the assumption of a constant depreciation rate has a long history, but has also been the subject of considerable debate. The assumption of a constant depreciation rate was challenged by, among others, Feldstein and Foot (1971), Eisner (1972), Eisner and Nadiri (1968, 1970), Feldstein (1974), Feldstein and Rothschild (1974) and Bitros and Kelejian (1974). It was forcefully defended by Jorgenson $(1974)^{42}$. Among other things he pointed out that some of the earlier studies on replacement investment were not fully consistent, in that they employed capital

\footnotetext{
${ }^{42}$ The validity of a constant depreciation rate has also been tested in several papers by Hulten and Wykoff $(1980,1981 a, b, c)$
} 
stock data that were generated under a different set of assumptions than those maintained in those studies. Within the modeling framework discussed here the capital stocks are generated in an internally consistent fashion from gross investment data. Thus, as a by-product, a consistent decomposition of gross investment into replacement investment and net investment can be obtained. In particular, replacement investment $I_{t}^{K R}$ is defined as the difference between the beginning of period stocks and what is left over from these stocks at the end of the period, i.e., $I_{t}^{K R}=K_{t-1}-K_{t}^{o}$. Net investment $I_{t}^{K E}$ is defined as the difference between gross investment and replacement investment, i.e., $I_{t}^{K E}=I_{t}^{K}-I_{t}^{K R}=K_{t}-K_{t}^{o}$. For the entire sample period net investment as a percent of gross investment was about 60 percent. As expected, this ratio exhibited cyclical patterns with a low of 41 percent in 1975. The ratio of net investment to gross investment based on the estimated model is much higher than the rates implied by the OBA capital stock series.

3. The study finds significant adjustment costs. The own accelerator coefficient for physical capital is approximately .20, while that for the R\&D capital is .15. The cross accelerator coefficients are small (about .02). The total adjustment costs are about $15 \%$ of total gross investments for each of these two types of capital.

4. The pattern of output elasticities reveal that the variable factors of production, labor and materials, respond strongly in the short-run to changes in output; in fact, they overshoot their long-run equilibrium values in the short-run. The output elasticities of the quasi-fixed factors, capital and R\&D, are small in the short-run but increase over time. The long-run output elasticities suggest an estimate of economics of scale of approximately 1.2. The own price elasticities are, as expected, all negative. The results also suggest that the cross price elasticities of labor and capital may be sensitive to whether or not the rate of depreciation is endogenous.

5. The study also provides a decomposition of the sources of total factor productivity growth. This decomposition is reproduced in Table 4.1 for both versions of the model. 
Table 4.1: Decomposition of TFP Growth in the U.S. Electrical Machinery Industry in Percentages: 1960-1980.

\begin{tabular}{lcc}
\hline & \multicolumn{2}{c}{ Model } \\
\cline { 2 - 3 } & $\begin{array}{c}\text { Estimated capital } \\
\text { stock: constant } \\
\text { depreciation rate }\end{array}$ & $\begin{array}{c}\text { Estimated capital } \\
\text { stock: variable } \\
\text { depreciation rate }\end{array}$ \\
\hline Technical change & 0.69 & 0.66 \\
$\begin{array}{c}\text { Scale effect } \\
\text { Adjustment cost effects } \\
\text { Temporary equilibrium } \\
\quad \text { effect }\end{array}$ & 0.83 & 0.93 \\
$\begin{array}{c}\text { Direct adjustment } \\
\text { cost effect }\end{array}$ & 0.42 & 0.39 \\
$\begin{array}{c}\text { Variable depreciation effect } \\
\text { Unexplained residual }\end{array}$ & 0.00 & 0.02 \\
\hline Total factor productivity & 0.03 & 0.02 \\
\hline
\end{tabular}

The decomposition shows that the estimate of productivity growth based on the traditional TFP measure is approximately three times larger than the estimate of pure technical change generated by the econometric model. The main source of the difference is the scale effect which represents about 46 percent of the growth in the traditional TFP measure. The remainder of the difference is mainly due to the presence of adjustment costs, which accounts for almost 21 percent of total factor productivity growth. The estimated pure technical change exhibits a very smooth pattern and increases over time.

Nadiri and Prucha (1996) employ a special case of the model in Section 3 - where the depreciation rates are modeled as constant but unknown to estimate the depreciation rates of both physical and R\&D capital for the U.S. total manufacturing sector. The depreciation rate of $R \& D$ capital was, in particular, estimated to be about 0.12 , which is quite similar to the ad hoc assumption of the $R \& D$ depreciation rate used in many studies that uses the 
R\&D capital stock as an input in the production function ${ }^{43}$. Given estimates for the depreciation rates, gross investment can again be decomposed into net and replacement investment. For the entire sample period net investment in R\&D in the U.S. total manufacturing as a percent of gross investment was 16 percent. However during the 1970s this percentage declined to 5 percent, reflecting the near collapse of $\mathrm{R} \& \mathrm{D}$ investment in that period.

\footnotetext{
${ }^{43}$ See, e.g., Griliches (1980), Bernstein and Nadiri (1988, 1991), Mohnen, Nadiri and Prucha (1983,1986), Mamuneas and Nadiri (1996), Nadiri and Prucha (1990a,b).
} 


\section{Effects of Misspecification: A Monte Carlo Study}

In this section we briefly explore, by means of a Monte Carlo study, the effects of model misspecification on the estimation of important characteristics of the production process such as technical change, scale and adjustment speed. The "true" model from which the data for the Monte Carlo study are generated has the same basic structure as the model for the U.S. electrical machinery sector considered in Prucha and Nadiri (1996), but differs in terms of the specification of the restricted cost function and in terms of the assumed expectation formation. The model considered by Prucha and Nadiri is discussed in detail in Section 3.2.1. The restricted cost function for that model is given by (3.16), which is a linear-quadratic function in $p^{L}$, $q^{K}, q^{R}, K_{-1} / Y^{\rho}, R_{-1} / Y^{\rho}, \Delta K / Y^{\rho}, \Delta R / Y^{\rho}, T$, multiplied by $Y^{\rho}$, where we have maintained the notation of Section 3.2.1. In contrast, the restricted cost function of the true model underlying this Monte Carlo study is linearquadratic in $p^{L}, q^{K}, q^{R}, K_{-1}, R_{-1}, \Delta K, \Delta R, Y, T$, which allows for an explicit analytic solution even under non-static expectations. In the following we use the abbreviations LQR (short for "linear-quadratic in ratios") and LQ (short for linear-quadratic) to denote the former and latter restricted cost function. The true model assumes that prices and output are generated by simple first order autoregressive processes and takes expectation to be rational (and thus non-static). Explicit expressions for the demand equations for the labor, materials, capital and R\&D of the true model and the equations for the forcing variables are given in Appendix C.

The selection of the true model parameters for the Monte Carlo study was guided by fitting a static version of the model to the U.S. electrical machinery data used in the Prucha and Nadiri study, and by estimating first order autoregressive processes for the forcing variables from those data. The aim was to select the true model parameters such that the generated data exhibited properties consistent with those found in the study by Prucha and Nadiri. The selection of the variance and covariances of the disturbance processes was also guided by those empirical results, as well as by computational considerations to keep the computing time within practical limits. In analogy 
to the study by Prucha and Nadiri the data were generated for the period 1960 to 1980, with the initial values taken from the data set for that study. Each Monte Carlo experiment consisted of 100 trials. $^{44}$

The $\mathrm{R}^{2}$ values (calculated as the squared correlation coefficient between the actual variables and their fitted values calculated from the reduced form based on true parameter values) for the factor demand equations were approximately .98; those for the forcing variables ranged from, .93 to .85 . Output based technical change, $\lambda_{Y}$, and scale, $\rho$, are computed from (2.15). Their values depend on the input and output mix. The median value of $\lambda_{Y}$, computed from the Monte Carlo sample, corresponding to the true parameter values decreased in a smooth pattern from 1.53 in 1961 to 1.00 in 1976 and 0.94 in 1980. The median value of $\rho$ corresponding to the true parameter values was 1.09 in 1961, 1.11 in 1976 and 1.12 in 1980. The true accelerator coefficients $m_{K K}, m_{K R}, m_{R K}$ and $m_{R R}$ take the values $0.22,-0.02,-0.01$, 0.15. The true depreciation rate $\delta^{K}$ was for simplicity taken to be constant and assumed to be 0.038 .

Table 5.1 gives a description of the respective Monte Carlo experiments. The first experiment re-estimates the true model from the generated data. As discussed above, the true model is based on the LQ restricted cost function, takes expectations to be rational, allows for non-constant returns to scale and for non-zero adjustment costs; the equations for the true model are given in Appendix C. In our second experiment we estimate the same model, except that expectations are misspecified in that they are taken to be static. The third experiment estimates again the same model, but imposes zero adjustment costs (and thus imposes incorrectly $m_{K K}=m_{R R}=1$ ). Of course, with zero adjustment costs expectations do not come into play. In experiment four we then misspecify the functional form of the restricted cost function. More specifically, we estimate the model discussed in Section 3.2.1 based on the restricted cost function LQR. We also take expectations to be static. Experiment five is as experiment four, except that here also scale is incorrectly assumed to be equal to unity. For each of the experiments we run two variants. Variant "A" takes the stock of capital (or equivalently, the depreciation rate of capital) as observed. Variant "B" takes the stock of capital as unobserved and estimates the (constant) depreciation rate of capital $\delta^{K}$ jointly with the other model parameters. As an estimation procedure

\footnotetext{
${ }^{44}$ The number of Monte Carlo trials is small, but is reflective of the considerable computational complexities underlying this study.
} 
we use 3SLS with lagged inputs, output, prices, and squares of those lagged values as instruments. The sample period is 1961 to 1980. The study was performed using TSP 4.4.

Table 5.1: Description of Monte Carlo Experiments

\begin{tabular}{|l|l|l|l|l|}
\hline \multirow{2}{*}{ Number } & \multicolumn{4}{|c|}{ Basic Characteristics of Estimated Model } \\
\cline { 2 - 5 } & Cost Function & Expectation & Returns to Scale & Adjustment Costs \\
\hline $1 \mathrm{~A}, 1 \mathrm{~B}$ & LQ & Rational & Non-Constant & Non-Zero \\
\hline $2 \mathrm{~A}, 2 \mathrm{~B}$ & LQ & Static & Non-Constant & Non-Zero \\
\hline $3 \mathrm{~A}, 3 \mathrm{~B}$ & LQ & Static* & Non-Constant & Zero \\
\hline $4 \mathrm{~A}, 4 \mathrm{~B}$ & LQR & Static & Non-Constant & Non-Zero \\
\hline $5 \mathrm{~A}, 5 \mathrm{~B}$ & LQR & Static & Constant & Non-Zero \\
\hline
\end{tabular}

*Expectations do not come into play, since the adjustment costs are zero.

In Tables 5.2 and 5.3 we report, respectively, on the estimation results obtained form the Monte Carlo experiments corresponding to variants A and $\mathrm{B}$ of the experiments. Rather than to report on all parameter estimates we focus on estimates of the adjustment coefficients, and the parameters determining those coeffcients, and on estimates of technical change $\lambda_{Y}$ and scale $\rho$. As in the Prucha and Nadiri study we report estimates for $\lambda_{Y}$ and $\rho$ in 1976. The estimated values in Tables 5.2 and 5.3 are Monte Carlo medians. The second column contains the true values for comparison. As a measure of spread of the respective estimates we report in parethesis their inter-quantile ranges. ${ }^{45}$ In Table 5.3 we also present estimates for the depreciation rate of capital $\delta^{K}$.

\footnotetext{
${ }^{45}$ Since $\lambda_{Y}$ and $\rho$ depend on the input and output mix, their values vary in respective
} 
Table 5.2: Estimates of Model Parameters, Technical Change, and Scale (Capital Stock Observed)

\begin{tabular}{|c|c|c|c|c|c|c|}
\hline Parameter & True Value & \multicolumn{5}{|c|}{ Estimates for Monte Carlo Experiment Number } \\
\hline & & $1 \mathrm{~A}$ & $2 \mathrm{~A}$ & $3 \mathrm{~A}$ & $4 \mathrm{~A}$ & $5 \mathrm{~A}$ \\
\hline$\alpha_{K K}$ & 0.420 & $\begin{array}{c}0.472 \\
(0.214)\end{array}$ & $\begin{array}{c}0.314 \\
(0.298)\end{array}$ & $\begin{array}{c}0.598 \\
(1.703)\end{array}$ & $\begin{array}{c}1.151 \\
(1.457)\end{array}$ & $\begin{array}{c}2.356 \\
(5.941)\end{array}$ \\
\hline$\alpha_{K R}$ & -0.066 & $\begin{array}{c}-0.096 \\
(0.097)\end{array}$ & $\begin{array}{c}-0 . .310 \\
(0.091)\end{array}$ & $\begin{array}{c}-0.336 \\
(1.314)\end{array}$ & $\begin{array}{c}-0.442 \\
(0.839)\end{array}$ & $\begin{array}{l}-1.232 \\
(3.338)\end{array}$ \\
\hline$\alpha_{R R}$ & 0.376 & $\begin{array}{c}0.391 \\
(0.138)\end{array}$ & $\begin{array}{c}0.338 \\
(0.177)\end{array}$ & $\begin{array}{c}0.585 \\
(1.534)\end{array}$ & $\begin{array}{c}0.357 \\
(0.632)\end{array}$ & $\begin{array}{c}0.921 \\
(1.987)\end{array}$ \\
\hline$\alpha_{\dot{K K}}$ & 5.616 & $\begin{array}{c}5.487 \\
(2.323)\end{array}$ & $\begin{array}{c}4.337 \\
(2.978)\end{array}$ & 0 & $\begin{array}{c}8.655 \\
(4.842)\end{array}$ & $\begin{array}{c}8.134 \\
(4.573)\end{array}$ \\
\hline$\alpha_{\dot{R} R}$ & 10.98 & $\begin{array}{c}12.52 \\
(6.487)\end{array}$ & $\begin{array}{c}13.05 \\
(4.870)\end{array}$ & 0 & $\begin{array}{r}8.645 \\
(7.204)\end{array}$ & $\begin{array}{c}10.27 \\
(10.37)\end{array}$ \\
\hline$m_{K K}$ & 0.217 & $\begin{array}{c}0.226 \\
(0.050)\end{array}$ & $\begin{array}{c}0.217 \\
(0.058)\end{array}$ & 1 & $\begin{array}{c}0.268 \\
(0.093)\end{array}$ & $\begin{array}{c}0.332 \\
(0.218)\end{array}$ \\
\hline$m_{K R}$ & -0.021 & $\begin{array}{c}-0.029 \\
(0.031)\end{array}$ & $\begin{array}{c}-0.012 \\
(0.043)\end{array}$ & 0 & $\begin{array}{c}-0.060 \\
(0.078)\end{array}$ & $\begin{array}{c}-0.183 \\
(0.161)\end{array}$ \\
\hline$m_{R K}$ & -0.011 & $\begin{array}{l}-0.013 \\
(0.013)\end{array}$ & $\begin{array}{l}-0.004 \\
(0.012)\end{array}$ & 0 & $\begin{array}{l}-0.066 \\
(0.164)\end{array}$ & $\begin{array}{l}-0.131 \\
(0.180)\end{array}$ \\
\hline$m_{R R}$ & 0.147 & $\begin{array}{c}0.144 \\
(0.024)\end{array}$ & $\begin{array}{c}0.125 \\
(0.034)\end{array}$ & 1 & $\begin{array}{c}0.134 \\
(0.177)\end{array}$ & $\begin{array}{c}0.119 \\
(0.199)\end{array}$ \\
\hline$\lambda_{Y}$ & $\begin{array}{c}1.000 \\
(0.167)\end{array}$ & $\begin{array}{c}0.968 \\
(0.287)\end{array}$ & $\begin{array}{c}0.604 \\
(0.490)\end{array}$ & $\begin{array}{c}1.296 \\
(0.217)\end{array}$ & $\begin{array}{c}0.503 \\
(0.454)\end{array}$ & $\begin{array}{c}1.216 \\
(0.323)\end{array}$ \\
\hline Scale & $\begin{array}{c}1.110 \\
(0.084)\end{array}$ & $\begin{array}{c}1.136 \\
(0.121)\end{array}$ & $\begin{array}{c}1.212 \\
(0.194)\end{array}$ & $\begin{array}{c}1.025 \\
(0.115)\end{array}$ & $\begin{array}{c}1.341 \\
(0.152)\end{array}$ & 1 \\
\hline
\end{tabular}

\footnotetext{
Monte Carlo trial even if evaluated at the true parameter values. It is for that reason that we also report an inter-quantile range for the true values of $\lambda_{Y}$ and $\rho$. The variability of the parameter estimates reflects the small sample size and the assumptions on the variances of the disturbance processes.
} 
Table 5.3: Estimates of Model Parameters, Technical Change, and Scale (Capital Stock Unobserved / Capital Depreciation Rate Estimated)

\begin{tabular}{|c|c|c|c|c|c|c|}
\hline Paramter & True Value & \multicolumn{5}{|c|}{ Estimates for Monte Carlo Experiment Number } \\
\hline & & 1B & $2 \mathrm{~B}$ & $3 \mathrm{~B}$ & $4 \mathrm{~B}$ & $5 \mathrm{~B}$ \\
\hline$\alpha_{K K}$ & 0.419 & $\begin{array}{c}0.469 \\
(0.422)\end{array}$ & $\begin{array}{c}0.218 \\
(0.466)\end{array}$ & $\begin{array}{c}1.350 \\
(5.003)\end{array}$ & $\begin{array}{c}0.414 \\
(1.151)\end{array}$ & $\begin{array}{c}0.774 \\
(1.129)\end{array}$ \\
\hline$\alpha_{K R}$ & -0.066 & $\begin{array}{l}-0.077 \\
(0.149)\end{array}$ & $\begin{array}{c}0.020 \\
(0.134)\end{array}$ & $\begin{array}{l}-0.035 \\
(0.955)\end{array}$ & $\begin{array}{c}-0.194 \\
(0.587)\end{array}$ & $\begin{array}{l}-0.596 \\
(0.898)\end{array}$ \\
\hline$\alpha_{R R}$ & 0.376 & $\begin{array}{c}0.414 \\
(0.178)\end{array}$ & $\begin{array}{c}0.362 \\
(0.214)\end{array}$ & $\begin{array}{c}0.375 \\
(0.614)\end{array}$ & $\begin{array}{c}0.408 \\
(0.719)\end{array}$ & $\begin{array}{c}0.477 \\
(1.001)\end{array}$ \\
\hline$\alpha_{\dot{K} \dot{K}}$ & 5.616 & $\begin{array}{c}5.403 \\
(3.710)\end{array}$ & $\begin{array}{c}4.862 \\
(2.923)\end{array}$ & 0 & $\begin{array}{c}9.581 \\
(9.299)\end{array}$ & $\begin{array}{c}6.465 \\
(5.594)\end{array}$ \\
\hline$\alpha_{\dot{R R}}$ & 10.98 & $\begin{array}{c}12.84 \\
(7.048)\end{array}$ & $\begin{array}{c}13.68 \\
(5.796)\end{array}$ & 0 & $\begin{array}{c}12.26 \\
(5.541)\end{array}$ & $\begin{array}{c}13.09 \\
(7.689)\end{array}$ \\
\hline$m_{K K}$ & 0.217 & $\begin{array}{c}0.224 \\
(0.110)\end{array}$ & $\begin{array}{c}0.194 \\
(0.171)\end{array}$ & 1 & $\begin{array}{c}0.165 \\
(0.249)\end{array}$ & $\begin{array}{c}0.246 \\
(0.157)\end{array}$ \\
\hline$m_{K R}$ & -0.021 & $\begin{array}{l}-0.024 \\
(0.038)\end{array}$ & $\begin{array}{c}0.010 \\
(0.058)\end{array}$ & 0 & $\begin{array}{l}-0.051 \\
(0.087)\end{array}$ & $\begin{array}{l}-0.164 \\
(0.147)\end{array}$ \\
\hline$m_{R K}$ & -0.011 & $\begin{array}{l}-0.010 \\
(0.018)\end{array}$ & $\begin{array}{c}0.004 \\
(0.020)\end{array}$ & 0 & $\begin{array}{l}-0.037 \\
(0.078)\end{array}$ & $\begin{array}{l}-0.067 \\
(0.092)\end{array}$ \\
\hline$m_{R R}$ & 0.147 & $\begin{array}{c}0.141 \\
(0.023)\end{array}$ & $\begin{array}{c}0.121 \\
(0.043)\end{array}$ & 1 & $\begin{array}{c}0.119 \\
(0.127)\end{array}$ & $\begin{array}{c}0.090 \\
(0.111)\end{array}$ \\
\hline$\lambda_{Y}$ & $\begin{array}{c}1.000 \\
(0.167)\end{array}$ & $\begin{array}{c}0.960 \\
(0.405)\end{array}$ & $\begin{array}{c}0.552 \\
(0.688)\end{array}$ & $\begin{array}{c}1.664 \\
(0.823)\end{array}$ & $\begin{array}{l}-0.003 \\
(1.872)\end{array}$ & $\begin{array}{c}0.816 \\
(0.982)\end{array}$ \\
\hline Scale & $\begin{array}{c}1.110 \\
(0.084)\end{array}$ & $\begin{array}{c}1.128 \\
(0.161)\end{array}$ & $\begin{array}{c}1.213 \\
(0.244)\end{array}$ & $\begin{array}{c}0.825 \\
(1.037)\end{array}$ & $\begin{array}{c}1.390 \\
(0.266)\end{array}$ & 1 \\
\hline$\delta_{K}$ & 0.038 & $\begin{array}{c}0.036 \\
(0.018)\end{array}$ & $\begin{array}{c}0.033 \\
(0.039)\end{array}$ & $\begin{array}{c}0.117 \\
(0.070)\end{array}$ & $\begin{array}{c}0.004 \\
(0.058)\end{array}$ & $\begin{array}{c}0.015 \\
(0.037)\end{array}$ \\
\hline
\end{tabular}


The estimates based on the true model, which are reported under experiments $1 \mathrm{~A}$ and $1 \mathrm{~B}$ in Tables 5.2 and 5.3 are, in general, close to the true values. We note that the inter-quantile ranges of the estimates are generally smaller for experiment $1 \mathrm{~A}$ than for experiment $1 \mathrm{~B}$, reflecting the fact that in the latter experiment also $\delta^{K}$ is being estimated in addition to the other model parameters. It is also interesting to note that the inter-quantile ranges for the estimates of the adjustment cost coefficients $\alpha_{\dot{K} \dot{K}}$ and $\alpha_{\dot{R} \dot{R}}$ are comparatively large. This observation is consistent with a similar finding in an earlier Monte Carlo study by Prucha and Nadiri (1986). In experiments 2A and $2 \mathrm{~B}$ expectations are misspecified as being static. The effect of this misspecification is to substantially decrease the estimates of technical change to .60 and .55 , respectively, as compared to a true value of 1.00 , and to increase the estimates of scale to 1.21, as compared to a true value of 1.11. If the model is further misspecified by assuming that adjustment costs are zero the estimates for technical change increase to 1.30 and 1.66, as reported under experiments 3A and 3B. Scale falls to 1.02 and .82, respectively. This type of misspecification also has a considerable effect on the estimate of $\delta^{K}$. The median estimate is .11 as compared to a true value of .038.

Misspecifying the functional form of the restricted cost function in terms of (3.16), and assuming static expectations, results in estimates of technical change of 0.5 and 0 , as reported under experiments $4 \mathrm{~A}$ and $4 \mathrm{~B}$, respectively. The estimate for scale increases to 1.30 and 1.39 , respectively. The estimates of the accelerator coefficients and the depreciation rate of capital are also fairly sensitive to this form of misspecification. Imposing constant returns to scale, as in experiments $5 \mathrm{~A}$ and $5 \mathrm{~B}$, results in less bias in the technical change estimates, and in estimates of $m_{K K}$ and $m_{R R}$ that are higher and lower than the true values. There is also substantial downward bias in the estimates of the depreciation rate of capital. These Monte Carlo results suggest that the estimates of model parameters and model characteristics may be quite sensitive to misspecification of the functional form, especially since the functional form misspecification imposed in this study may be considered as modest in that (3.16) can be viewed as a second order approximation of the true restricted cost function. 


\section{Concluding Remarks}

In this paper we have discussed some recent advances in modeling and in the estimation of dynamic factor demand, and have argued that this approach provides a powerful framework to analyze the determinants of the production structure, factor demand and technical change. The basic message of this paper can be summarized briefly. The conventional index number approach will measure the rate of technical change correctly if certain assumptions about the underlying technology of the firm and output and input markets hold. Furthermore, the conventional index number approach is appealing in that it can be easily implemented. However, if the underlying assumptions do not hold, then the conventional index number approach will, in general, yield biased estimates of technical change.

The index number approach also does not provide detailed insight into the dynamics of the production process and the determinants of factor demand and factor accumulation. The dynamic factor demand modeling approach reviewed in this paper provides a general framework to estimate the structure of the underlying technology and to relate the investment decisions and variation of technical change. Of course, in this approach there is, as in any other econometric investigation, the danger of misspecification. However, the basic appeal of this modeling strategy is its flexibility, that enables it to incorporate and analyze in a consistent framework both theoretical considerations and institutional factors that influence technical change, and to test various hypothesis concerning the specification of the technology and the optimizing behavior of the firm.

The dynamic factor demand modeling framework described in this paper enables us to examine a number of issues of both basic research and policy interest. Using the model it is possible to identify the possible biases in the conventional measure of total factor productivity growth. These biases can result from scale effects, the difference between marginal products and longrun factor rental prices in temporary equilibrium due to adjustment costs, the direct effect of adjustment costs as they influence output growth, and the selection of the depreciation rate by the firm. The model presented in this paper can be used to estimate the structure of the underlying technology and to specify the magnitudes of these biases if they are present. If the biases are 
not isolated relying on the conventional TFP measure will, e.g., overestimate technical change in the presence of increasing returns to scale and positive output growth.

The model also provides an analytical framework for estimating the response of input demands to changes in relative prices, exogenous technical change, and other exogenous variables that may shift the production or cost function. Since a clear distinction is drawn between variable and quasi-fixed inputs due to the presence of adjustment costs, the short-, intermediate- and long-run responses of output, factors of production and productivity growth can be estimated. (Of course, the approach does not impose the existence of adjustment costs and quasi-fixity, but rather leaves that to be determined empirically.) The class of models reviewed also allows for non-static expectations and non-separability among the quasi-fixed factors of production. It is therefore possible to estimate possible substitution or complementaries in the short-, intermediate- and long-runs among various types of capital such as physical, R\&D and human capital.

It is also possible to formulate and estimate an appropriate measure of capacity utilization consistent with the underlying production technology. Moreover, the model allows for the decision on depreciation rates of various quasi-fixed factors of production such as physical and R\&D capital to be endogenous. We note, however, that models in which the depreciation rate is constant are included as special cases. The framework thus allows for the econometric testing of the constancy hypothesis. Estimating the depreciation rates permits generating consistent capital stock series which may differ from the official estimates. It also allows the decomposition of gross investments of various types of capital into the net and replacement investments. The time profiles of these two types of investment have important analytical and policy implications.

To illustrate the workings of the model, we have discussed briefly some empirical results from several studies based on the dynamic factor demand model. These examples indicate how it is possible to account for the influences of scale, relative price movements, the rate of innovation due to $R \& D$ efforts and R\&D spillovers, and financial decisions concerning the level of debt and dividend payouts on the production structure and technical change. The overall conclusion reached from these examples is that the econometric modeling approach allows us to identify the contribution of a complex and often competing set of forces that shape productivity growth, and to test their significance statistically. Generally speaking, the empirical results based on 
dynamic factor demand models suggest that the estimated rate of technological change is often much smaller and smoother than the conventionally measured total factor productivity growth. Also, there is evidence of substantial degree of interrelatedness embedded in the production process of the firm that could not be captured using simple formulations of the firm's technology. The evidence from several studies suggests that some factors of production such as physical and R\&D capital are quasi-fixed in the short-run. Also, there is evidence that economies of scale characterizes the production process in some industries and that the elasticity of factor substitution is often much smaller than unity. Investment in R\&D is an integral part of the production structure and often significantly contributes to a reduction in cost. In addition R\&D spillovers among firms, industries and economies often reduce the cost of production of the recipient. Dynamic factor demand models also permit studying the production and financial decisions of the firm in a consistent framework and to analyze the effect of taxes and other exogenous policy instruments on these decisions.

To illustrate how estimates of important characteristics of the production process can be affected by various forms of misspecification a Monte Carlo study was undertaken. The results suggest, in particular, that estimates of the rate of technical change are sensitive to misspecification of the expectation formation process, to misspecification regarding whether or not the firms is in temporary or long-run equilibrium, and to misspecifications of the functional form of the cost/production function including scale. The exhibited sensitivity of technical change (and other model characteristics) to misspecification suggests that adopting simple specifications for reasons of convenience may result in serious estimation biases. This points to the importance of specification testing in the estimation of the cost/production functions and derived factor demands. Dynamic factor demand models provide a general framework for carrying out specification tests, and yield important insights in the complexity of the production decisions.

However, estimation of dynamic factor demand models is often challenging. These models are often complex and the estimation of these models requires considerable effort. Nonetheless, in order to measure technical change properly and to capture the dynamics of the adjustment of factor demands, and to analyze effects of relative prices and other exogenous variables such as taxes, subsidies, R\&D spillovers, etc., on factor demand and productivity growth, the dynamic factor demand modeling framework presented in this paper is an important tool of analysis. 


\section{A Appendix: Supplementary Material for Sec- tion 2}

Derivation of the Expressions in Equation (2.4). Differentiation of $F(a Y, V, X, \Delta X, T+\delta)=0$ w.r.t. $\delta$ yields

$$
\left[\sum_{i=1}^{k} \frac{\partial F}{\partial\left(a Y_{i}\right)} Y_{i}\right] \frac{\partial a}{\partial \delta}+\frac{\partial F}{\partial T}=0
$$

The formula on the r.h.s. of the first equation in (2.4) now follows immediately form the above expression, observing that $a=1$ for $\delta=0$. The formulae on the r.h.s. of the second and third equation of (2.4) are obtained analogously by differentiating $F(Y, b V, b X, b \Delta X, T+\delta)=0$ and $F(c Y, \kappa V, \kappa X, \kappa \Delta X, T)=0$ w.r.t. $\delta$ and $\kappa$, respectively.

Derivation of the Expressions in Equation (2.6). Substitution of (2.5) into (2.1) and differentiating w.r.t. $Z=V, X, \Delta X, T$ yields

$$
\frac{\partial F}{\partial Z}=-\frac{\partial F}{\partial Y} \frac{\partial f}{\partial Z}, \quad Z=V, X, \Delta X, T .
$$

Substitution of those expressions into (2.4) then gives the expressions in (2.6).

Derivation of the Expressions in Equation (2.35). To derive the approximate expression for input based technical change in (2.35) assume, e.g., that $\ln \left(M_{\tau}\right)=\ln \left(M\left(Y_{\tau}, L_{\tau}, X_{\tau}, \Delta X_{\tau}, T_{\tau}\right)\right)$ is approximately linear quadratic in $\ln \left(Y_{\tau}\right), \ln \left(L_{\tau}\right), \ln \left(X_{\tau}\right), \ln \left(\Delta X_{\tau}\right)$, and $T_{\tau}=\tau$ (and that $\left.\Delta X_{\tau}>0\right)$. It then follows from Diewert's (1976) quadratic approximation lemma that

$$
\begin{aligned}
& \ln \left(M_{\tau}\right)-\ln \left(M_{\tau-1}\right) \\
& \doteq \frac{1}{2} \sum_{i=1}^{k}\left[\frac{\partial M_{\tau}}{\partial Y_{\tau i}} \frac{Y_{\tau i}}{M_{\tau}}+\frac{\partial M_{\tau-1}}{\partial Y_{\tau-1, i}} \frac{Y_{\tau-1, i}}{M_{\tau-1}}\right] \Delta \ln \left(Y_{\tau i}\right) \\
& +\frac{1}{2} \sum_{j=1}^{m-1}\left[\frac{\partial M_{\tau}}{\partial L_{\tau j}} \frac{L_{\tau j}}{M_{\tau}}+\frac{\partial M_{\tau-1}}{\partial L_{\tau-1, j}} \frac{L_{\tau-1, j}}{M_{\tau-1}}\right] \Delta \ln \left(L_{\tau j}\right) \\
& +\frac{1}{2} \sum_{l=1}^{n}\left[\frac{\partial M_{\tau}}{\partial X_{\tau l}} \frac{X_{\tau l}}{M_{\tau}}+\frac{\partial M_{\tau-1}}{\partial X_{\tau-1, l}} \frac{X_{\tau-1, l}}{M_{\tau-1}}\right] \Delta \ln \left(X_{\tau l}\right)
\end{aligned}
$$




$$
\begin{aligned}
& +\frac{1}{2} \sum_{l=1}^{n}\left[\frac{\partial M_{\tau}}{\partial \Delta X_{\tau l}} \frac{\Delta X_{\tau l}}{M_{\tau}}+\frac{\partial M_{\tau-1}}{\partial \Delta X_{\tau-1, l}} \frac{\Delta X_{\tau-1, l}}{M_{\tau-1}}\right] \Delta \ln \left(\Delta X_{\tau l}\right) \\
& +\frac{1}{2}\left[\frac{\partial M_{\tau}}{\partial T_{\tau}} \frac{1}{M_{\tau}}+\frac{\partial M_{\tau-1}}{\partial T_{\tau-1}} \frac{1}{M_{\tau-1}}\right] .
\end{aligned}
$$

By (2.7) and (2.10) we have

$$
\begin{aligned}
\frac{\partial M_{\tau}}{\partial Y_{\tau i}} \frac{Y_{\tau i}}{M_{\tau}} & =\bar{g}_{\tau i} \frac{C_{\tau}}{M_{\tau}}, \quad i=1, \ldots, k, \\
\frac{\partial M_{\tau}}{\partial L_{\tau j}} \frac{L_{\tau j}}{M_{\tau}} & =-\bar{s}_{\tau, j+1}^{V} \frac{C_{\tau}}{M_{\tau}}, \quad j=1, \ldots, m-1, \\
\frac{\partial M_{\tau}}{\partial X_{\tau l}} \frac{X_{\tau l}}{M_{\tau}} & =-\bar{s}_{l \tau}^{X} \frac{C_{\tau}}{M_{\tau}}, \quad l=1, \ldots, n, \\
\frac{\partial M_{\tau}}{\partial X_{\tau l}} \frac{\Delta X_{\tau l}}{M_{\tau}} & =-\bar{s}_{l \tau}^{\Delta X} \frac{C_{\tau}}{M_{\tau}}, \quad l=1, \ldots, n, \\
\frac{\partial M_{\tau}}{\partial T_{\tau}} \frac{1}{M_{\tau}} & =-\lambda_{\tau}^{X} \frac{C_{\tau}}{M_{\tau}}
\end{aligned}
$$

Recall that $V_{\tau}=\left(M_{\tau}, L_{\tau}^{\prime}\right)^{\prime}$. Substitution of the above expressions into (A.3), rearranging terms, and premultiplying with $\left(\bar{s}_{\tau 1}^{V}+\bar{s}_{\tau-1,1}^{V}\right) / 2$ with $\bar{s}_{\tau 1}^{V}=M_{\tau} / C_{\tau}$ yields

$$
\begin{aligned}
& \frac{1}{2}\left(\lambda_{\tau}^{X} w_{\tau}+\lambda_{\tau-1}^{X} w_{\tau-1}\right) \\
& \doteq \frac{1}{2} \sum_{i=1}^{k}\left[\bar{g}_{\tau i} w_{\tau}+\bar{g}_{\tau-1, i} w_{\tau-1}\right] \Delta \ln \left(Y_{\tau i}\right) \\
& -\frac{1}{2} \sum_{j=1}^{m}\left[\bar{s}_{\tau j}^{V} w_{\tau}+\bar{s}_{\tau-1, j}^{V} w_{\tau-1}\right] \Delta \ln \left(V_{\tau j}\right) \\
& -\frac{1}{2} \sum_{l=1}^{n}\left[\bar{s}_{l \tau}^{X} w_{\tau}+\bar{s}_{l, \tau-1}^{X} w_{\tau-1}\right] \Delta \ln \left(X_{\tau l}\right) \\
& -\frac{1}{2} \sum_{l=1}^{n}\left[\bar{s}_{l \tau}^{\Delta X} w_{\tau}+\bar{s}_{l, \tau-1}^{\Delta X} w_{\tau-1}\right] \Delta \ln \left(\Delta X_{\tau l}\right)
\end{aligned}
$$

with $w_{\tau}=2 \bar{s}_{\tau 1}^{V} /\left(\bar{s}_{\tau 1}^{V}+\bar{s}_{\tau-1,1}^{V}\right)$. Assuming that $\bar{s}_{\tau 1}^{V} \doteq \bar{s}_{\tau-1,1}^{V}$ we obtain the expression given in (2.35). 
Derivation of the Expressions in Equations (2.39) and (2.40). We make use of the following lemma in deriving the decompositions of the conventional measure of total factor productivity growth in continuous time given in equations (2.39) and (2.40).

Lemma A.1 : Suppose

$$
\begin{aligned}
\lambda^{a} & =\sum_{i=1}^{k}\left(\alpha_{i}^{*} / \alpha^{*}\right) \mu_{i}-\sum_{j=1}^{r}\left(\alpha_{j} / \alpha\right) \eta_{j}, \\
\lambda^{b} & =\varepsilon \sum_{i=1}^{k}\left(\beta_{i}^{*} / \beta^{*}\right) \mu_{i}-\sum_{j=1}^{r+s}\left(\beta_{j} / \beta\right) \eta_{j},
\end{aligned}
$$

with $\alpha^{*}=\sum_{i=1}^{k} \alpha_{i}^{*}, \alpha=\sum_{j=1}^{r} \alpha_{j}, \beta^{*}=\sum_{i=1}^{k} \beta_{i}^{*}, \beta=\sum_{j=1}^{r+s} \beta_{j}$. Then

$$
\lambda^{a}=\lambda^{b}+(1-\varepsilon) \mu^{b}-\left(\mu^{b}-\mu^{a}\right)+\left(\eta^{b}-\eta^{a}\right)
$$

where $\mu^{a}=\sum_{i=1}^{k}\left(\alpha_{i}^{*} / \alpha^{*}\right) \mu_{i}, \mu^{b}=\sum_{i=1}^{k}\left(\beta_{i}^{*} / \beta^{*}\right) \mu_{i}, \eta^{a}=\sum_{j=1}^{r}\left(\alpha_{j} / \alpha\right) \eta_{j}$ and $\eta^{b}=\sum_{j=1}^{r+s}\left(\beta_{j} / \beta\right) \eta_{j}$. Furthermore

$$
\begin{array}{r}
\mu^{b}-\mu^{a}=\sum_{i=1}^{k}\left[\left(\beta_{i}^{*} / \beta^{*}\right)-\left(\alpha_{i}^{*} / \alpha^{*}\right)\right] \mu_{i} \\
=\sum_{i=1}^{k}\left(\beta_{i}^{*} / \beta^{*}\right)\left(\mu_{i}-\mu^{a}\right) \\
=\sum_{i=1}^{k}\left[\left(\beta_{i}^{*}-\alpha_{i}^{*}\right) / \beta^{*}\right]\left(\mu_{i}-\mu^{a}\right),
\end{array}
$$

and

$$
\begin{array}{r}
\eta^{b}-\eta^{a}=\sum_{j=1}^{r}\left[\left(\beta_{j} / \beta\right)-\left(\alpha_{j} / \alpha\right)\right] \eta_{j}+\sum_{j=r+1}^{r+s}\left(\beta_{j} / \beta\right) \eta_{j} \\
=\sum_{j=1}^{r+s}\left(\beta_{j} / \beta\right)\left(\eta_{j}-\eta^{a}\right) \\
=\sum_{j=1}^{r}\left[\left(\beta_{j}-\alpha_{j}\right) / \beta\right]\left(\eta_{j}-\eta^{a}\right)+\sum_{j=r+1}^{r+s}\left(\beta_{j} / \beta\right)\left(\eta_{j}-\eta^{a}\right) .
\end{array}
$$


Proof. Clearly

$$
\lambda^{b}=\varepsilon \mu^{b}-\eta^{b}=(\varepsilon-1) \mu^{b}+\left(\mu^{b}-\mu^{a}\right)+\left(\mu^{a}-\eta^{a}\right)-\left(\eta^{b}-\eta^{a}\right) .
$$

Observing that $\lambda^{a}=\mu^{a}-\eta^{a}$ we immediately obtain (A.7) from the above equation. The first expressions on the r.h.s. of (A.9) follows directly from the definitions of $\eta^{b}$ and $\eta^{a}$. The second expression is seen to hold observing that $\sum_{j=1}^{r+s}\left(\beta_{i} / \beta\right)=1$. The third expression on the r.h.s. of (A.9) is now readily seen to reduce to the second expression, observing that $\sum_{j=1}^{r}\left(\alpha_{j} / \beta\right)\left(\eta_{j}-\eta^{a}\right)=$ $(\alpha / \beta) \sum_{j=1}^{r}\left(\alpha_{j} / \alpha\right) \eta_{j}-(\alpha / \beta) \eta^{a}=0$. The expressions on the r.h.s. of (A.8) are seen to hold analogously.

The decomposition in (2.39) and (2.40) now follows from (2.25) and (2.32) and the above lemma with

$$
\begin{array}{ccc}
\lambda^{a} & =T \dot{F} P / T F P, \quad \lambda^{b}=\lambda^{X}, & \\
\mu^{a}= & \dot{Y}^{a} / Y^{a}, \quad \mu^{b}=\dot{Y}^{b} / Y^{b}, & \\
\eta^{a}= & \dot{F}^{a} / F^{a}, \quad \eta^{b}=\dot{F}^{b} / F^{b}, & \\
\varepsilon=\rho^{-1}, r=m+n, s=n, \text { and } & \\
\mu_{i}=\dot{Y}_{i} / Y_{i}, & \alpha_{i}^{*}=p_{i}^{Y} Y_{i}, & \\
& \beta_{i}^{*}=\left(\partial G / \partial Y_{i}\right) Y_{i}, & \\
\eta_{j}=\dot{V}_{j} / V_{j} & \alpha_{j}=p_{j}^{V} V_{j} & \text { for } i=1, \ldots, k \\
& \beta_{j}=p_{j}^{V} V_{j} & \\
\eta_{l+m}=\dot{X}_{l} / X_{l} & \alpha_{l+m}=c_{l}^{X} X_{l} & \\
& \beta_{l+m}=\left(-\partial G / \partial X_{l}\right) X_{l} & \\
\eta_{l+m+n}=\ddot{X}_{l} / \dot{X}_{l} & \beta_{l+m+n}=\left(-\partial G / \partial X_{l}\right) \dot{X}_{l} & \text { for } l=1, \ldots, m
\end{array}
$$

with

$$
\begin{aligned}
\alpha^{*} & =\sum_{i=1}^{k} \alpha_{i}^{*}=R^{+}, & \beta^{*} & =\sum_{i=1}^{k} \beta_{i}^{*}=R, \\
\alpha & =\sum_{j=1}^{m+n} \alpha_{j}=C^{+}, & \beta & =\sum_{j=1}^{m+2 n} \beta_{j}=C .
\end{aligned}
$$


Derivation of the Expressions in Equations (2.43) and (2.44). To derive the decomposition in (2.43) and (2.44) recall that for $\tau=t, t-1$ :

$$
\begin{aligned}
\Delta \ln Y_{t}^{a, \tau} & =\sum_{i=1}^{k} s_{\tau i}^{Y} \Delta \ln \left(Y_{t i}\right), \\
\Delta \ln F_{t}^{a, \tau} & =\sum_{j=1}^{m} s_{\tau j}^{V} \Delta \ln \left(V_{t j}\right)+\sum_{l=1}^{n} s_{\tau l}^{X} \Delta \ln \left(X_{t l}\right) .
\end{aligned}
$$

Analogously define for $\tau=t, t-1$ :

$$
\begin{aligned}
\Delta \ln Y_{t}^{b, \tau} & =\sum_{i=1}^{k} \bar{s}_{\tau i}^{Y} \Delta \ln \left(Y_{t i}\right), \\
\Delta \ln F_{t}^{b, \tau} & =\sum_{j=1}^{m} \bar{s}_{\tau j}^{V} \Delta \ln \left(V_{t j}\right)+\sum_{l=1}^{n} \bar{s}_{\tau l}^{X} \Delta \ln \left(X_{t l}\right)+\sum_{l=1}^{n} \bar{s}_{\tau l}^{\Delta X} \Delta \ln \left(\Delta X_{t l}\right) .
\end{aligned}
$$

Furthermore define for $\tau=t, t-1$ :

$$
\begin{aligned}
\Delta \ln T F P_{t}^{\tau} & \doteq \Delta \ln Y_{t}^{a, \tau}-\Delta \ln F_{t}^{a, \tau}=\sum_{i=1}^{k} s_{\tau i}^{Y} \Delta \ln \left(Y_{t i}\right) \\
& -\sum_{j=1}^{m} s_{\tau j}^{V} \Delta \ln \left(V_{t j}\right)-\sum_{l=1}^{n} s_{\tau l}^{X} \Delta \ln \left(X_{t l}\right)
\end{aligned}
$$

and

$$
\begin{aligned}
\lambda_{t}^{\tau}= & \rho_{\tau}^{-1} \Delta \ln Y_{t}^{b, \tau}-\Delta \ln F_{t}^{b, \tau}=\rho_{\tau}^{-1} \sum_{i=1}^{k} \bar{s}_{\tau i}^{Y} \Delta \ln \left(Y_{t i}\right) \\
& -\sum_{j=1}^{m} \bar{s}_{\tau j}^{V} \Delta \ln \left(V_{t j}\right)-\sum_{l=1}^{n} \bar{s}_{\tau l}^{X} \Delta \ln \left(X_{t l}\right)-\sum_{l=1}^{n} \bar{s}_{\tau l}^{\Delta X} \Delta \ln \left(\Delta X_{t l}\right) .
\end{aligned}
$$

Given (2.28) we then have

$$
\Delta \ln T F P_{t}=\frac{1}{2}\left[\Delta \ln T F P_{t}^{t}+\Delta \ln T F P_{t}^{t-1}\right] .
$$

Furthermore, given (2.35) we have

$$
\frac{1}{2}\left(\lambda_{t}^{X}+\lambda_{t-1}^{X}\right) \doteq \frac{1}{2}\left(\lambda_{t}^{t}+\lambda_{t}^{t-1}\right),
$$


observing that $\sum_{i=1}^{k} \bar{g}_{t i}=1 / \rho_{t}$, where $\rho_{t}$ denotes the scale elasticity, and observing that in light of (2.41) $\bar{g}_{t i}=\rho_{t}^{-1} \bar{s}_{t i}^{Y}$.

We next utilize the above lemma to decompose $\Delta \ln T F P_{t}^{\tau}$ for $\tau=t$ and $\tau=t-1$ based on (A.13) and (A.14). To this effect define

$$
\begin{array}{rlrl}
\lambda^{a} & =\Delta \ln T F P_{t}^{\tau}, & \lambda^{b}=\lambda_{t}^{\tau}, \\
\mu^{a}=\Delta \ln Y_{t}^{a, \tau}, & \mu^{b}=\Delta \ln Y_{t}^{b, \tau}, \\
\eta^{a}=\Delta \ln F_{t}^{a, \tau}, & \eta^{b}=\Delta \ln F_{t}^{b, \tau} .
\end{array}
$$

Furthermore define $\varepsilon=\rho_{\tau}^{-1}, r=m+n, s=n$, and

$$
\begin{array}{lll}
\mu_{i}=\Delta \ln \left(Y_{t i}\right), & \alpha_{i}^{*}=p_{\tau i}^{Y} Y_{\tau i}, & \text { for } i=1, \ldots, k \\
& \beta_{i}^{*}=\left(\partial G_{\tau} / \partial Y_{\tau i}\right) Y_{\tau i}, & \\
\eta_{j}=\Delta \ln \left(V_{t j}\right) & \alpha_{j}=p_{\tau j}^{V} V_{\tau j} & \text { for } j=1, \ldots, m \\
& \beta_{j}=p_{\tau j}^{V} V_{\tau j} & \\
\eta_{l+m}=\Delta \ln \left(X_{t l}\right) & \alpha_{l+m}=c_{\tau l}^{X} X_{\tau l} & \text { for } l=1, \ldots, n \\
& \beta_{l+m}=\left(-\partial G_{\tau} / \partial X_{\tau l}\right) X_{\tau l} & \\
\eta_{l+m+n}=\Delta \ln \left(\Delta X_{t l}\right) & \beta_{l+m+n}=\left(-\partial G_{\tau} / \partial \Delta X_{\tau l}\right) \Delta X_{\tau l} & \text { for } l=1, \ldots, n
\end{array}
$$

with

$$
\begin{array}{rlrl}
\alpha^{*} & =\sum_{i=1}^{k} \alpha_{i}^{*}=R_{\tau}^{+}, & \beta^{*}=\sum_{i=1}^{k} \beta_{i}^{*}=R_{\tau}, \\
\alpha=\sum_{j=1}^{m+n} \alpha_{j}=C_{\tau}^{+}, & \beta=\sum_{j=1}^{m+2 n} \beta_{j}=C_{\tau} .
\end{array}
$$

Applying the above lemma to (A.13) and (A.14), and recalling the definition of the respective shares in (2.35) and (2.36) then gives the following decomposition:

$$
\begin{aligned}
\Delta \ln T F P_{t}^{\tau} \doteq & \lambda_{t}^{\tau}+\left(1-1 / \rho_{\tau}\right) \Delta \ln Y_{t}^{b, \tau} \\
& +\left(\Delta \ln Y_{t}^{a, \tau}-\Delta \ln Y_{t}^{b, \tau}\right)+\left(\Delta \ln F_{t}^{b, \tau}-\Delta \ln F_{t}^{a, \tau}\right)
\end{aligned}
$$

with

$$
\begin{aligned}
& \Delta \ln Y_{t}^{a, \tau}-\Delta \ln Y_{t}^{b, \tau} \\
= & \sum_{i=1}^{k}\left(\frac{\left(p_{\tau i}^{Y}-\partial G_{\tau} / \partial Y_{\tau i}\right) Y_{\tau i}}{R_{\tau}}\right)\left(\Delta \ln \left(Y_{t i}\right)-\Delta \ln Y_{t}^{a, \tau}\right)
\end{aligned}
$$




$$
\begin{aligned}
& \Delta \ln F_{t}^{b, \tau}-\Delta \ln F_{t}^{a, \tau} \\
= & \sum_{l=1}^{n}\left(\frac{\left(-\partial G_{\tau} / \partial X_{\tau l}-c_{\tau l}^{X}\right) X_{\tau l}}{C_{\tau}}\right)\left(\Delta \ln \left(X_{t l}\right)-\Delta \ln F_{t}^{a, \tau}\right) \\
& \sum_{l=1}^{n}\left(\frac{\left(-\partial G_{\tau} / \partial \Delta X_{\tau l}\right) \Delta X_{\tau l}}{C_{\tau}}\right)\left(\Delta \ln \left(\Delta X_{t l}\right)-\Delta \ln F_{t}^{a, \tau}\right) .
\end{aligned}
$$

The decomposition in (2.43) and (2.44) now follows upon substitution of the above decomposition of $\Delta \ln T F P_{t}^{\tau}$ into (A.15) and utilizing (A.16). 


\section{B Appendix: Supplementary Material for Sec- tion 3}

\section{B.1 Interpretation of Optimality Conditions}

For a further interpretation of the first order conditions (3.9) and (3.10) for the quasi-fixed factors $K_{\tau}$ and $R_{\tau}$ given in Section 3.1.1 denote the normalized variable cost function corresponding to the variable inputs (only) as

$$
\begin{aligned}
g_{\tau} & =g\left(p_{\tau}^{L}, q_{\tau}^{K}, Y_{\tau}, K_{\tau-1}, R_{\tau-1}, \Delta K_{\tau}, \Delta R_{\tau}, T_{\tau}\right) \\
& =\hat{M}_{\tau}+\left(p_{\tau}^{L}\right)^{\prime} \hat{L}_{\tau}
\end{aligned}
$$

We can then rewrite $(3.7)$ as

$$
G_{\tau}=g_{\tau}-\left(q_{\tau}^{K}\right)^{\prime} \hat{K}_{\tau}^{o}
$$

Define furthermore

$$
\hat{R}_{\tau}^{o}=R_{\tau}^{o}=\left(I-\delta_{\tau}^{R}\right) R_{\tau-1}
$$

analogously to $K_{\tau}^{o}$ as the vector of "old" stocks left over at the end of the period from $R_{\tau-1}$, and observe that

$$
\left(I-\delta_{\tau}^{R}\right) E_{\tau} q_{\tau+1}^{R} /\left(1+r_{\tau+1}\right)=E_{\tau}\left[\partial \hat{R}_{\tau+1}^{o} / \partial R_{\tau}\right] q_{\tau+1}^{R} /\left(1+r_{\tau+1}\right)
$$

and $\partial \hat{R}_{\tau+1}^{o} / \partial K_{\tau}=0$. In light of the above definition of $c^{R}$ we can then rewrite (3.9) and (3.10) as

$$
\begin{aligned}
& -E_{\tau} \frac{\partial g_{\tau+1}}{\partial K_{\tau}} /\left(1+r_{\tau+1}\right)+E_{\tau}\left(q_{\tau}^{K}\right)^{\prime} \frac{\partial \hat{K}_{\tau+1}^{o}}{\partial K_{\tau}} /\left(1+r_{\tau+1}\right) \\
& +E_{\tau}\left(q_{\tau}^{R}\right)^{\prime} \frac{\partial \hat{R}_{\tau+1}^{o}}{\partial K_{\tau}} /\left(1+r_{\tau+1}\right) \\
= & q_{\tau}^{K}+\left\{\frac{\partial G_{\tau}}{\partial \Delta K_{\tau}}-E_{\tau} \frac{\partial G_{\tau+1}}{\partial \Delta K_{\tau+1}} /\left(1+r_{\tau+1}\right)\right\}, \\
& -E_{\tau} \frac{\partial g_{\tau+1}}{\partial R_{\tau}} /\left(1+r_{\tau+1}\right)+E_{\tau}\left(q_{\tau}^{K}\right)^{\prime} \frac{\partial \hat{K}_{\tau+1}^{o}}{\partial R_{\tau}} /\left(1+r_{\tau+1}\right)
\end{aligned}
$$




$$
\begin{aligned}
& +E_{\tau}\left(q_{\tau}^{R}\right)^{\prime} \frac{\partial \hat{R}_{\tau+1}^{o}}{\partial R_{\tau}} /\left(1+r_{\tau+1}\right) \\
= & q_{\tau}^{R}+\left\{\frac{\partial G_{\tau}}{\partial \Delta R_{\tau}}-E_{\tau} \frac{\partial G_{\tau+1}}{\partial \Delta R_{\tau+1}} /\left(1+r_{\tau+1}\right)\right\}
\end{aligned}
$$

The above reformulation of the stochastic Euler equations (3.9) and (3.10) shows that - although not immediately obvious - the two sets of first order conditions have the same basic structure. They have the following economic interpretation: The optimizing firm invests in the quasi-fixed factors $K$ and $R$ until, at the margin (and properly discounted), the reduction in the variable cost $g$, plus the increase in the value of the "old" stocks, equals the acquisition price, plus current period adjustment costs, minus the expected adjustment cost that would have occurred if the investment were undertaken in the next period (rather than the current one).

For further interpretation, assume that the (relative) prices and the discount rate are constant. Assume further that not only the depreciation rates of the quasi-fixed factors, but also those of the quasi-fixed factors $K$ are exogenously given and constant, so that

$$
\begin{aligned}
& \partial \hat{K}_{\tau+1}^{o} / \partial K_{\tau}=\left(I-\delta_{\tau}^{K}\right), \quad \partial \hat{K}_{\tau+1}^{o} / \partial R_{\tau}=0, \\
& \partial \hat{R}_{\tau+1}^{o} / \partial K_{\tau}=0, \quad \partial \hat{R}_{\tau+1}^{o} / \partial R_{\tau}=\left(I-\delta_{\tau}^{R}\right) \text {. }
\end{aligned}
$$

Finally assume that both $K$ and $R$ can be varied without adjustment cost. In this case the above Euler equations reduce to the usual long-run first order conditions

$$
\begin{aligned}
& -E_{\tau} \frac{\partial g_{\tau+1}}{\partial K_{\tau}}=q^{K}\left(r I+\delta_{\tau}^{K}\right), \\
& -E_{\tau} \frac{\partial g_{\tau+1}}{\partial R_{\tau}}=q^{R}\left(r I+\delta_{\tau}^{R}\right),
\end{aligned}
$$

which equate the respective reductions of the variable cost with the respective rental prices.

\section{B.2 Some Mathematical Derivations}

Derivation of the Total Factor Productivity Decompositions Discussed in Section 3.1.2. The discussion assumes that the Divisia index 
for aggregate output $Y^{a}$, aggregate input $F^{a}$, and total factor productivity TFP is defined as in Section 2.2 with $X=\left[K^{\prime}, R^{\prime}\right]^{\prime}$ and $V=\left[M, L^{\prime}\right]^{\prime}$. Let

$$
G=G\left(p^{L}, q^{K}, Y, X, \dot{X}, t\right)=\hat{M}+\left(p^{L}\right)^{\prime} \hat{L}-\left(q^{K}\right)^{\prime} \hat{K}^{o}
$$

be the continuous time analog of (3.7). Furthermore, let

$$
\begin{aligned}
\bar{g}_{i} & =\frac{\partial G}{\partial Y_{i}} \frac{Y_{i}}{C}, \quad \bar{s}_{i}^{Y}=\frac{\bar{g}_{i}}{\sum_{i=1}^{k} \bar{g}_{i}}=\frac{\left(\partial G / \partial Y_{i}\right) Y_{i}}{R} \\
\bar{s}_{j}^{V} & =\frac{p_{j}^{V} V_{j}}{C}, \quad \bar{s}_{l}^{K^{o}}=\frac{q_{l}^{K} K_{l}^{o}}{C}, \\
\bar{s}_{l}^{X} & =\frac{-\partial G}{\partial X_{l}} \frac{X_{l}}{C}, \quad \bar{s}_{l}^{\dot{X}}=\frac{-\partial G}{\partial \dot{X}_{l}} \frac{\dot{X}_{l}}{C} .
\end{aligned}
$$

with $R=\sum_{i=1}^{k}\left(\partial G / \partial Y_{i}\right) Y_{i}$ and $C=G\left(p^{L}, q^{K}, Y, X, \dot{X}, t\right)-\sum_{l}\left(\partial G / \partial X_{l}\right) X_{l}-$ $\sum_{l}\left(\partial G / \partial \dot{X}_{l}\right) \dot{X}_{l}$. Analogously to the discussion in Section 2.2 consider the following alternative index for aggregate output, say $Y^{b}$, defined by

$$
\frac{\dot{Y}^{b}}{Y^{b}}=\sum_{i=1}^{k} \bar{s}_{i}^{Y} \frac{\dot{Y}_{i}}{Y_{i}}
$$

Furthermore, consider the following index for aggregate input, say $F^{b}$, defined by

$$
\frac{\dot{F}^{b}}{F^{b}}=\sum_{j=1}^{m} \bar{s}_{j}^{V} \frac{\dot{V}_{j}}{V_{j}}-\sum_{l} \bar{s}_{l}^{K^{o}} \frac{\dot{K}_{l}^{o}}{K_{l}^{o}}+\sum_{l=1}^{n} \bar{s}_{l}^{X} \frac{\dot{X}_{l}}{X_{l}}+\sum_{l=1}^{n} \bar{s}_{l} \frac{\ddot{X}_{l}}{\dot{X}_{l}} .
$$

By arguments similar to those in Section 2.2 it is readily seen that we can write the growth accounting equation for input based technical change as

$$
\lambda^{X}=\rho^{-1} \frac{\dot{Y}^{b}}{Y^{b}}-\frac{\dot{F}^{b}}{F^{b}},
$$

observing that $\sum_{i=1}^{k} \bar{g}_{i}=1 / \rho$, where $\rho$ denotes the scale elasticity. Furthermore, analogous argumentation as in Section 2.2 and utilizing Lemma A.1 yields the following decomposition of the conventional measure of total factor productivity growth in continuous time:

$$
\frac{T \dot{F} P}{T F P}=\lambda^{X}+(1-1 / \rho) \frac{\dot{Y}^{b}}{Y^{b}}+\left(\frac{\dot{Y}^{a}}{Y^{a}}-\frac{\dot{Y}^{b}}{Y^{b}}\right)+\left(\frac{\dot{F}^{b}}{F^{b}}-\frac{\dot{F}^{a}}{F^{a}}\right)
$$


with

$$
\begin{aligned}
\frac{\dot{Y}^{a}}{Y^{a}}-\frac{\dot{Y}^{b}}{Y^{b}}= & \sum_{i}\left(\frac{\left(p_{i}^{Y}-\partial G / \partial Y_{i}\right) Y_{i}}{R}\right)\left(\frac{\dot{Y}_{i}}{Y_{i}}-\frac{\dot{Y}^{a}}{Y^{a}}\right) \\
\frac{\dot{F}^{b}}{F^{b}}-\dot{F}^{a}= & \sum_{l}\left(\frac{\left(-\partial G / \partial K_{l}-(1+r) q_{l}^{K}\right) K_{l}}{C}\right)\left(\frac{\dot{K}_{l}}{K_{l}}-\frac{\dot{F}^{a}}{F^{a}}\right) \\
& \sum_{j}\left(\frac{\left(-\partial G / \partial R_{j}-c_{j}^{R}\right) R_{j}}{C}\right)\left(\frac{\dot{R}_{j}}{R_{j}}-\frac{\dot{F}^{a}}{F^{a}}\right) \\
& +\sum_{l}\left(\frac{\left(-\partial G / \partial \dot{K}_{l}\right) \dot{K}_{l}}{C}\right)\left(\frac{\ddot{K}_{l}}{\dot{K}_{l}}-\frac{\dot{F}^{a}}{F^{a}}\right) \\
& +\sum_{j}\left(\frac{\left(-\partial G / \partial \dot{R}_{j}\right) \dot{R}_{j}}{C}\right)\left(\frac{\ddot{R}_{j}}{\dot{R}_{j}}-\frac{\dot{F}^{a}}{F^{a}}\right) \\
& +\sum_{l}\left(\frac{-q_{l}^{K} K_{l}^{o}}{C}\right)\left(\frac{\dot{K}_{l}^{o}}{K_{l}^{o}}-\frac{\dot{K}_{l}}{K_{l}}\right)
\end{aligned}
$$

observing that $c^{K}=\left(r+\delta^{K}\right) q^{K}, c^{R}=\left(r+\delta^{R}\right) q^{R}$ and with $K^{o}=\left(1-\delta^{K}\right) K$.

Derivation of the Expressions in Equations (3.18). The optimal demands for the quasi-fixed factors $K_{t}$ and $R_{t}$ given in (3.18) are the solution of the set of Euler equations (3.17), where the solution space is taken to be the class of processes that are of mean exponential order less that $(1+r)^{1 / 2}$. Solving (3.17) is a standard problem in the optimal control literature. Rather than to solve (3.17) directly, we derive those expressions here, e.g., as a special case of Theorem 3.1 given in Subsection 3.2.2. Let

$$
X_{t}=\left[\begin{array}{c}
K_{t} \\
R_{t}
\end{array}\right], \quad A=\left[\begin{array}{cc}
\alpha_{K K} & \alpha_{K R} \\
\alpha_{K R} & \alpha_{R R}
\end{array}\right], \quad B=\left[\begin{array}{cc}
\alpha_{\dot{K} \dot{K}} & 0 \\
0 & \alpha_{\dot{R} \dot{R}}
\end{array}\right],
$$

and define

$$
\underline{B}=B, \quad \underline{G}=A+(2+r) B,
$$

and $(\tau=t, t+1, \ldots)$

$$
(1+r) \underline{a}_{\tau}=-\left[\begin{array}{l}
{\left[\alpha_{K}+\alpha_{K T} T_{t}+\alpha_{K L} p_{t}^{L}+q_{t}^{K}\left(1+r+\alpha_{K K^{o}}\right)\right] \widehat{Y}_{t}^{1 / \rho}} \\
{\left[\alpha_{R}+\alpha_{R T} T_{t}+\alpha_{R L} p_{t}^{L}+q_{t}^{R}\left(r+\delta^{R}\right)\right] \widehat{Y}_{t}^{1 / \rho} .}
\end{array}\right]
$$


Is is now readily seen that (3.17) can be rewritten as

$$
-\underline{B} X_{\tau+1}+\underline{G} X_{\tau}-(1+r) \underline{B}^{\prime} X_{\tau-1}=(1+r) \underline{a}_{\tau},
$$

i.e., (3.17) is a special case of the difference equation system (3.27). Applying Theorem 3.1 in Section 3.2.2, and observing that $\underline{a}_{\tau}=\underline{a}_{t}$ yields the following solution for $X_{t}$ :

$$
\begin{aligned}
X_{t} & =M X_{t}^{*}+(I-M) X_{t-1}, \quad X_{t}^{*}=\underline{A}^{-1} \underline{a}_{t}, \\
\underline{A} & =\left(I-M^{\prime}\right)^{-1}\left(r I+M^{\prime}\right) \underline{B} M /(1+r)
\end{aligned}
$$

where $M$ satisfies the quadratic matrix equation

$$
-\underline{B}(I-M)^{2}+\underline{G}(I-M)-(1+r) \underline{B}^{\prime}=0,
$$

and where $\underline{B}(I-M)$ is symmetric.

Upon substitution of (B.2) into (B.6) the quadratic matrix equation for $M$ reduces to $(3.19)$, i.e.,

$$
B M^{2}+(A+r B) M-A=0 .
$$

Solving this equation for $A$ yields

$$
\begin{aligned}
A & =B M(r I+M)(I-M)^{-1} \\
& =\left(I-M^{\prime}\right)^{-1}\left(r I+M^{\prime}\right)(B M)^{\prime},
\end{aligned}
$$

where the second expression follows from the symmetry of $A$. Since $\underline{B}=\underline{B}^{\prime}=$ $B$ the symmetry of $\underline{B}(I-M)$ implies that also $B M$ is symmetric. Thus a comparison of (B.8) with the expression for $\underline{A}$ in (B.5) yields $\underline{A}=A /(1+r)$. The expression for $X_{t}$ in (B.5) thus reduces to

$$
X_{t}=M X_{t}^{*}+(I-M) X_{t-1}, \quad X_{t}^{*}=A^{-1}(1+r) \underline{a}_{t},
$$

which is equivalent to the expression given for $K_{t}$ and $R_{t}$ in (3.18).

\section{B.3 Extension of the Reparameterization Approach for a General Class of Models}

In the following we extend the discussion of the re-parameterization given in Section 3.2.2. 
Based on (3.32) we can re-paramterize the model in terms of $M$ and $\underline{B}$, and estimate $M$ and $\underline{B}$ rather than the original model parameters $\underline{G}$ and $\underline{B}$. According to Theorem 3.1 the matrix $S=\underline{B}(I-M)$ is symmetric. To impose the symmetry of $S$ we may also express $\underline{G}$ in terms of $S$ and $\underline{B}$ as

$$
\underline{G}=S+(1+r) \underline{B^{\prime}} S^{-1} \underline{B},
$$

and estimate $S$ and $\underline{B}$. To this effect we would then also rewrite (3.30) in the new parametrization. Observing that $M \underline{A}^{-1}=M[D \underline{B} M /(1+r)]^{-1}=$ $(1+r)(D \underline{B})^{-1}$ and $(I-M)=\underline{B}^{-1} S$ we obtain from (3.30):

$$
\begin{aligned}
X_{t} & =(1+r)(D \underline{B})^{-1} J_{t}+\underline{B}^{-1} S X_{t-1}, \\
J_{t} & =D \sum_{\tau=t}^{\infty}(I+D)^{-(\tau-t+1)} \underline{a}_{\tau}, \\
D & =(1+r) \underline{B}^{\prime} S^{-1}-I .
\end{aligned}
$$

Inspection of the optimal control solution (3.30) or (B.11) for $X_{t}$ shows its dependence on $\underline{a}_{\tau}=E_{t} \phi_{\tau}$, i.e., its dependence on conditional expectations of the forcing variables $\phi_{\tau}$ for $\tau=t, t+1, \ldots$ So far we have not specified the process for the forcing variables. Taking guidance from the optimal control models considered by Epstein and Yatchew (1985) and Madan and Prucha (1989) we now assume that ${ }^{46}$

$$
\phi_{\tau}=\pi+\Pi_{w} w_{\tau}+\Pi_{q} q_{\tau}+\Pi_{q}^{*} q_{\tau+1},
$$

where the $w_{t}$ and $q_{t}$ are determined by an autoregressive process:

$$
\left[q_{t}^{\prime}, w_{t}^{\prime}\right]^{\prime}=\nu+\sum_{i=1}^{p} \Theta_{i}\left[q_{t-i}^{\prime}, w_{t-i}^{\prime}\right]^{\prime}+\xi_{t} .
$$

We assume that this process is of mean exponential order less than $(1+r)^{1 / 2}$, with the $\xi_{t}$ 's distributed i.i.d. with zero means and finite variances. We assume furthermore that $w_{t}$ and $q_{t}$ are known at time $t$, and that the elements

\footnotetext{
${ }^{46}$ The specifications considered in those papers are slightly less general than that considered here, in that those papers consider particular specifications of the underlying technology. In the model considered by Madan and Prucha (1989) the elements of $w_{t}$ may be thought of as representing current factor costs such as wages, and the elements of $q_{t}$ may be thought of as representing after tax acquisition prices. Also, in that paper $\Pi_{w}$ and $\Pi_{q}$ represent selector matrices, and $\Pi_{q}^{*}$ represents $(I-\delta)$ times a selector matrix.
} 
of $\pi, \Pi_{w}, \Pi_{q}$ and $\Pi_{q}^{*}$ are functions of known constants, and/or elements of $\underline{G}$ and $\underline{B}$ (or $S$ and $\underline{B}$ ), and/or of parameters identified through other aspects of the model.

In computing $J_{t}=D \sum_{\tau=t}^{\infty}(I+D)^{-(\tau-t+1)} \underline{a}_{\tau}$ we assume that expectations on $w_{t}$ and $q_{t}$ are formed rationally. In light of (B.13) those expectations for $\tau=t, t+1, \ldots$ will be linear functions of current and lagged values of $w_{t}$ and $q_{t}$ (up to lags of order $p-1$ ). Consequently $J_{t}$ must be of the form

$$
J_{t}=\alpha+\sum_{i=0}^{p-1} \beta_{i}\left[q_{t-i}^{\prime}, w_{t-i}^{\prime}\right]^{\prime} .
$$

In principle we can express the vector $\alpha$ and the matrices $\beta_{1}, \ldots, \beta_{p-1}$ in terms of $\nu, \Theta_{1}, \ldots, \Theta_{p}, \pi, \Pi_{w}, \Pi_{q}, \Pi_{q}^{*}$ and $D$. However, this leads to rather complex expressions. Consequently, following Epstein and Yatchew (1985) and Madan and Prucha (1989) we may again try a re-parameterization where the vector $\nu$ and the matrices $\Theta_{1}, \ldots, \Theta_{p}$ are expressed in terms of $\alpha, \beta_{1}, \ldots, \beta_{p-1}, \pi, \Pi_{w}$, $\Pi_{q}, \Pi_{q}^{*}$ and $D$. As demonstrated below, this leads to the following expressions for $\nu$ and $\Theta_{1}, \ldots, \Theta_{p}$ :

$$
\begin{aligned}
\nu & =\Gamma D(\alpha-\pi), \quad \Gamma=\left\{\beta_{0}+D\left[\Pi_{q}^{*}, 0\right]\right\}^{-1}, \\
\Theta_{1} & =\Gamma\left\{(I+D) \beta_{0}-D\left[\Pi_{q}, \Pi_{w}\right]-\beta_{1}\right\} \\
\Theta_{i} & =\Gamma\left\{(I+D) \beta_{i-1}-\beta_{i}\right\}, \quad i=2, \ldots, p
\end{aligned}
$$

where $\beta_{p}=0$ and where we have assumed implicitly that $\Gamma$ is nonsingular .

In total, the re-parameterized model now consists of the quasi-fixed factor demand equations (B.11), with $J_{t}$ defined by (B.14), and where $\left[q_{t-i}^{\prime}, w_{t-i}^{\prime}\right]^{\prime}$ is given by (B.13) and $\nu, \Theta_{1}, \ldots, \Theta_{p}$ by (B.15). Additionally, as in the example considered in Section 3.2.1, the model can be augmented by demand equations for variable factors, etc. The discussion concerning actual econometric estimation of the factor demand equations given with the example of Section 3.2.1 also applies here.

In the following we now demonstrate that (B.15) holds indeed. The proof uses techniques analogous to those used by Epstein and Yatchew (1985). Their setup is contained as a special case of the model considered here. Recall that $D=(1+r)\left(I-M^{\prime}\right)^{-1}-I$ and $M=I-V \Lambda V^{-1}$. Consequently $D=V^{\prime-1} \Phi V^{\prime}-I$ with $\Phi=(1+r) \Lambda^{-1}$. (Since $\Lambda$ is a diagonal matrix whose diagonal elements are less than $(1+r)^{1 / 2}$ in modulus, $\Phi$ is a diagonal matrix 
where the diagonal elements are greater than $(1+r)^{1 / 2}$ in modulus.) It is now readily seen that

$$
D(I+D)^{-1} \sum_{s=0}^{\infty}(I+D)^{-s}=I .
$$

Recalling that $\underline{a}_{\tau}=E_{t} \phi_{\tau}$ it follows from (B.11), (B.12) and (B.16)that

$$
\begin{aligned}
J_{t}= & D \sum_{\tau=t}^{\infty}(I+D)^{-(\tau-t+1)} \underline{a}_{\tau}=D(I+D)^{-1} \sum_{s=0}^{\infty}(I+D)^{-s} \underline{a}_{t+s} \\
= & D(I+D)^{-1} \sum_{s=0}^{\infty}(I+D)^{-s}\left[\pi+\Pi_{w} E_{t} w_{t+s}+\Pi_{q} E_{t} q_{t+s}+\Pi_{q}^{*} E_{t} q_{t+s+1}\right] \\
= & \pi-\left[D \Pi_{q}^{*}, 0\right]\left[\begin{array}{c}
q_{t} \\
w_{t}
\end{array}\right] \\
& +D(I+D)^{-1} \sum_{s=0}^{\infty}(I+D)^{-s}\left[\Pi_{q}+(I+D) \Pi_{q}^{*}, \Pi_{w}\right]\left[\begin{array}{c}
E_{t} q_{t+s} \\
E_{t} w_{t+s}
\end{array}\right] .
\end{aligned}
$$

Observing that $E_{t} E_{t+1} q_{t+s}=E_{t} q_{t+s}$ and $E_{t} E_{t+1} w_{t+s}=E_{t} w_{t+s}$ it follows further that

$$
\begin{aligned}
E_{t} J_{t+1}= & \pi-\left[D \Pi_{q}^{*}, 0\right]\left[\begin{array}{c}
E_{t} q_{t+1} \\
E_{t} w_{t+1}
\end{array}\right] \\
& +D(I+D)^{-1} \sum_{s=0}^{\infty}(I+D)^{-s}\left[\Pi_{q}+(I+D) \Pi_{q}^{*}, \Pi_{w}\right]\left[\begin{array}{c}
E_{t} q_{t+s+1} \\
E_{t} w_{t+s+1}
\end{array}\right] .
\end{aligned}
$$

Since $D(I+D)^{-1}=(I+D)^{-1} D$ and

$$
\left[\begin{array}{c}
E_{t} q_{t+1} \\
E w_{t+1}
\end{array}\right]=\nu+\sum_{i=0}^{p-1} \Theta_{i+1}\left[\begin{array}{c}
q_{t-i} \\
w_{t-i}
\end{array}\right]
$$

it is now readily seen that

$$
\begin{aligned}
& J_{t}-(I+D)^{-1} E_{t} J_{t+1} \\
= & {\left[I-(I+D)^{-1}\right] \pi+D(I+D)^{-1}\left[\Pi_{q}, \Pi_{w}\right]\left[\begin{array}{c}
q_{t} \\
w_{t}
\end{array}\right] } \\
& +\left[D(I+D)^{-1} \Pi_{q}^{*}, 0\right]\left[\begin{array}{c}
E_{t} q_{t+1} \\
E_{t} w_{t+1}
\end{array}\right] \\
= & {\left[I-(I+D)^{-1}\right] \pi+\left[D(I+D)^{-1} \Pi_{q}^{*}, 0\right] \nu }
\end{aligned}
$$




$$
\begin{aligned}
& +D(I+D)^{-1}\left\{\left[\Pi_{q}, \Pi_{w}\right]+\left[\Pi_{q}^{*}, 0\right] \Theta_{1}\right\}\left[\begin{array}{c}
q_{t} \\
w_{t}
\end{array}\right] \\
& +\sum_{i=1}^{p-1}\left[D(I+D)^{-1} \Pi_{q}^{*}, 0\right] \Theta_{i+1}\left[\begin{array}{c}
q_{t-i} \\
w_{t-i}
\end{array}\right] .
\end{aligned}
$$

Alternatively, using the expression for $J_{t}$ given in (B.14) and argumentation analogous to that above yields

$$
\begin{aligned}
& J_{t}-(I+D)^{-1} E_{t} J_{t+1} \\
= & {\left[I-(I+D)^{-1}\right] \alpha-(I+D)^{-1} \beta_{0} \nu } \\
& +\sum_{i=0}^{p-1}\left[\beta_{i}-(I+D)^{-1}\left[\beta_{0} \Theta_{i+1}+\beta_{i+1}\right]\right]\left[\begin{array}{c}
q_{t-i} \\
w_{t-i}
\end{array}\right] .
\end{aligned}
$$

The expressions in (B.15) are now obtained by comparing the "matrices of coefficients" in (B.20) and (B.21). Fore example, comparing the "intercepts" yields

$$
\left[I-(I+D)^{-1}\right] \pi+\left[D(I+D)^{-1} \Pi_{q}^{*}, 0\right] \nu=\left[I-(I+D)^{-1}\right] \alpha-(I+D)^{-1} \beta_{0} \nu,
$$

which implies

$$
\nu=\Gamma D(\alpha-\pi), \quad \Gamma=\left\{\beta_{0}+D\left[\Pi_{q}^{*}, 0\right]\right\}^{-1} .
$$

Comparing the "matrices of coefficients" next to $\left[q_{t}^{\prime}, w_{t}^{\prime}\right]^{\prime}$ yields

$$
D(I+D)^{-1}\left\{\left[\Pi_{q}, \Pi_{w}\right]+\left[\Pi_{q}^{*}, 0\right] \Theta_{1}\right\}=\beta_{0}-(I+D)^{-1}\left[\beta_{0} \Theta_{1}+\beta_{1}\right],
$$

which implies

$$
\Theta_{1}=\Gamma\left\{(I+D) \beta_{0}-D\left[\Pi_{q}, \Pi_{w}\right]-\beta_{1}\right\} .
$$

The expressions for the remaining $\Theta_{i}$ 's in (B.15) are found analogously. 


\section{Appendix: Supplementary Material for Sec- tion 5}

In this appendix we give the specific equations for the "true" model used to generate the data for the Monte Carlo study discussed in Section 5. We use the same notation as in Section 3.2.1. Furthermore, it proves helful to denote with $X_{t}=\left[K_{t}, R_{t}\right]$ the vector of the quasi-fixed factors. We assume that relative prices and output are generated according to the following simple first order autoregressive processes:

$$
\begin{aligned}
p_{t}^{L} & =\rho_{0 L}+\rho_{1 L} p_{t-1}^{L}+\eta_{t}^{L}, \\
q_{t}^{K} & =\rho_{0 K}+\rho_{1 K} q_{t-1}^{K}+\eta_{t}^{K}, \\
q_{t}^{R} & =\rho_{0 R}+\rho_{1 R} q_{t-1}^{R}+\eta_{t}^{R}, \\
Y_{t} & =\rho_{0 Y}+\rho_{1 Y} Y_{t-1}+\eta_{t}^{Y},
\end{aligned}
$$

with $\left(\eta_{t}^{L}, \eta_{t}^{K}, \eta_{t}^{R}, \eta_{t}^{Y}\right)$ distributed i.i.d. multivariate normal. Given expectations are formed rationally the factor demand equations are given by

$$
\begin{aligned}
M_{t}= & \alpha_{o}+\alpha_{K} K_{t-1}+\alpha_{R} R_{t-1}+\alpha_{Y} Y_{t}+\alpha_{T} T_{t}-\frac{1}{2} \alpha_{L L}\left(p_{t}^{L}\right)^{2} \\
& +\frac{1}{2} \alpha_{K K}\left(K_{t-1}\right)^{2}+\alpha_{K R} K_{t-1} R_{t-1}+\frac{1}{2} \alpha_{R R}\left(R_{t-1}\right)^{2} \\
& +\alpha_{K Y} K_{t-1} Y_{t}+\alpha_{R Y} R_{t-1} Y_{t} \\
& +\frac{1}{2} \alpha_{\dot{K} \dot{K}}\left(\Delta K_{t}\right)^{2}+\frac{1}{2} \alpha_{\dot{R} R}\left(\Delta R_{t}\right)^{2}+\varepsilon_{t}^{M} \\
L_{t}= & \alpha_{L}+\alpha_{L L} p_{t}^{L}+\alpha_{L K} K_{t-1}+\alpha_{L R} R_{t-1}+\alpha_{L Y} Y_{t}+\varepsilon_{t}^{L}
\end{aligned}
$$

and

$$
\begin{aligned}
& \Delta X_{t}=\left\{B^{-1}+(1+r)[C-r B]^{-1}\right\} \\
& {\left[\begin{array}{l}
\alpha_{K}+\alpha_{L K} \frac{\rho_{0 L}}{1-\rho_{1 L}}+\left(1+r+\alpha_{K^{o} K^{o}}\right) \frac{\rho_{0 K}}{1-\rho_{1 K}}+\alpha_{K Y} \frac{\rho_{0 Y}}{1-\rho_{1 Y}} \\
\left.\alpha_{R}+\alpha_{L R} \frac{\rho_{0 L}}{1-\rho_{1 L}}+\frac{\rho_{0 K}}{1-\rho_{1 K}}+\left(r+\delta^{R}\right) \frac{\rho_{0 R}}{1-\rho_{1 R}}\right)+\alpha_{R Y} \frac{\rho_{0 Y}}{1-\rho_{1 Y}}
\end{array}\right]}
\end{aligned}
$$




$$
\begin{aligned}
& +\left\{B^{-1}+\frac{1+r}{\rho_{1 L}}\left[C-\frac{1+r-\rho_{1 L}}{\rho_{1 L}} B\right]^{-1}\right\}\left[\begin{array}{l}
\alpha_{L K}\left[p_{t}^{L}-\frac{\rho_{0 l}}{1-\rho_{1 L}}\right] \\
\alpha_{L R}\left[p_{t}^{L}-\frac{\rho_{0 l}}{1-\rho_{1 L}}\right]
\end{array}\right] \\
& +\left\{B^{-1}+\frac{1+r}{\rho_{1 K}}\left[C-\frac{1+r-\rho_{1 K}}{\rho_{1 K}} B\right]^{-1}\right\}\left[\begin{array}{l}
\frac{1+r}{\rho_{1 K}}+\alpha_{K^{o} K}\left[q_{t}^{K}-\frac{\rho_{0 K}}{1-\rho_{1 K}}\right] \\
0
\end{array}\right] \\
& +\left\{B^{-1}+\frac{1+r}{\rho_{1 R}}\left[C-\frac{1+r-\rho_{1 R}}{\rho_{1 R}} B\right]^{-1}\right\}\left[\begin{array}{l}
0 \\
\frac{1+r}{\rho_{1 R}}-\left(1-\delta^{R}\right)\left[q_{t}^{R}-\frac{\rho_{0 R}}{1-\rho_{1 R}}\right]
\end{array}\right] \\
& +\left\{B^{-1}+\frac{1+r}{\rho_{1 Y}}\left[C-\frac{1+r-\rho_{1 Y}}{\rho_{1 Y}} B\right]^{-1}\right\}\left[\begin{array}{l}
\alpha_{K Y}\left[Y_{t}-\frac{\rho_{0 Y}}{1-\rho_{1 Y}}\right] \\
\alpha_{R Y}\left[Y_{t}-\frac{\rho_{0 Y}}{1-\rho_{1 Y}}\right]
\end{array}\right] \\
& +B^{-1} C X_{t-1}+\left[\begin{array}{c}
\varepsilon_{t}^{K} \\
\varepsilon_{t}^{R}
\end{array}\right] .
\end{aligned}
$$

The innovations $\left(\varepsilon_{t}^{M}, \varepsilon_{t}^{L}, \varepsilon_{t}^{K}, \varepsilon_{t}^{R}\right)$ are assumed to be distributed i.i.d. multivariate normal. (The innovation processes $\left(\eta_{t}^{L}, \eta_{t}^{K}, \eta_{t}^{R}, \eta_{t}^{Y}\right)$ and $\left(\varepsilon_{t}^{M}, \varepsilon_{t}^{L}, \varepsilon_{t}^{K}, \varepsilon_{t}^{R}\right)$ are taken to be independent.) For simplicity we assume that

$$
K_{t}^{o}=-\alpha_{K^{o} K} K_{t-1}
$$

that is, the depreciation rate of capital $\delta^{K}=1+\alpha_{K^{o} K}$ is constant. Gross investment in capital and R\&D is given by

$$
I_{t}^{K}=K_{t}-K_{t}^{o}, \quad I_{t}^{R}=R_{t}-\left(1-\delta^{R}\right) R_{t-1} .
$$

The derivation of the above factor demand equations utilizes Theorem 3.1 and is analogous to the derivation in Section 3.2.1. In analogy to the study by Prucha and Nadiri (1996) the data are generated for the period 1960 to 1980, with the initial values as in the data set for that study. For each Monte Carlo trial we first obtained random drawings for the innovations and then solve (C.1) - (C.5) to generate data for $p_{t}^{L}, q_{t}^{K}, q_{t}^{R}, Y_{t}, M_{t}, L_{t}, K_{t}, R_{t}, K_{t}^{o}$, $I_{t}^{K}$, and $I_{t}^{R}$.

To estimate the above model in the case where the depreciation rate of capital is assumed to be unknown we express $K_{t}$ as

$$
K_{t}=\sum_{i=0}^{t-1} \alpha_{K^{o} K}^{i} I_{t-i}^{K}+\alpha_{K^{o} K}^{t} K_{0}
$$

and substitute this expression into (C.2) - (C.5). The model is then estimated using the approach discussed in Prucha (1997). 


\section{References}

[1] Abel, A.B. 1981. A dynamic model of investment and capacity utilization. Quarterly Journal of Economics XCVI, 379-403.

[2] Abel, A.B. 1983. Optimal investment under uncertainty. American Economic Review 73, 228-233.

[3] Abel, A.B., and J.C. Eberly. 1994. A unified model of investment under uncertainty. American Economic Review 84, 1369-1384.

[4] Arrow, K.J. 1968. Optimal capital policy with irreversible investment. In J.N. Wolfe, ed., Value, Capital and Growth. papers in Honour of Sir John Hicks. Edinburgh: Edinburgh University Press, 1-19.

[5] Auerbach, A.J., and K. Hassett. 1992. Tax policy and business fixed investment in the United States. Journal of Public Economics 47, 141170 .

[6] Berndt, E.R., and M.A. Fuss. 1981. Productivity measurement using capital asset valuation to adjust for variations in utilization. Working Paper No. 8125, Institute for Policy Analysis, Toronto.

[7] Berndt, E.R., and M.A. Fuss. 1986. Productivity measurement with adjustments for variations in capacity utilization and other forms of temporary equilibrium. Journal of Econometrics 33, 7-29.

[8] Berndt, E.R., and M.A. Fuss. 1989. Economic capacity utilization and productivity measurement for multiproduct firms with multiple quasifixed inputs. Working Paper No. 2932, National Bureau of Economic Research, Cambridge.

[9] Berndt, E.R., M. Fuss, and L. Waverman. 1980. Dynamic Adjustment Models of Industrial Energy Demand: Empirical Analysis for U.S. Manufacturing, 1947-1974. Palo Alto: Electric Power Research Institute, Final Report EPRI EA-1613. 
[10] Berndt, E.R., and C.J. Morrison. 1981. Capacity utilization measures: Underlying economic theory and an alternative approach. American Economic Review 71, 48-52.

[11] Berndt, E.R., C.J. Morrison, and G.C. Watkins. 1981. Dynamic models of energy demand: An assessment and comparison. In E.R. Berndt and B.C. Fields, eds., Measuring and Modeling Natural Resource Substitution. Cambridge: M.I.T. Press, 259-289.

[12] Berndt, E.R., and D. Wood. 1975. Technology, prices and the derived demand for energy. Review of Economics and Statistics 62, 259-268.

[13] Bernstein, J.I. 1983. Investment, labour skills, and variable factor utilization in the theory of the firm. Canadian Journal of Economics 16, 463-479.

[14] Bernstein, J.I., 1988a. Costs of production, intra- and interindustry R\&D spillovers: Canadian evidence. Canadian Journal of Economics 21, 324-347.

[15] Bernstein, J.I. 1988b. Multiple outputs, adjustment costs and the structure of production for Bell Canada. International Journal of Forecasting 4, 207-219.

[16] Bernstein, J.I. 1988c. Dynamic factor demands and adjustment costs An analysis of Bell Canada's technology. Information Economics and Policy 3(1), 5-24.

[17] Bernstein, J.I., 1989a. The structure of Canadian interindustry R\&D spillovers and the rates of return to R\&D. Journal of Industrial Economics 21, 324-347.

[18] Bernstein, J.I. 1989b. An examination of the equilibrium specification and structure of production for Canadian telecommunications. Journal of Applied Econometrics 4(3), 265-282.

[19] Bernstein, J.I. 1994a. Exports, margins and productivity growth: With an application to the Canadian softwood lumber industry. Review of Economics and Statistics 76, 291-301. 
[20] Bernstein, J.I. 1994b. Taxes, incentives and production: the case of Turkey. Journal of Development Economics 45, 55-79.

[21] Bernstein, J.I., and P. Mohnen. 1988. Exports, markups and productivity growth in three Canadian high-tech industries. Working Paper No. 8809D, Department of Economics, Université du Québec à Montréal, Montréal.

[22] Bernstein, J.I., and P. Mohnen. 1991. Price cost margins, exports and productivity growth: With an application to Canadian industries. Canadian Journal of Economics 24, 638-659.

[23] Bernstein, J.I., and P. Mohnen. 1998. International R\&D spillovers between U.S. and Japanese R\&D intensive sectors. Journal of International Economics 44, 315-338.

[24] Bernstein, J.I., and M.I. Nadiri. 1987a. Corporate taxes and incentives and the structure of production: A selected survey. In J.M. Mintz and D.T. Purves, eds., The Impact of Taxation on Business Activity. Kingston: John Deutsch Institute for the Study of Economic Policy.

[25] Bernstein, J.I., and M.I. Nadiri. 1987b. Investment, depreciation and capital utilization. Economic Research Report No. 87-08, Department of Economics, New York University, New York.

[26] Bernstein, J.I., and M.I. Nadiri. 1988. Interindustry R\&D spillovers, rates of return, and production in high-tech industries. American Economic Review 78, 429-434.

[27] Bernstein, J.I., and M.I. Nadiri. 1989. Research and development and intra-industry spillovers: An empirical application of dynamic duality. Review of Economic Studies 56, 249-267.

[28] Bernstein, J.I., and M.I. Nadiri. 1991. Product demand, cost of production spillovers, and the social rate of return. Working Paper No. 3625, National Bureau of Economic Research, Cambridge.

[29] Bernstein, J.I., and M.I. Nadiri. 1993. Production, financial structure and productivity growth in US manufacturing. NBER Working Paper No. 4309, National Bureau of Economic Research, Cambridge. 
[30] Bernstein, J.I., and A. Shah. 1994. Taxes and production: the case of Pakistan. International Tax and Public Finance 1, 227-245.

[31] Bertola, G. 1988. Adjustment costs and dynamic factor demand: Investment and employment under uncertainty. Ph.D. Dissertation, Massachusetts Institute of Technology, Department of Economics.

[32] Binder, M., and M.H. Pesaran. 1995. Multivariate rational expectations models and macroeconometric modelling: A review and some new results. In M.H. Pesaran and M. Wickens, eds., Handbook of Applied Econometrics, Vol. I, Oxford: Basil Blackwell, 139 - 187.

[33] Binder, M., and M.H. Pesaran. 1997. Multivariate linear rational expectations models: Characterization of the nature of the solutions and their fully recursive computation. Econometric Theory (forthcoming).

[34] Bischoff, C.W., and E.C. Kokkelenberg. 1987. Capacity utilization and depreciation-in-use. Applied Economics 19, 995-1007.

[35] Bitros, G., and H. Kelejian. 1974. On the variability of the replacement investment capital stock ratio: Some evidence from capital scrappage. Review of Economics and Statistics 56, 270-278.

[36] Blanchard, O.J., and C.M. Kahn. 1980. Solution of linear difference models under rational expectations. Econometrica 38, 1305 - 1311.

[37] Boskin, M.J., and L.J. Lau. 1991. Capital Formation and Economic Growth. In Technology and Economics: Papers Commemorating Ralph Landau's service to the National Academy of Engineering. Washington, D.C.: National Academy Press, 47-56.

[38] Boskin, M.J., and L.J. Lau. 1992a. International and Intertemporal Comparison of Productive Efficiency: An Application of the Metaproduction Function Approach to the Group-of-Five (G-5) Countries. Economic Studies Quarterly 43, 298-312.

[39] Boskin, M.J., and L.J. Lau. 1992b. Capital, Technology, and Economic Growth. In N. Rosenberg, R. Landau, and D.C. Mowery, eds., Technology and the Wealth of Nations. Stanford: Stanford University Press, $17-55$. 
[40] Broze, L., C. Gouriéroux, and A. Szafarz. 1985. Solutions of dynamic linear rational expectations models. Econometric Theory 1, 341 - 368.

[41] Broze, L., C. Gouriéroux, and A. Szafarz. 1990. Reduced Forms of Rational Expectations Models, Chur: Harwood Academic Publishers.

[42] Broze, L., C. Gouriéroux, and A. Szafarz. 1995. Solutions of multivariate rational expectations models. Econometric Theory 11, 229 - 257.

[43] Broze, L., and A. Szafarz. 1991. The Econometric Analysis of NonUniqueness in Rational Expectations Models. Amsterdam: NorthHolland.

[44] Caballero, R.J. 1991. On the sign of the investment-uncertainty relationship. American Economic Review 81, 279-288.

[45] Cassing, S., and T. Kollintzas. 1991. Recursive factor of production interrelations and endogenous cycling. International Economic Review $32,417-440$.

[46] Caves, D.W., L.R. Christensen, and W.E. Diewert. 1982a. The economic theory of index numbers and the measurement of input, output, and productivity. Econometrica 50, 1393-1414.

[47] Caves, D.W., L.R. Christensen, and W.E. Diewert. 1982b. Multilateral comparisons of output, input, and productivity using superlative index numbers. Economic Journal 92, 73-86.

[48] Caves, D.W., L.R. Christensen, and J.A. Swanson. 1980. Productivity in U.S. railroads, 1951-1974. Bell Journal of Economics 11, 166-181.

[49] Caves, D.W., L.R. Christensen, and J.A. Swanson. 1981. Productivity growth, scale economies, and capacity utilization in U.S. railroads, 1955-74. American Economic Review 71, 994-1002.

[50] Christensen, L.R., D.W. Jorgenson, and L.J. Lau. 1971. Conjugate duality and the transcendental logarithmic functions. Econometrica 39, 255-256.

[51] Christensen, L.R., D.W. Jorgenson, and L.J. Lau. 1973. Transcendental logarithmic production frontiers. Review of Economics and Statistics $55,28-45$. 
[52] Cummins, J.G., and K.A. Hassett. 1992. The effect of taxation on investment: New evidence from firm level panel data. National Tax Journal 45, 243-251.

[53] Denny, M., M.A. Fuss, and L. Waverman. 1981a. The measurement and interpretation of total factor productivity in regulated industries, with an application to Canadian telecommunications. In T. Cowing and R. Stevenson, eds., Productivity Measurement in Regulated Industries. New York: Academic Press, 179-218.

[54] Denny, M., M.A. Fuss, and L. Waverman. 1981b. Substitution possibilities for energy: Evidence from U.S. and Canadian manufacturing industries. In E.R. Berndt and B.C. Field, eds., Modeling and Measuring Natural Resource Substitution. Cambridge: MIT Press, 230-258.

[55] Diewert, W.E. 1971. An application of the Shephard duality theorem: A generalized Leontief production function. Journal of Political Economy $79,481-507$.

[56] Diewert, W.E. 1974. Applications of duality theory. In M. Intriligator, and D.A. Kendrick, eds., Frontiers of Qantitative Economics, Vol. II. Amsterdam: North Holland, 106-171.

[57] Diewert, W.E. 1976. Exact and superlative index numbers. Journal of Econometrics 4, 115-145.

[58] Diewert, W.E. 1977. Walras' theory of capital formation and the existence of a temporary equilibrium. In G. Schwödiauer, ed., Equilibrium and Disequilibrium in Economic Theory. Dordrecht: D. Reidel Publishing Co., 73-126.

[59] Diewert, W.E. 1980. Aggregation problems in the measurement of capital. In D. Usher, ed., The Measurement of Capital. Chicago: University of Chicago Press, 433-528.

[60] Diewert, W.E. 1982. Duality approaches to microeconomic theory. In K.J. Arrow and M.D. Intriligator, eds., Handbook of Mathematical Economics, Volume II. Amsterdam: North Holland, 535-599. 
[61] Diewert, W.E., and D.A. Lawrence. 1996. The deadweight costs of taxation in New Zealand. Canadian Journal of Economics XXIX, Special Issue, S658-673.

[62] Diewert, W.E., and D.A. Lawrence. 1998. The deadweight costs of capital taxation in Australia. Department of Economics, The University of British Columbia, Discussion Paper No. 98-01.

[63] Diewert, W.E., and T.J. Wales. 1987. Flexible functional forms and curvature conditions. Econometrica 55, 43-68.

[64] Dixit, A.K. 1991. Irreversible investment with price ceilings. Journal of Political Economy XCIX, 541-557.

[65] Dixit, A.K. 1992. Investment and hysteresis. Journal of Economic Perspectives 6, 107-132.

[66] Dixit, A.K., and R.S. Pindyck. 1994. Investment under Uncertainty. Pinceton: Princeton University Press.

[67] Dubey, A. 1996. Optimal investment plans of a firm with alternative planning horizon and tax expectations: an empirical study of the U.S. durable goods industry. Ph.D. Dissertation, University of Maryland, Department of Economics.

[68] Eisner, R. 1972. Components of capital expenditures: Replacement and modernization versus expansion. Review of Economics and Statistics 54, 297-305.

[69] Eisner, R., and M.I. Nadiri. 1968. On investment behavior and neoclassical theory. Review of Economics and Statistics 50, 369-382.

[70] Eisner, R., and M.I. Nadiri. 1970. Once more on that 'Neoclassical theory of investment behavior'. Review of Economics and Statistics $52,216-222$.

[71] Eisner, R., and R. Strotz. 1963. Determinants of business investment. In Impacts of Monetary Policy (Commision on Money and Credit). Englewood Cliffs: Prentice Hall. 
[72] Epstein, L.G., and M. Denny. 1980. Endogenous capital utilization in a short- run production model: Theory and empirical application. Journal of Econometrics 12, 189-207.

[73] Epstein, L.G., and A.J. Yatchew. 1985. The empirical determination of technology and expectations: A simplified procedure. Journal of Econometrics 27, 235-258.

[74] Fazari, S., R. Hubbard, and B. Petersen. 1996. Financing constraints and corporate investment. In Z.J. Acs, ed., Small Firms and Economic Growth. Cheltenham: Elgar.

[75] Feldstein, M.S. 1974. Tax incentives, stabilization policy, and the proportional replacement hypothesis: Some negative conclusions. Southern Economic Journal 40, 544-552.

[76] Feldstein, M. 1994. Fiscal policies, capital formation, and capitalism. Working Paper No. 4885, National Bureau of Economic Research, Cambridge.

[77] Feldstein, M.S., and D.K. Foot. 1971. The other half of gross investment: Replacement and modernization expenditures. Review of Economics and Statistics 53, 49-58.

[78] Feldstein, M.S., and M. Rothschild. 1974. Towards an economic theory of replacement investment. Econometrica 42, 393-423.

[79] Fuss, M.A. 1994. Productivity growth in Canadian telecommunications. Canadian Journal of Economics 27(2), 371-392.

[80] Fuss, M.A., and D. McFadden. 1978a. Production Economics: A Dual Approach to Theory and Applications, Vol. I. New York: NorthHolland.

[81] Fuss, M.A., and D. McFadden. 1978b. Production Economics: A Dual Approach to Theory and Applications, Vol. II. New York: NorthHolland.

[82] Fuss, M.A., D. McFadden, and Y. Mundlak. 1978. A survey of functional forms in the economic analyis of production. In M.A. Fuss and D. McFadden, eds., Production Economics: A Dual Approach to Theory and Applications. New York: North Holland, 219-268. 
[83] Galeotti, M. 1990. Specification of the technology for neoclassical investment theory: Testing the cost of adjustment approach. Review of Economics and Statistics LXXII, 471-480.

[84] Galeotti, M. 1996. The international dimension of neoclassical production theory. Journal of Economic Surveys 10, 421-460.

[85] Galeotti M., and F. Schiantarelli. 1997. The cyclicality of markups in a model with adjustment costs: Econometric evidence for US industry. Oxford Bulletin of Economics and Statistics, forthcoming.

[86] Gallant, A.R. 1987. Nonlinear Statistical Models. New York: Wiley.

[87] Gallant, A.R., and H. White. 1988. A Unified Theory of Estimation and Inference for Nonlinear Dynamic Models. New York: Basil Blackwell.

[88] Good, D., M.I. Nadiri, and R. Sickles. 1997. Index number and factor demand approaches to the estimation of productivity. In M.H. Pesaran and P. Schmidt, eds., Handbook of Applied Econometrics, Volume II Microeconometrics. Oxford: Basil Blackwell.

[89] Gordon, S. 1996. How long is the firm's forecast horizon? Journal of Economic Dynamics and Control 20, 1145-1176.

[90] Goto, A., and Suzuki, K. 1989. R\&d capital, rate of return on R\&D investment and spillover of $\mathrm{R} \& \mathrm{D}$ in Japanese manufacturing industries. Review of Economics and Studies 71, 555-564.

[91] Gould, J.P. 1968. Adjustment costs in the theory of investment of the firm. Review of Economic Studies 35, 47-55.

[92] Greenwald, B.C., M. Kohn, and J.E. Stiglitz. 1990. Financial market imperfections and productivity growth. Journal of Economic Behavior and Organization 13, 321-345.

[93] Griliches, Z. 1980. Returns to research and development expenditures in the private sector. In J. Kendrick and B. Vaccara, eds., New Developments in Productivity Measurement and Analysis. Chicago: University of Chicago Press, 419-454. 
[94] Griliches, Z. 1987. Productivity: Measurement problems. In J. Eatwell, M. Milgate, and P. Newman, eds., The New Palgrave: A Dictionary of Economics. New York: Stockton Press.

[95] Griliches, Z. 1992. The search for R\&D spillovers. Scandinavian Journal of Economics 94(0), Supplement, S29-47.

[96] Griliches, Z. 1996. The theory of the residual: A historical note. Journal of Economic Literature XXXIV, 1324-1330.

[97] Hall, E.R. 1988. The relation between price and marginal cost in the United States industry. Journal of Political Economy 96, 921-947.

[98] Hall, R.E., and D.W. Jorgenson. 1971. Application of theory of optimum capital accumulation. In G. Fromm, ed., Tax Incentives and Capital Spending. Washington, DC: The Brookings Institution, 9-60.

[99] Hansen, L.P. 1982. Large sample properties of generalized method of moments estimators. Econometrica 50, 1029-1054.

[100] Hansen, L.P., and T.J. Sargent. 1980. Formulating and estimating dynamic linear rational expectations models. Journal of Economic Dynamics and Control 2, 7-46.

[101] Hansen, L.P., and T.J. Sargent. 1981. Linear rational expectations models for dynamically interrelated variables. In R.E. Lucas, Jr. and T.J. Sargent, eds., Rational Expectations and Econometric Practice, Vol. I. Minneapolis: University of Minnesota Press,127-156.

[102] Hansen, L.P., and T.J. Sargent. 1982. Instrumental variables procedures for estimating linear rational expectations models. Journal of Monetary Economics 9, 263-296.

[103] Hansen, L.P., and K.J. Singleton. 1982. Generalized instrumental variables estimation of nonlinear rational expectations models. Econometrica 50, 1269-1286.

[104] Hayami, Y., and V.W. Ruttan. 1970. Agricultural productivity differences among countries. American Economic Review 60, 895-911.

[105] Hayami, Y., and V.W. Ruttan. 1985. Agricultural Development: An International Perspective. Baltimore: Johns Hopkins University Press. 
[106] Hayashi, F. 1982. Tobin's marginal and average q: A neoclassical interpretation. Econometrica 50, 213-224.

[107] Hicks, J.R. 1946. Value and Capital, 2nd edition. Oxford: Oxford University Press.

[108] Honkapohija, S., and V. Kanniainen. 1985. Adjustment cost, optimal capacity utilization, and the corporation tax. Oxford Economic Papers 37, 486-499.

[109] Hulten, C.R. 1973. Divisia index numbers. Econometrica 41, 1017-1026.

[110] Hulten, C.R. 1986. Productivity change, capacity utilization, and sources of efficiency growth. Journal of Econometrics 33, 31-50.

[111] Hulten, C.R. 1987. The Divisia index. In J. Eatwell, M. Milgate and P. Newman, eds., The New Palgrave: A Dictionary of Economics. New York: Stockton Press.

[112] Hulten, C.R., and F.C. Wykoff. 1980. Economic depreciation and the taxation of structures in the United States manufacturing industries: An empirical analysis. In D. Usher, The Measurement of Capital, Studies in Income and Wealth, Vol.45, National Bureau of Economic Research. Chicago: University of Chicago Press.

[113] Hulten, C.R., and F.C. Wykoff. 1981a. The measurement of economic depreciation. In C.R. Hulten, ed., Depreciation, Inflation, and the Taxation of Income from Capital. Washington, D.C.: The Urban Institute.

[114] Hulten, C.R., and F.C. Wykoff. 1981b. The estimation of economic depreciation using vintage asset prices. Journal of Econometrics 15, 367-396.

[115] Hulten, C.R., and F.C. Wykoff. 1981c. Economic depreciation and accelerated depreciation: An evaluation of the Conable-Jones 10-5-3 proposal. National Tax Journal 34, 45-60.

[116] Jorgenson, D.W. 1963. Capital theory and investment behavior. American Economic Review 35, 247-259.

[117] Jorgenson, D.W. 1966. Rational distributed lag functions. Econometrica $34,135-149$. 
[118] Jorgenson, D.W. 1974. The economic theory of replacement and depreciation. In W. Sellekaerts, ed., Essays in Honor of Jan Tinbergen, Economic Theory and Miscellaneous. Amsterdam: North Holland, 189221.

[119] Jorgenson, D.W. 1986. Econometric methods for modeling producer behavior. In Z. Griliches and M.D. Intriligalator, eds., Handbook of Econometrics, Volume III. Elsevier Science Publishers, 1841-1915.

[120] Jorgenson, D.W. 1995a. Productivity - Vol I: Postwar U.S. Economic Growth. Cambridge: MIT Press.

[121] Jorgenson, D.W. 1995a. Productivity - Vol II: International Comparison of Economic Growth.Cambridge: MIT Press.

[122] Jorgenson, D.W. 1996a. Capital Theory and Investment Behavior. Cambridge: MIT Press.

[123] Jorgenson, D.W. 1996b. Tax Policy and the Cost of Capital. Cambridge: MIT Press.

[124] Jorgenson, D.W., and Z. Griliches. 1967. The explanation of productivity change. Review of Economic Studies 34, 249-283.

[125] Jorgenson, D.W., and J.A. Stephenson. 1967. The time structure of investment behavior in the United States. Review of Economics and Statistics 49, 16-27.

[126] Kennan, J. 1979. The estimation of partial adjustment models with rational expectations. Econometrica 47, 1441-1456.

[127] Kim, J.-I., and L.J. Lau. 1994. The sources of economic growth of the East Asian Newly Industrialized Countries. Journal of the Japanese and International Economies 8, 235-71.

[128] Kim, J.-I., and L.J. Lau. 1996. The sources of Asian Pacific economic growth. Canadian Journal of Economics 29, 448-54.

[129] Kim, M., and V. Maksimovic. 1990. Technology, debt, and the exploitation of growth options. Journal of Finance 45, 795-816. 
[130] King, R.G., and M.R. Watson. 1995. System reduction and solution algorithms for singular linear difference systems under rational expectations.University of Virginia and Northwestern University, mimeo.

[131] King, R.G., and M.R. Watson. 1996. The solution of singular linear difference systems under rational expectations. University of Virginia and Princeton University, mimeo.

[132] Kokkelenberg, E.C. 1984. The specification and estimation of interrelated factor demands under uncertainty. Journal of Economic Dynamics and Control 7, 181-207.

[133] Kokkelenberg, E.C., and C.W. Bischoff. 1986. Expectations and factor demand. Review of Economics and Statistics 68, 423-431.

[134] Kollintzas, T. 1985. The symmetric linear rational expectations model. Econometrica 53, 963-976.

[135] Kollintzas, T. 1986. A non-recursive solution for the linear rational expectations model. Journal of Economic Dynamics and Control 10, 327-332.

[136] Kollintzas, T., and J.-B. Choi. 1985. A linear rational expectations equilibrium model of aggregate investment with endogenous capital utilization and maintenance. Department of Economics, University of Pittsburgh, mimeo.

[137] Koyck, L.M. 1954. Distributed Lags and Investment Analysis. Amsterdam: North Holland Publishing Company.

[138] Lahiri, L., and P. Schmidt. 1978. On the estimation of triangular structural systems. Econometrica 46, 1217-1221.

[139] Lau, L.J. 1976. A characterization of the normalized restricted profit function. Journal of Economic Theory 12, 131-163.

[140] Lau, L.J. 1986. Functional forms in econometric model building. In Z. Griliches and M.D. Intriligator, eds., Handbook of Econometrics, Vol III. New York: North Holland, 1515-1566. 
[141] Lau, L.J., and P.A. Yotopoulos. 1989. Function approach to technological change in world agriculture. Journal of Development Economics $31,241-69$.

[142] Lee, Y.J., and J.K. Kwon. 1994. Interpretation and measurement of capacity utilization: The case of Korean manufacturing. Applied Economics 26, 981-990.

[143] Lucas, R.E. 1967a. Adjustment costs and the theory of supply. Journal of Political Economy 75, 321-334.

[144] Lucas, R.E. 1967b. Optimal investment policy and the flexible accelerator. International Economic Review 8, 78-85.

[145] Madan, D.B., and I.R. Prucha. 1989. A note on the estimation of nonsymmetric dynamic factor demand models. Journal of Econometrics $42,275-283$.

[146] Malinvaud, E. 1953. Capital accumulation and the efficient allocation of resources. Econometrica 21,233-268.

[147] Malinvaud, E. 1969. First order certainty equivalence. Econometrica 37, 706-719.

[148] Mamuneas, T., and M.I. Nadiri. 1996. Public R\&D policies and cost behavior of the US manufacturing industries. Journal of Public Economics $63,57-81$.

[149] McFadden, D. 1978. Cost, revenue and profit functions. In M. Fuss and D. McFadden, eds., Production Economics: A Dual Approach to Theory and Applications, Vol. I. New York: North-Holland, 3-109.

[150] Mohnen, P., 1990. R\&D and productivity growth: A survey of the literature. Université du Québec à Montréal, CERPE, Cahier de Recherche No. 57.

[151] Mohnen, P.A. 1992a. The Relationship Between R\&D and Productivity Growth in Canada and Other Industrialized Countries. Ottawa: Canada Communication Group. 
[152] Mohnen, P.A. 1992b. International R\&D spillovers in selected OECD countries. Université du Québec à Montréal, Département des sciences économiques, Cahier No. 9208.

[153] Mohnen, P., and N. Lépine. 1991. R\&D, R\&D spillovers and payments for technology: Canadian evidence. Structural Change and Economic Dynamics 2(1), 213-228.

[154] Mohnen, P.A., M.I. Nadiri, and I.R. Prucha. 1983. R\&D, production structure, and productivity growth in the U.S., Japanese, and German manufacturing sectors. In Proceedings of the Conference of Qualitative Studies of Research and Development in Industry. Paris: INSEE, 173221.

[155] Mohnen, P.A., M.I. Nadiri, and I.R. Prucha. 1986. R\&D, production structure, and rate of return in the U.S., Japanese and German manufacturing sectors: A nonseparable dynamic factor demand model. European Economic Review 30, 749-771.

[156] Morrison, C.J. 1983. Productivity measurement with non-static expectations and varying capacity utilization: An integrated approach. Paper presented at the 1983 NBER Summer Workshop on Investment and Productivity. Cambridge, mimeo.

[157] Morrison, C.J. 1985a. Primal and dual capacity utilization: An application to productivity measurement in the U.S. automobile industry. Journal of Business and Economic Statistics 3, 312-324.

[158] Morrison, C.J. 1985b. On the economic interpretation and measurement of optimal capacity utilization with anticipatory expectations. Review of Economic Studies 52, 295-310.

[159] Morrison, C.J. 1986a. Productivity measurement with non-static expectations and varying capacity utilization: An integrated approach. Journal of Econometrics 33, 51-74.

[160] Morrison, C.J. 1986b. Structural models of dynamic factor demands with nonstatic expectations: An empirical assessment of alternative expectations specifications. International Economic Review 27, 365386. 
[161] Morrison, C.J. 1988. Quasi-fixed inputs in the U.S. and Japanese manufacturing: A generalized Leontief restricted cost function approach. Review of Economics and Statistics 70(2), 275-287.

[162] Morrison, C.J. 1989. Unraveling the productivity growth slowdown in the U.S., Canada and Japan: The effects of subequilibrium, scale and markups. Working Paper No. 2993, National Bureau of Economic Research, Cambridge.

[163] Morrison, C.J. 1990. Decisions of firms and productivity growth with fixed input constraints: An empirical comparison of U.S. and Japanese manufacturing. In C.R. Hulten, ed., Productivity Growth in Japan and the U.S. Chicago: University of Chicago Press, 135-167.

[164] Morrison, C.J. 1992a. Unraveling the productivity growth slowdown in the United States, Canada and Japan: The effects of subequilibrium, scale economies and markups. The Review of Economics and Statistics 74(3), 381-393.

[165] Morrison, C.J. 1992b. Markups in U.S. and Japanese manufacturing: A short-run econometric analysis. Journal of Business \& Economic Statistics 10 (1), 51-63.

[166] Morrison, C.J. 1997. Assessing the productivity of information technology equipment in U.S. manufacturing industries. Review of Economics and Statistics 79, 471-481.

[167] Morrison, C.J., and E.R. Berndt. 1981. Short-run labor productivity in a dynamic model. Journal of Econometrics, 16, 339-365.

[168] Morrison, C.J., and D. Siegel. 1997. External capital factors and increasing returns in U.S. manufacturing. Review of Economics and Statistics 79, 647-654.

[169] Mortenson, D.T. 1973. Generalized costs of adjustment and dynamic factor demand theory. Econometrica 41, 657-665.

[170] Mussa, M. 1977. External and internal adjustment costs and the theory of aggregate and firm investment. Economica 44, 163-178. 
[171] Nadiri, M.I. 1993. Innovations and Technological Spillovers. Working Paper No. 4223, National Bureau of Economic Research, Cambridge.

[172] Nadiri, M.I. and S. Kim. 1996. International R\&D Spillovers, Trade and Productivity in Major OECD Countries. Working Paper No. 5801, National Bureau of Economic Research, Cambridge.

[173] Nadiri, M.I., and B. Nandi. 1997. The changing structure of cost and demand for the U.S. telecommunications industry. Information Economics and Policy 9(4), 319-347.

[174] Nadiri, M.I., and I.R. Prucha. 1983. Nonstatic expectations, adjustment costs and the production structure and synamic factor demand for AT\&T. Paper presented at the 1983 NBER Summer Workshop on Investment and Productivity. Cambridge, mimeo.

[175] Nadiri, M.I., and I.R. Prucha. 1984. Production structure, R\&D and productivity growth in the U.S. Bell system: Estimation from dynamic factor demand functions under nonstatic expectations. Department of Economics, New York University and University of Maryland, mimeo.

[176] Nadiri, M.I., and I.R. Prucha. 1986. Comparison and analysis of productivity growth and R\&D investment in the electrical machinery industries of the United States and Japan, Working Paper No. 1850, National Bureau of Economic Research, Cambridge.

[177] Nadiri, M.I., and I.R. Prucha. 1990a. Comparison and analysis of productivity growth and R\&D investment in the electrical machinery industries of the United States and Japan. In C.R. Hulten, ed., Productivity Growth in Japan and the U.S. Chicago: University of Chicago Press, 109-133.

[178] Nadiri, M.I., and I.R. Prucha. 1990b. Dynamic factor demand models, productivity measurement, and rates of return: Theory and an empirical application to the U.S. Bell system. Structural Change and Economic Dynamics, 2, 263-289.

[179] Nadiri, M.I., and I.R. Prucha. 1996. Estimation of the depreciation rate of physical and R\&D capital in the U.S. total manufacturing sector. Economic Inquiry 34, 43-56. 
[180] Nadiri, M.I., and S. Rosen. 1969. Interrelated factor demand functions. American Economic Review 59, 457-471.

[181] Nadiri, M.I., and S. Rosen. 1973. A Disequilibrium Model of Demand for Factors of Production. New York: Columbia University Press.

[182] Nadiri, M.I., and M.A. Schankerman. 1981a. Technical change, returns to scale, and the productivity slowdown. American Economic Review 71, 314-319.

[183] Nadiri, M.I., and M.A. Schankerman. 1981b. The structure of production, technological change, and the rate of growth of total factor productivity in the U.S. Bell system. In T. Cowing and R. Stevenson, eds., Productivity Measurement in Regulated Industries. New York: Academic Press, 219-247.

[184] Otha, M. 1974. A note on the duality between production and cost functions: Returns to scale and rate of technical progress. Economic Studies Quarterly 25, 63-65.

[185] Pindyck, R.S. 1988. Irreversible investment, capacity choice, and the value of the firm. American Economic Review 78, 969-985.

[186] Pindyck, R.S. 1991. Irreversibility, uncertainty and investment. Journal of Economic Literature 29, 1110-1152.

[187] Pindyck, R.S., and J.J. Rotemberg. 1983a. Dynamic factor demands under rational expectations. Scandinavian Journal of Economics 85, 223-238.

[188] Pindyck, R.S., and J.J. Rotemberg. 1983b. Dynamic factor demands and the effects of energy price shocks. American Economic Review 73, 1066-1079.

[189] Pötscher, B.M., and I.R. Prucha. 1991a. Basic structure of the asymptotic theory in dynamic nonlinear econometric models, Part I: Consistency and approximation concepts. Econometric Reviews 10, 125-216.

[190] Pötscher, B.M., and I.R. Prucha. 1991b. Basic structure of the asymptotic theory in dynamic nonlinear econometric models, Part II: Asymptotic normality. Econometric Reviews 10, 253-325. 
[191] Pötscher, B.M., and I.R. Prucha. 1997. Dynamic Nonlinear Econometric Models: Asymptotic Theory. New York: Springer Verlag.

[192] Prucha, I.R. 1987. The variance-covariance matrix of the maximum likelihood estimator in triangular structural systems: Consistent Estimation. Econometrica 55, 977-978.

[193] Prucha, I.R. 1990. Comments on C.J. Morrison, Decisions of firms and productivity growth with fixed input constraints: An empirical comparison of U.S. and Japanese manufacturing. In C.R. Hulten, ed., Productivity Growth in Japan and the U.S. Chicago: University of Chicago Press, 167-172.

[194] Prucha, I.R. 1995. On the econometric estimation of a constant rate of depreciation. Empirical Economics 20, 299-302.

[195] Prucha, I.R. 1997. Estimation of a variable rate of depreciation: A dummy variable approach. Structural Change and Economic Dynamics 8, 319-325.

[196] Prucha, I.R., and M.I. Nadiri. 1982. Formulation and estimation of dynamic factor demand equations under non-static expectations: A finite horizon model. Technical Paper No. 26, National Bureau of Economic Research, Cambridge. (Revised March 1994).

[197] Prucha, I.R., and M.I. Nadiri. 1986. A comparison of alternative methods for the estimation of dynamic factor demand models under nonstatic expectations. Journal of Econometrics 33, 187-211.

[198] Prucha, I.R., and M.I. Nadiri. 1988. On the computation of estimators in systems with implicitly defined variables. Economics Letters 26, 141145 .

[199] Prucha, I.R., and M.I. Nadiri. 1990. Endogenous capital utilization and productivity measurement in dynamic factor demand models: Theory and an application to the U.S. electrical machinery industry. Working Paper No. 90-19, Department of Economics, University of Maryland, and Working Paper No. 3680, National Bureau of Economic Research, Cambridge. 
[200] Prucha, I.R., and M.I. Nadiri. 1991. On the specification of accelerator coefficients in dynamic factor demand models. Economics Letters 35, 123-129.

[201] Prucha, I.R., and M.I. Nadiri. 1996. Endogenous capital utilization and productivity measurement in dynamic factor demand models: Theory and an application to the U.S. electrical machinery industry. Journal of Econometrics 71, 343-379.

[202] Richter, M.K. 1966. Invariance axioms and economic indices. Econometrica 34, 739-755.

[203] Schramm, R. 1970. The influence of relative prices, production conditions and adjustment costs on investment behaviour. Review of Economic Studies 37, 361-376.

[204] Shapiro, M.D. 1986. Capital utilization and capital accumulation: Theory and evidence. Journal of Applied Econometrics 1, 211-234.

[205] Shephard, R.W. 1953. Theory of Cost and Production Functions. Princeton: Princeton University Press.

[206] Simon, H.A. 1956. Dynamic programming under certainty equivalence with a quadratic criterion function. Econometrica 24, 74-81.

[207] Solow, R.M. 1957. Technical change and the aggregate production function. Review of Economics and Statistics 39, 312-320.

[208] Srinivasan, S. 1995. Estimation of own R\&D, R\&D spillovers and exogenous technical change effects in some U.S. high-technology industries. Ph.D. Dissertation, University of Maryland, Department of Economics.

[209] Steigerwald, D.G., and C. Stuart. 1997. Econometric estimation of foresight: Tax policy and investment in the United States. Review of Economics and Statistics 79, 32-40.

[210] Steigum, E. Jr. 1983. A financial theory of investment behavior. Econometrica 51(3), 637-645.

[211] Stokey, N.L., R.E. Lucas, and E.C. Prescott. 1989. Recursive Methods in Economic Dynamics. Cambridge: Harvard University Press. 
[212] Theil, H. 1957. A note on certainty equivalence in dynamic planning. Econometrica 25, 346-349.

[213] Tobin, J. 1969. A general equilibrium approach to monetary theory. Journal of Money, Credit and Banking 1, 15-29.

[214] Treadway, A.B. 1969. On rational enterpreneurial behavior and the demand for investment. Review of Economic Studies 36, 227-239.

[215] Treadway, A.B. 1970. Adjustment costs and variable inputs in the theory of the competitive firm. Journal of Economic Theory 2, 329-347.

[216] Treadway, A.B. 1971. The rational multivariate flexible accelerator. Econometrica 39, 845-855.

[217] Treadway, A.B. 1974. The globally optimal flexible accelerator. Journal of Economic Theory 7, 17-39.

[218] Uhlig, H. 1995. A toolkit for analyzing nonlinear dynamic stochastic models easily. Discussion Paper 101, Federal Reserve Bank of Minneapolis.

[219] Uzawa, H. 1969. Time preference and the Penrose effect in a two-class model of economic growth. Journal of Political Economy 77, 628-652.

[220] Watkins, G.C. 1991. Short- and long-term equilibria. Energy Economics 13, 2-9.

[221] Watkins, G.C. and E.R. Berndt. 1992. Dynamic models of input demand: A comparison under different formulations of adjustment costs. In J. Moroney, ed., Advances in the Economics of Energy and Resources, Vol. 7. Greenwich: JAI Press, 159-188. 